\author{
UNIVERSIDADE DE SÃO PAULO \\ ESCOLA DE ENGENHARIA DE SÃO CARLOS \\ DEPARTAMENTO DE ENGENHARIA DE ESTRUTURAS
}

FERNANDA DE OLIVEIRA SANTOS

Modelo constitutivo incremental explícito para o concreto confinado baseado na teoria da plasticidade e dano

São Carlos

2018 



\title{
Modelo constitutivo incremental explícito para o concreto confinado baseado na teoria da plasticidade e dano
}

\author{
VERSÃO CORRIGIDA \\ A versão original encontra-se na Escola de Engenharia de São Carlos
}

Dissertação apresentada ao Departamento de Engenharia de Estruturas da Escola de Engenharia de São Carlos, Universidade de São Paulo, como parte dos requisitos para obtenção do título de Mestre em Engenharia Civil (Estruturas).

Orientador: Prof. Dr. Ricardo Carrazedo

São Carlos 
AUTORIZO A REPRODUÇÃO TOTAL OU PARCIAL DESTE TRABALHO, POR QUALQUER MEIO CONVENCIONAL OU ELETRÔNICO, PARA FINS DE ESTUDO E PESQUISA, DESDE QUE CITADA A FONTE.

Ficha catalográfica elaborada pela Biblioteca Prof. Dr. Sérgio Rodrigues Fontes da EESC/USP com os dados inseridos pelo(a) autor(a).

Santos, Fernanda de Oliveira

S237m Modelo constitutivo incremental explícito para o concreto confinado baseado na teoria da plasticidade e dano / Fernanda de Oliveira Santos; orientador Ricardo Carrazedo. São Carlos, 2018.

Dissertação (Mestrado) - Programa de Pós-Graduação em Engenharia Civil (Engenharia de Estruturas) e Área de Concentração em Estruturas -- Escola de Engenharia de São Carlos da Universidade de São Paulo, 2018.

1. Concreto. 2. Confinamento. 3. Plasticidade. 4. Dano. 5. Reforço. 6. Pilares. I. Título. 


\section{FOLHA DE JULGAMENTO}

Candidata: Engenheira FERNANDA DE OLIVEIRA SANTOS.

Título da dissertação: "Modelo constitutivo incremental explícito para o concreto confinado baseado na teoria da plasticidade e dano".

Data da defesa: 25/04/2018.

Comissão Julgadora:

Prof. Dr. Ricardo Carrazedo (Orientador)

(Escola de Engenharia de São Carlos/EESC)

Profa. Dra. Gláucia Maria Dalfré

(Universidade Federal de São Carlos/UFSCar)

Prof. Dr. Armando Lopes Morenos Junior

(Universidade Estadual de Campinas/UNICAMP)
Resultado:

APROVADO
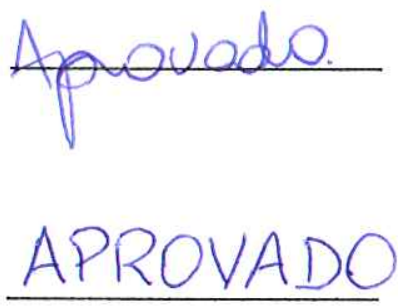

Coordenador do Programa de Pós-Graduação em Engenharia Civil (Engenharia de Estruturas):

Prof. Titular Humberło Breves Coda

Presidente da Comissão de Pós-Graduação:

Prof. Associado Luís Fernando Cosła Alberto 



\section{AGRADECIMENTOS}

Acima de tudo a Deus, pela vida, amparo e força.

Aos meus pais, Valmir e Zilda, pelo apoio, compreensão, paciência e amor incondicional.

Ao Henrique, pelo apoio, companheirismo, incentivo e amor.

À Universidade de São Paulo e à Escola de Engenharia de São Carlos (EESC-USP), pelo acolhimento nesses sete anos.

Ao meu orientador, Ricardo Carrazedo, pela confiança, orientações e suporte no desenvolvimento da pesquisa.

Aos demais professores do Departamento de Engenharia de Estruturas (SET), pelos ensinamentos e inúmeras contribuições.

Aos meus colegas do Programa de Pós Graduação do Departamento de Estruturas, pela amizade e companheirismo.

À CAPES (Fundação Coordenação de Aperfeiçoamento de Pessoal de Nível Superior), pela bolsa de estudo. 



\section{RESUMO}

SANTOS, F.O. Modelo constitutivo incremental explícito para o concreto confinado baseado na teoria da plasticidade e dano. 2018. 101p. Dissertação (Mestrado em Engenharia Civil (Estruturas)) - Escola de Engenharia de São Carlos, Universidade de São Paulo, São Carlos, 2018.

O confinamento de pilares de concreto por meio de camisas de aço ou compósitos possui uma função importante na preservação, recuperação e reforço de estruturas, pois proporciona aumento de resistência e ductilidade desses elementos estruturais. Porém, grande parte dos modelos existentes apresenta limitações na previsão do comportamento do concreto confinado, principalmente por serem dependentes do tipo de confinamento. Portanto, este trabalho apresenta um modelo para descrição do comportamento tensão-deformação do concreto submetido a qualquer tipo de confinamento uniforme, ativo ou passivo, e confinado com diferentes materiais confinantes - aço ou compósitos. O modelo constitutivo associa plasticidade e dano a fim de prever adequadamente a resistência, deformabilidade e redução de rigidez elástica do concreto confinado. O modelo é desenvolvido para um processo incremental explícito de implementação, permitindo, portanto, o seu desenvolvimento em qualquer tipo de planilha. Finalmente, o modelo foi validado por meio de um conjunto representativo de experimentos encontrados na literatura.

Palavras-chave: Concreto. Confinamento. Plasticidade. Dano. Reforço. Pilares. 



\begin{abstract}
SANTOS, F.O. Explicit incremental constitutive model for confined concrete based on the theory of plasticity and damage. 2018. 101p. Dissertation (M. Sc. in Civil Engineering (Structures)) - School of Engineering of São Carlos, University of São Paulo, São Carlos, 2018 .
\end{abstract}

Confinement of concrete columns through steel or composites jackets has an important function in the preservation, recovery and strengthening of structures, because it provides increased strength and ductility of these structural elements. However, most of the existing models have limitations in the prediction of the behavior of confined concrete, mainly because they are dependent on the type of confinement. This work presents a model for the description of the stress-strain behavior of the concrete submitted to any type of uniform confinement, active or passive, and confined with different confinement materials, steel or composites. The constitutive model associates plasticity and damage in order to predict with accuracy the strength, ultimate strain and reduction of elastic stiffness of the confined concrete. The model is developed by an explicit incremental implementation process allowing, therefore, its development in any type of spreadsheet. Finally, the model was validated through a representative set of experiments found in the literature.

Keywords: Concrete. Confinement. Plasticity. Damage. Strengthening. Columns. 



\section{SUMÁRIO}

1 INTRODUÇÃO .............................................................................................................................15

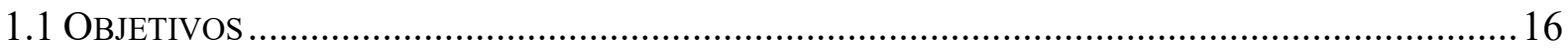

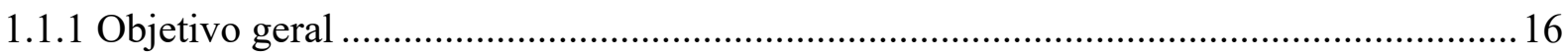

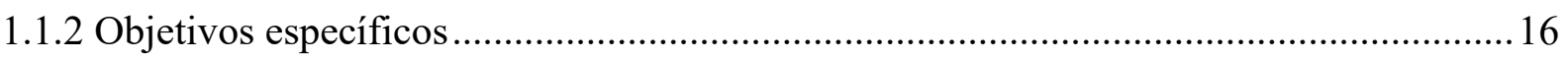

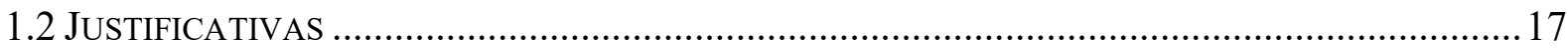

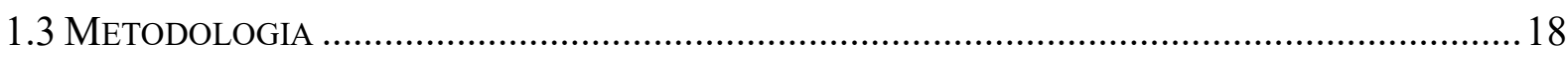

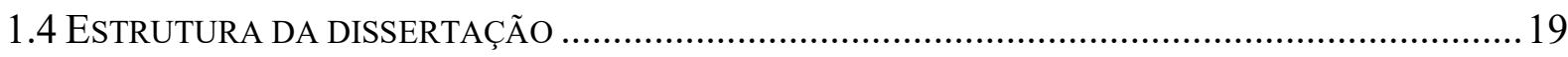

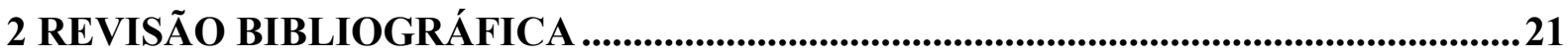

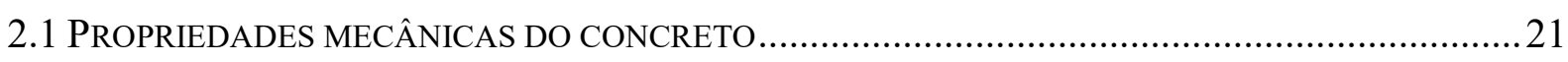

2.1.1 Comportamento do concreto sob carregamento uniaxial monotônico e cíclico...............22

2.1.2 Comportamento do concreto sob carregamento triaxial monotônico.................................24

2.1.3 Comportamento do concreto sob carregamento triaxial cíclico .......................................27

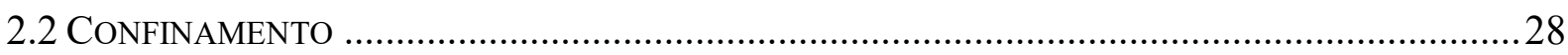

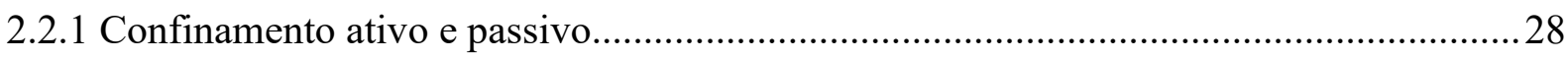

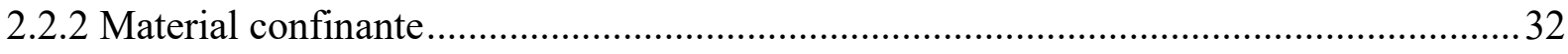

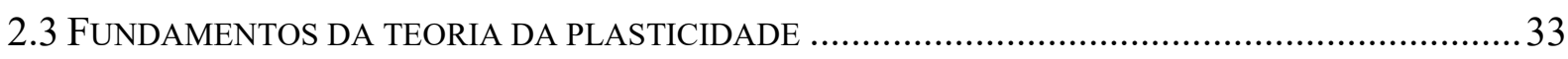

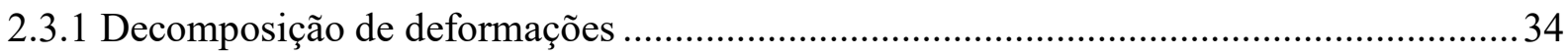

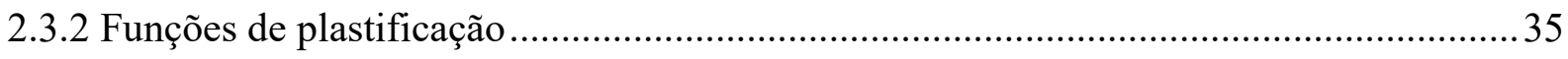

2.3.2.1 Definição da superfície de plastificação/ruptura no espaço das tensões principais .....36

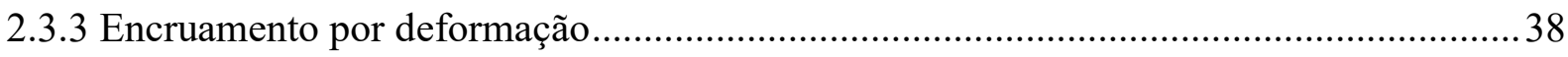

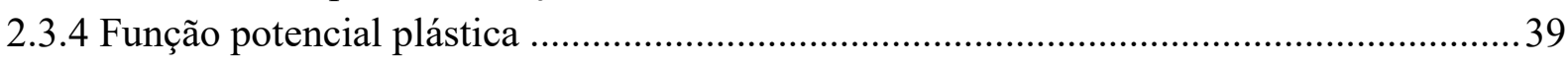

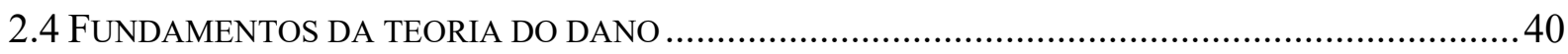

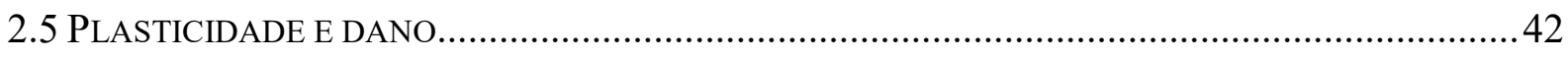

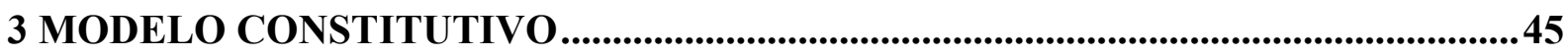

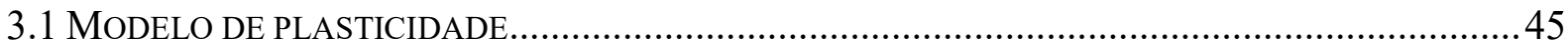

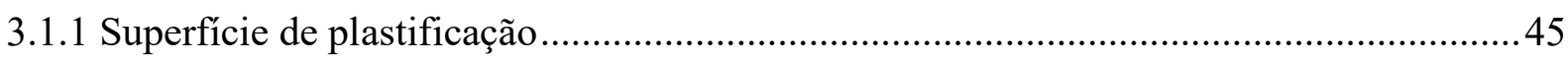

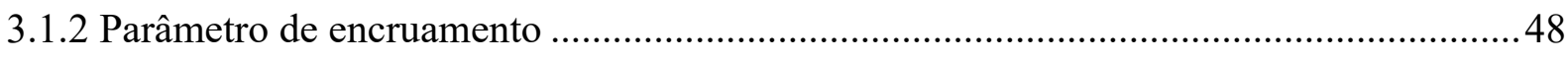

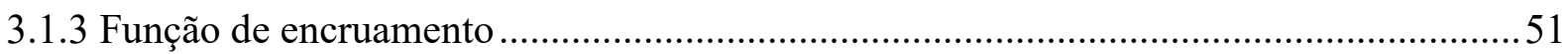

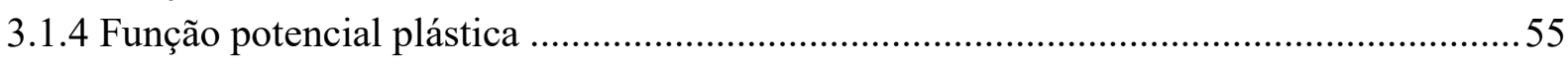

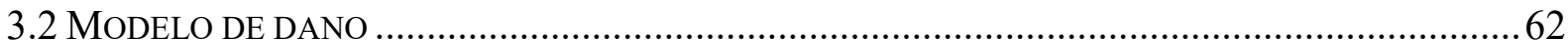

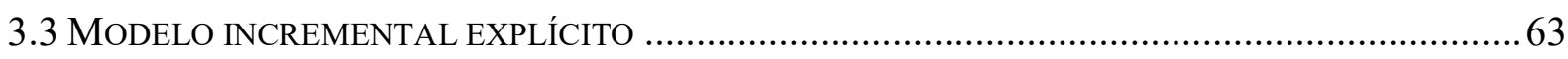

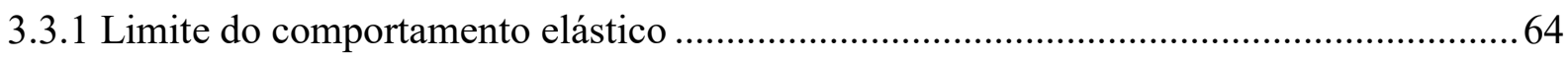

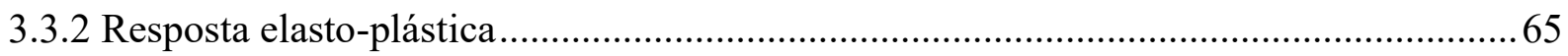

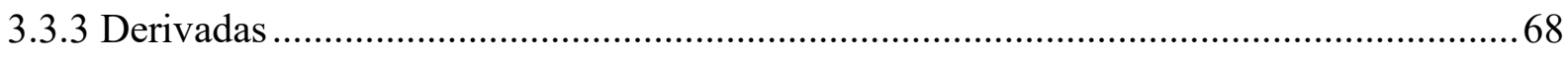

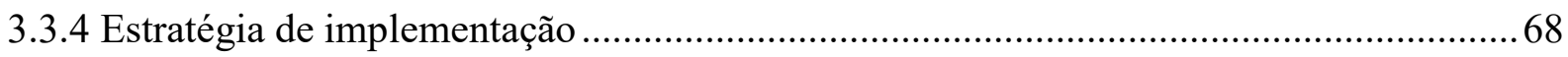




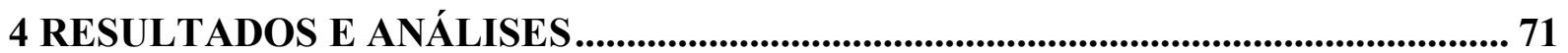

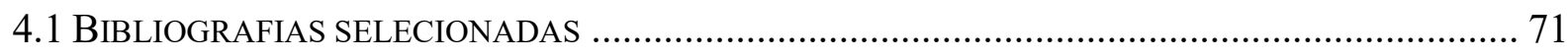

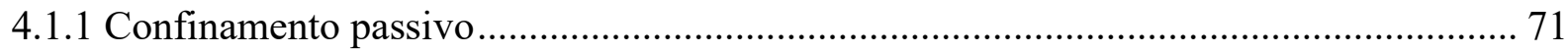

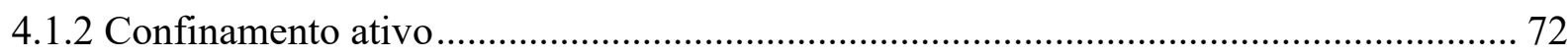

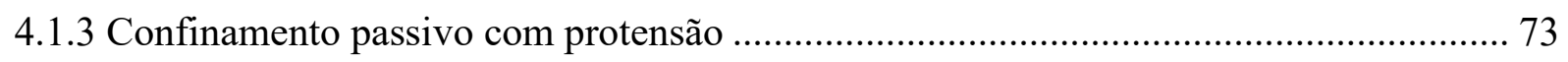

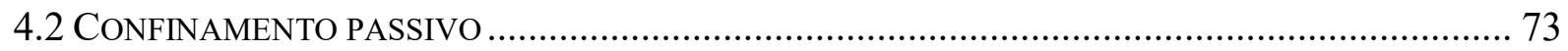

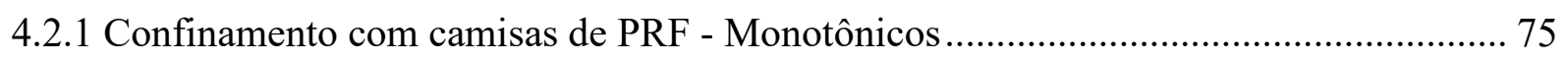

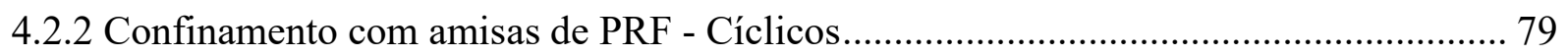

4.2.3 Confinamento com camisas de aço - com e sem protensão .............................................. 84

4.2.4 Confinamento com camisas de PRF - com e sem protensão.......................................... 87

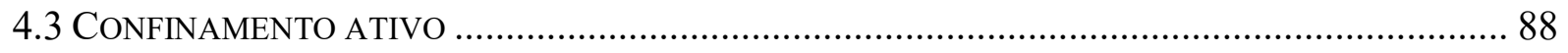

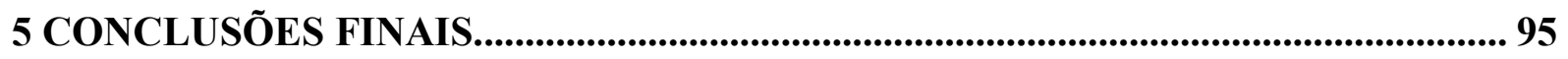

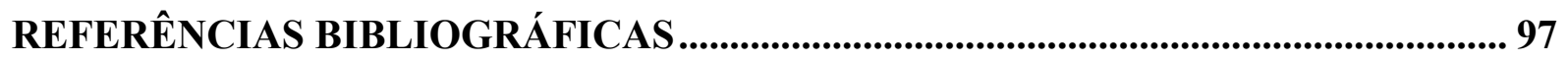




\section{INTRODUÇÃO}

Os elementos estruturais de concreto, amplamente usados nas construções, sofrem deterioração com o passar do tempo e apresentam problemas estruturais. Mehta e Gerwick (1982) agruparam as causas físicas de deterioração em duas categorias. A primeira inclui desgaste da superfície ou perda de massa devido à abrasão, erosão ou cavitação; a segunda categoria inclui causas como fissuras devido a gradientes de temperaturas e umidade normais, cristalização de sais nos poros, carga estrutural (sobrecarga, impacto e cargas cíclicas) e exposição a temperaturas extremas (incêndio, ciclos de congelamento e descongelamento).

Para solucionar problemas estruturais relacionados à segunda categoria, mais especificamente relacionados a carga estrutural em elementos comprimidos, aponta-se o uso de confinamento como uma alternativa eficiente pois inúmeros estudos, como Richart et al. (1928), Imran e Pantazapoulou (1996) e Sfer et al. (2002) demonstraram que o efeito de confinamento em pilares gera considerável aumento de resistência e ductilidade. Portanto, camisas de concreto, aço ou compósitos são alternativas para recuperação de pilares existentes danificados em situações de extrapolação da resistência mecânica ou em situações em que é necessário aumento de ductilidade, essencial em situações sísmicas, por exemplo. Além disso, o uso de confinamento viabiliza a construção de pilares de alto desempenho, como proposto por Vincent e Ozbakkaloglu (2013).

Em relação aos tipos de materiais confinantes mais comuns, observa-se que os Polímeros Reforçados com Fibra (PRF) ganharam destaque nas pesquisas por oferecerem vantagens como rapidez na execução e alta relação entre resistência e massa, como citado por Mirmiran e Shahaway (1997). Quanto ao tipo de confinamento, esse pode ser classificado como confinamento ativo ou passivo. O confinamento ativo consiste na existência de uma pressão lateral constante independente do desenvolvimento de deformações laterais que pode ser exercida por fluidos ou por materiais como fios de ligas metálicas com memória de forma, citados em estudos como o de Park et al.(2011). No confinamento passivo ocorre aumento de pressão lateral devido à restrição da deformação transversal com o uso de camisas ou pela própria armadura transversal. Estudos como o de Lim e Ozbakkaloglu (2014a), demonstram 
que o concreto comporta-se de forma diferente sob esses dois tipos de confinamento. Além disso, segundo experimentos de Grassl (2004) o tipo de material confinante (aço ou PRF) também influencia consideravelmente o comportamento tensão-deformação do concreto.

Para a segurança e economia no projeto de reforço, o comportamento do concreto confinado com diferentes materiais confinantes sob carregamentos monotônicos e cíclicos deve ser bem compreendido e representado. Sendo assim, ao longo do tempo muitos estudos aplicaram modelos constitutivos existentes e propuseram novos modelos com o objetivo de representar o comportamento do concreto confinado. Porém, de modo geral, algumas limitações podem ser citadas nesses modelos, tais a impossibilidade dos modelos analíticos de representarem ambos os tipos de confinamento (ativo e passivo), ou a dificuldade na previsão da resistência e deformabilidade do concreto, até mesmo em modelos constitutivos mais complexos baseados nos princípios da plasticidade, principalmente quando se trata de confinamento com PRF. Nesse sentido, desenvolve-se este trabalho, visando uma representação do comportamento do concreto confinado em geral, focando em uma abordagem que facilite a aplicação prática do modelo constitutivo.

\subsection{Objetivos}

\subsubsection{Objetivo geral}

Esta pesquisa tem por objetivo geral desenvolver um modelo constitutivo unificado para representação do comportamento do concreto confinado ativa e passivamente submetido a carregamentos monotônicos e cíclicos, baseando-se em princípios da plasticidade e dano, de forma que sejam representadas adequadamente a resistência, deformabilidade e perda de rigidez elástica do concreto ao longo dos ciclos de carregamento e descarregamento.

\subsubsection{Objetivos específicos}

Os objetivos específicos da pesquisa são:

- Priorizar formulações mais simples com menor número possível de parâmetros, que apresentem preferencialmente significados físicos claros e possam ser obtidos por meio de ensaios simples. 
-Utilização de processo incremental explícito de implementação para o desenvolvimento do modelo, obtido por meio de arranjo adequado das equações e consideração de pequenos incrementos para a análise, permitindo, portanto, o desenvolvimento da implementação em qualquer tipo de planilha, a fim de facilitar a aplicação prática do modelo.

\subsection{Justificativas}

A utilização de técnicas que permitam reforçar e recuperar estruturas gerando pouca intervenção é muito importante para a preservação de estruturas com grande valor comercial, patrimônios históricos e estruturas cuja interrupção da utilização seria muito prejudicial. Nesse sentido, a utilização de confinamento em pilares de concreto por meio de camisas de aço ou compósitos mostra-se muito eficaz. Os efeitos dessa técnica são amplamente estudados, sendo indiscutíveis os benefícios gerados, como aumento de resistência e ductilidade desses elementos.

Para a segurança e economia no projeto de reforço, o comportamento do concreto confinado deve ser adequadamente representado. No entanto, devido à complexidade do concreto e diferenças relevantes no comportamento decorrente dos diferentes tipos de confinamento e materiais confinantes, nem sempre os modelos são eficazes. Sendo assim, os modelos para representação do comportamento mecânico do concreto sob confinamento foram alvos de muitos estudos. Muitos autores propuseram modelos analíticos, calibrados empiricamente, para previsão de curvas tensão - deformação do concreto confinado. Porém, esses modelos estão restritos a um tipo específico de confinamento e são dependentes do conjunto de dados experimentais utilizados para a calibração. Por outro lado, alguns autores basearam-se na teoria da plasticidade e/ou dano para formulação de modelos constitutivos, associados predominantemente a softwares de elementos finitos, para análise mais ampla do comportamento do material em diferentes elementos estruturais. Alguns deles propuseram modelos baseados apenas na plasticidade clássica, podendo representar adequadamente o comportamento do material apenas sob carregamentos monotônicos, já que não são capazes de descrever a perda de rigidez elástica devido processo de microfissuração em carregamentos cíclicos. Outros se basearam na teoria do dano, porém esses modelos não são capazes de prever adequadamente a evolução das deformações plásticas. Dessa forma, a união de 
plasticidade e dano, proposta por alguns autores, é apontada como uma solução para representação do comportamento do concreto sob confinamento submetido não só a carregamentos monotônicos, mas também carregamentos cíclicos, o que seria importante para análise de estruturas reais submetidas a efeitos repetitivos.

Em relação aos modelos existentes, muitos deles ainda apresentam algumas limitações: restrição na aplicabilidade para ambos os tipos de confinamento, ativo e passivo; incapacidade de representação do trecho da curva tensão-deformação no pós-pico, especialmente para baixos níveis de confinamento, para os quais os experimentos indicam um comportamento suavemente descendente dessa curva; representação inadequada da dilatação característica do concreto, afetando principalmente os resultados obtidos para resistência e deformação última do concreto sob confinamento passivo. Além disso, a utilização de muitos modelos está associada a processos trabalhosos de implementação e calibração devido utilização de muitos parâmetros, sendo que alguns deles não apresentam significado físico associado ou são de difícil obtenção pois exigem experimentos complexos.

Portanto, seria de suma importância desenvolver um modelo unificado, com processo de implementação simples e de fácil calibração por meio de utilização de poucos parâmetros para previsão do comportamento tensão-deformação do concreto submetido a diferentes tipos de confinamento e materiais confinantes e que seja capaz de prever a resistência, deformabilidade e perda de rigidez elástica do material em carregamentos cíclicos.

\subsection{Metodologia}

Primeiramente a análise teórica fundamenta-se em uma ampla revisão bibliográfica, a fim de entender o desenvolvimento científico do assunto, identificando as limitações existentes e as possibilidades para utilização da teoria da plasticidade e dano para representação adequada do comportamento do concreto confinado.

Modelos de plasticidade e dano de diferentes autores foram considerados, sendo que, para obtenção do modelo unificado, foram considerados critérios e funções de diferentes estudos, além de hipóteses consideradas pertinentes por meio de análise dos dados experimentais existentes. Todos os critérios adotados visaram à simplificação do modelo 
constitutivo, evitando incorporar prejuízos às respostas do modelo e buscando melhorias na resposta tensão-deformação e perda de rigidez elástica.

As equações do modelo proposto baseado na plasticidade e dano foram rearranjadas a fim de gerar um procedimento incremental de natureza explícita, resultando em um modelo constitutivo simples que dispense processo iterativo para que seja facilmente desenvolvido em qualquer tipo de planilha. Neste trabalho, a rotina de implementação foi desenvolvida na linguagem de programação Python.

Posteriormente, o modelo foi validado e devidamente calibrado por meio de um conjunto representativo de dados experimentais selecionados em bibliografias existentes, com variação de tipo de confinamento, materiais confinantes, resistência do concreto, níveis de confinamento, rigidez e espessuras de camisas de confinamento, de forma que seja garantida a representatividade do modelo.

\subsection{Estrutura da dissertação}

Este trabalho está organizado em capítulos da seguinte forma: o presente capítulo, Capítulo 1, é destinado a exposição geral do problema a ser tratado. Além disso, apresenta os objetivos, justificativas e metodologia empregados no trabalho.

O Capítulo 2 destina-se a exposição do estado da arte.

O Capítulo 3 apresenta o desenvolvimento do modelo, com funções e critérios adotados.

O Capítulo 4 apresenta os resultados obtidos pelo modelo e comparações com dados experimentais retirados da bibliografia existente.

O Capítulo 5 apresenta as principais conclusões e considerações finais deste trabalho juntamente com sugestões para trabalhos futuros.

No capítulo Referências são apresentadas as principais referências que embasaram o presente estudo. 


\section{REVISÃO BIBLIOGRÁFICA}

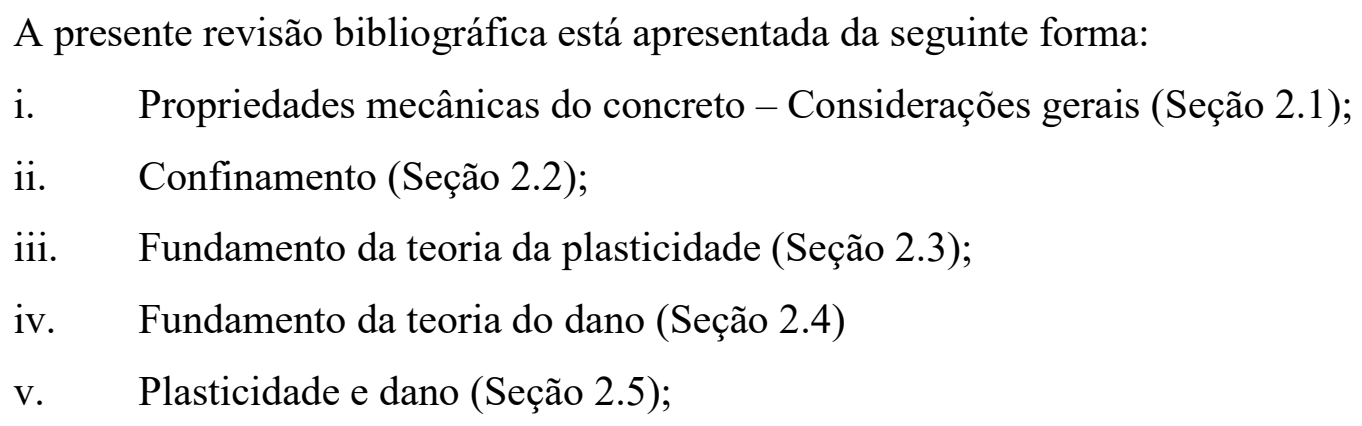

\subsection{Propriedades mecânicas do concreto}

O concreto é um material heterogêneo constituído basicamente de cimento, agregados ar e água. No entanto, aditivos e adições são usados cada vez mais para melhorar as propriedades do material. Segundo Mehta e Monteiro (1994), o tipo, a quantidade, o tamanho, a forma e distribuição de todos esses componentes, unidos para formação do material compósito, constituem a sua microestrutura. Forma-se, portanto, uma microestrutura complexa, que dificulta a elaboração de modelos realistas capazes de reproduzir com confiabilidade o comportamento do concreto.

Chen (1982) explica que o concreto apresenta três propriedades fundamentais: grande número de microfissuras na região entre agregados e pasta de cimento, chamada de zona de transição; pasta de cimento com alta porosidade; vazios de diferentes dimensões preenchidos por ar e/ou água. Essas propriedades afetam fortemente o comportamento mecânico do concreto, que será discutido brevemente a seguir, com ênfase para os estados de compressão uniaxial e triaxial. 
2.1.1 Comportamento do concreto sob carregamento uniaxial monotônico e cíclico

Como identificado em estudos de Chen (1982), a formação e propagação de fissuras é fator determinante no comportamento não-linear do concreto. Sendo que a curva tensãodeformação obtida por um ensaio de compressão uniaxial (representada na Figura 1a) pode ser dividida em diferentes fases. Até $30 \%$ da resistência à compressão uniaxial $\left(f_{c}\right)$ a configuração inicial de microfissuras existentes antes da aplicação de carregamento não sofre alterações significativas. Na fase intermediária (entre $0,30 f_{c}$ e $0,75 f_{c}$ ) a propagação das microfissuras é estável, ou seja, as microfissuras não aumentam se o nível de tensão for mantido constante. Aproximadamente a $75 \%$ da resistência à compressão - chamada de tensão crítica - o sistema de microfissuras fica instável devido a considerável interação entre elas, resultando em aumento de fissuras mesmo sem acréscimo de carregamento. Essa última fase abrange a parte descendente da curva tensão-deformação que se desenvolve até atingir a deformação última $\left(\varepsilon_{u}\right)$. Quanto à evolução das deformações volumétricas, demonstrada na Figura 1b, verifica-se que até a tensão crítica, ocorre uma compactação volumétrica do concreto, porém, a partir dessa tensão ocorre inversão do sentido da deformação volumétrica, tendendo a uma expansão volumétrica, o que pode ser justificado pelo aumento excessivo da deformação lateral devido a um intenso processo de fissuração.

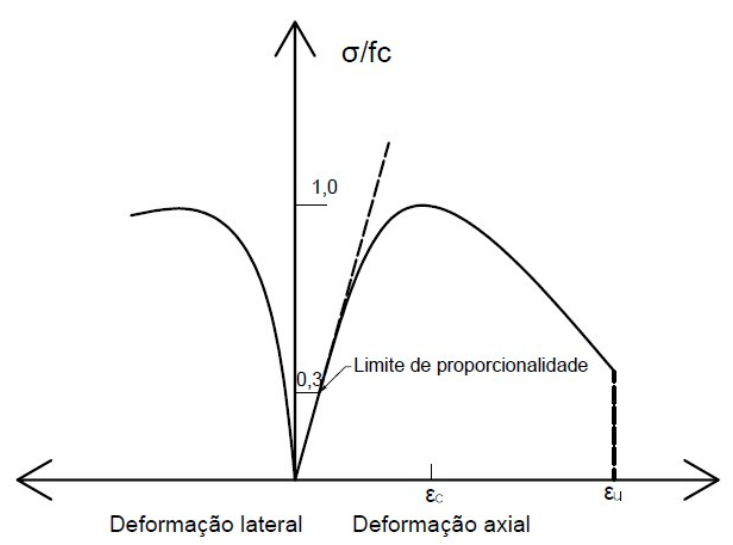

a)

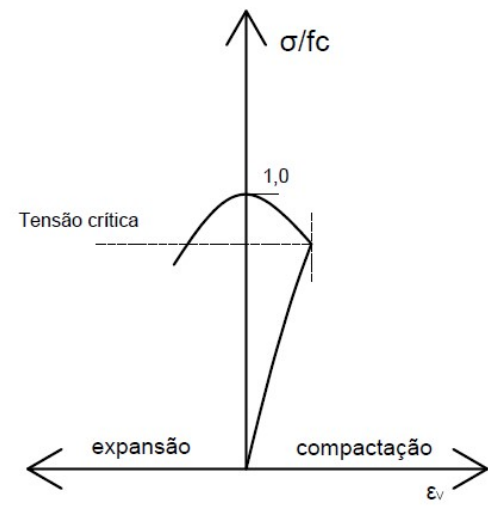

b)

Figura 1. Comportamento do concreto sob compressão uniaxial (a) Curva típica de tensãodeformação axial e lateral (b) Curva tensão - deformação volumétrica Fonte: Chen (1982)

As curvas tensão-deformação descritas anteriormente são semelhantes para concretos de diferentes resistências, no entanto, conforme descrito por Chen (1982), concretos de alta resistência (acima de $50 \mathrm{MPa}$ ) apresentam comportamento linear até próximo da resistência 
última, devido a diferenças significativas na sua microestrutura que resultam em menor microfissuração até próximo da ruptura. Além disso, concretos de alta resistência apresentam comportamento mais frágil no trecho descendente da curva tensão-deformação, quando comparado a concretos de resistência normal.

Em relação ao comportamento do concreto submetido à compressão uniaxial cíclica, resultados experimentais de Sinha et al. (1964) mostraram que a curva tensão-deformação do carregamento monotônico uniaxial representa a envoltória da resposta tensão-deformação do carregamento cíclico. Além desse, outros estudos, como Karsan e Jirsa (1969), indicam que o processo de microfissuração causa degradação da rigidez elástica do material, conforme demonstrado na Figura 2, que apresenta um ensaio de compressão cíclico típico. A curva de descarregamento (ponto de descarregamento até tensão nula) apresenta forma côncava e é caracterizada, inicialmente, por alta rigidez, que decresce gradualmente, reduzindo consideravelmente para baixas tensões no trecho pós-pico da curva tensão-deformação. Além disso, destaca-se no comportamento do concreto sob ensaio cíclico, que as curvas de recarregamento (partindo de tensão nula até o ponto de descarregamento) se aproximam de uma reta. Sendo que, conforme apontado pelos autores, o formato e inclinação dessas curvas dependem da quantidade de dano irreversível no concreto.

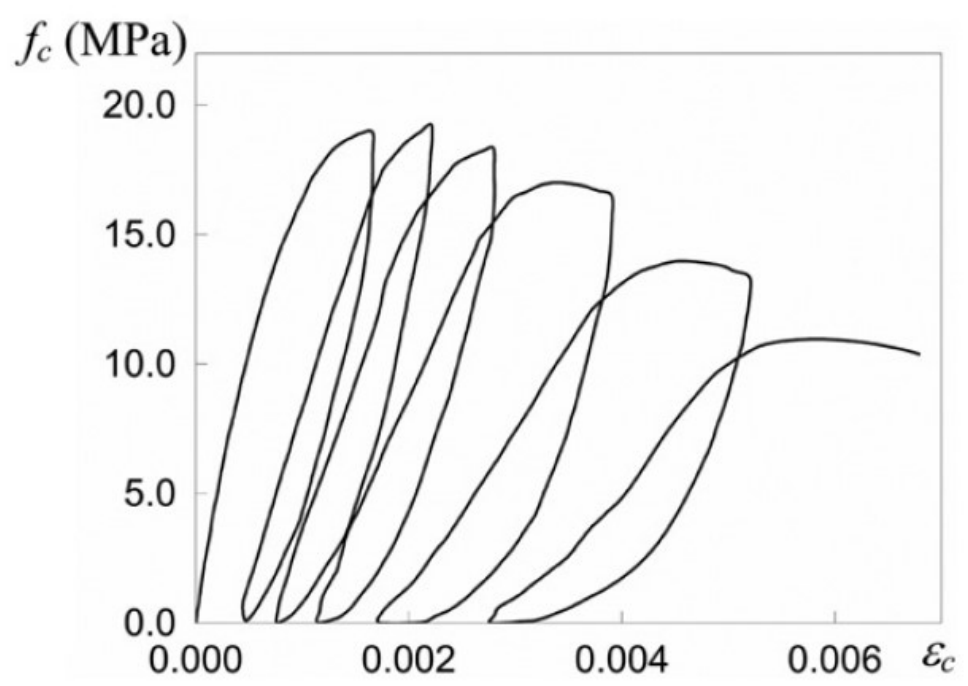

Figura 2. Carregamento uniaxial cíclico.

Fonte: Karsan e Jirsa (1969)

Para previsão do comportamento do concreto submetido a carregamentos cíclicos, cujo comportamento típico foi descrito anteriormente, modelos semi-empíricos foram propostos. Esses modelos baseiam-se em premissas teóricas aproximadas de forma que o 
cálculo seja consistente com observações experimentais. Sima, Roca e Molins (2008) desenvolveram um modelo para previsão desse comportamento na compressão e na tração, considerando parâmetros de dano diferentes para os dois casos. Breccolotti et al. (2015) também apresentou um modelo constitutivo capaz de descrever a acumulação de dano em concreto submetido a compressão uniaxial para diferentes histórias de carregamento (ciclos de tensões constantes, ciclos de carga e descarga a partir da envoltória e ciclos de tensões aleatórios), baseado no modelo de Sima, Roca e Molins (2008) com algumas modificações.

\subsubsection{Comportamento do concreto sob carregamento triaxial monotônico}

O comportamento do concreto submetido a um estado triaxial de tensão é relativamente complexo e a falha do material depende das combinações e magnitudes das tensões aplicadas. Tratando mais especificamente da compressão triaxial, é demonstrado em inúmeros estudos (Richart et al. (1928), Imran e Pantazopoulou (1996) e Sfer et al. (2002)) que o concreto pode apresentar características de fragilidade, pós-pico com amolecimento ou com encruamento que variam consideravelmente com o nível de confinamento. Porém, conclui-se que o concreto demonstra predominantemente tendência de aumento de resistência e ductilidade com o aumento de tensão de confinamento, conforme indicado nas curvas experimentais tensão-deformação de Imran e Pantazopoulou (1996) da Figura 3, indicando que para baixas tensões de confinamento as curvas apresentam pico bem definidos e curvas suavemente descendentes no pós-pico. No entanto, com o acréscimo da pressão de confinamento o pico de tensão aumenta e a curva pós-pico tende a ser crescente até a ruptura, com aumento significativo da capacidade de deformação. 


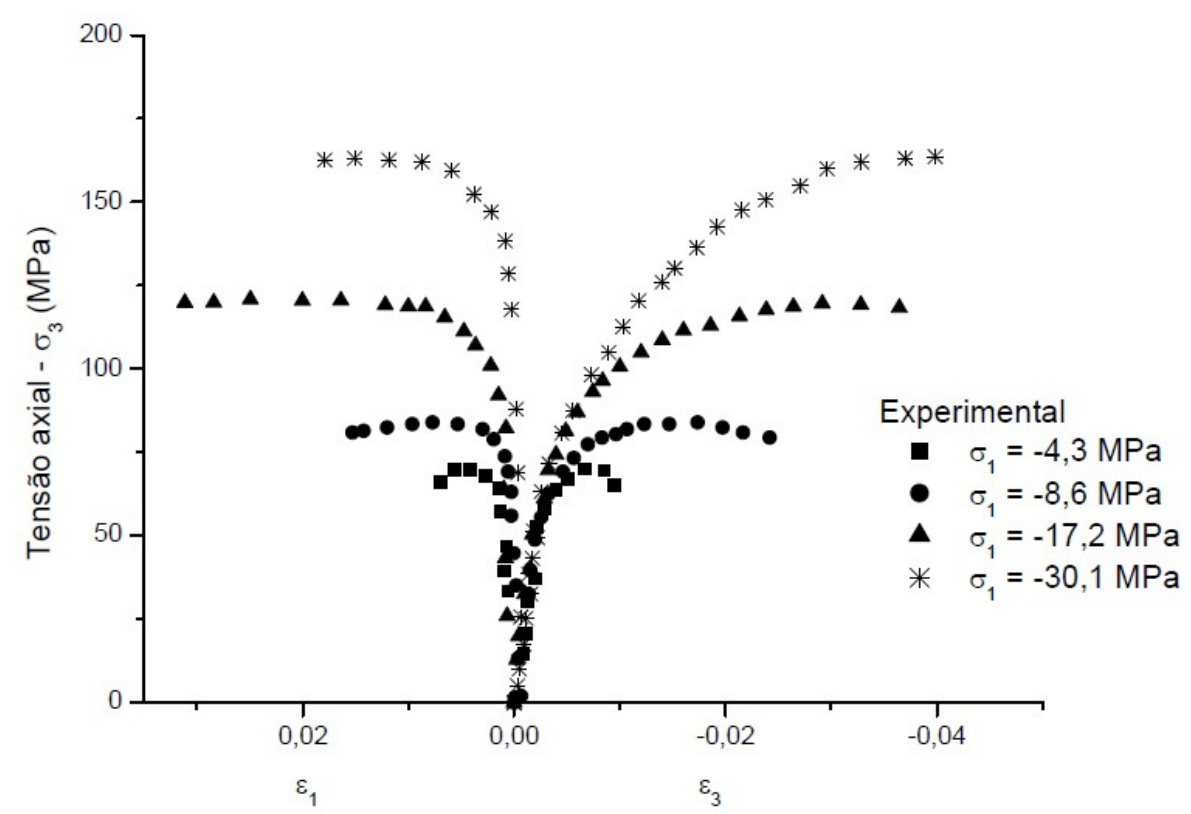

Figura 3. Tensão axial - deformação lateral $\left(\varepsilon_{1}\right) /$ axial $\left(\varepsilon_{3}\right)$ para diferentes tensões laterais de confinamento.

Fonte: Imran e Pantazopoulou (1996).

Ao analisar a deformação volumétrica do concreto submetido à compressão triaxial, autores como Imran e Pantazopoulou (1996) - para confinamento ativo - e Berthet et al. (2005) - para confinamento com PRF, demonstraram por meio de experimentos que existe a tendência de compactação volumétrica do concreto com o aumento do nível de confinamento, que ocorre para altas pressões laterais no confinamento ativo e maior número de camadas de PRF e/ou maior rigidez da camisa no confinamento passivo. Esse comportamento está descrito nas Figuras 4 e 5 para o confinamento ativo e passivo, respectivamente.

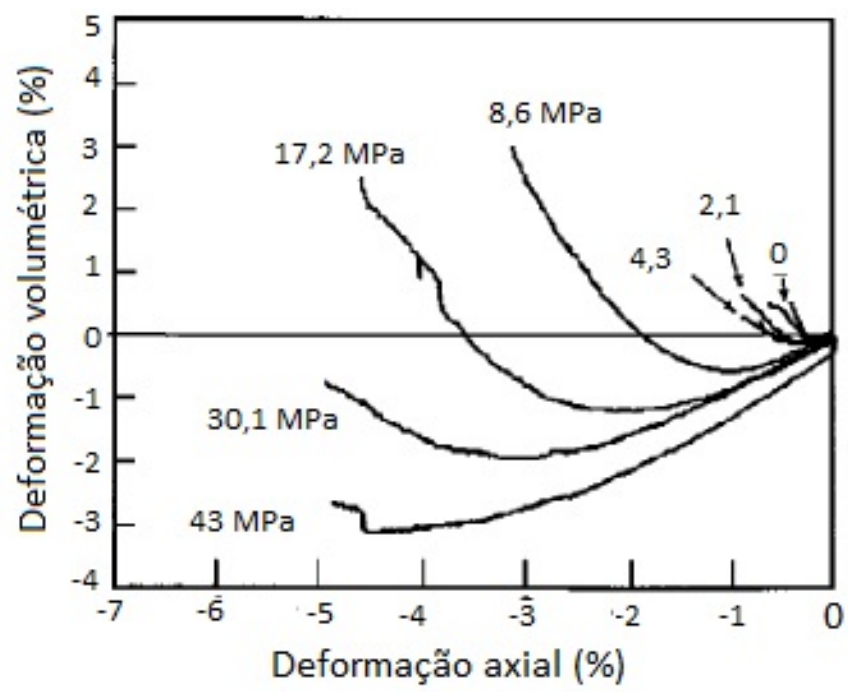

Figura 4. Comportamento das deformações volumétricas no confinamento ativo Fonte: Imran e Pantazopoulou (1996) 


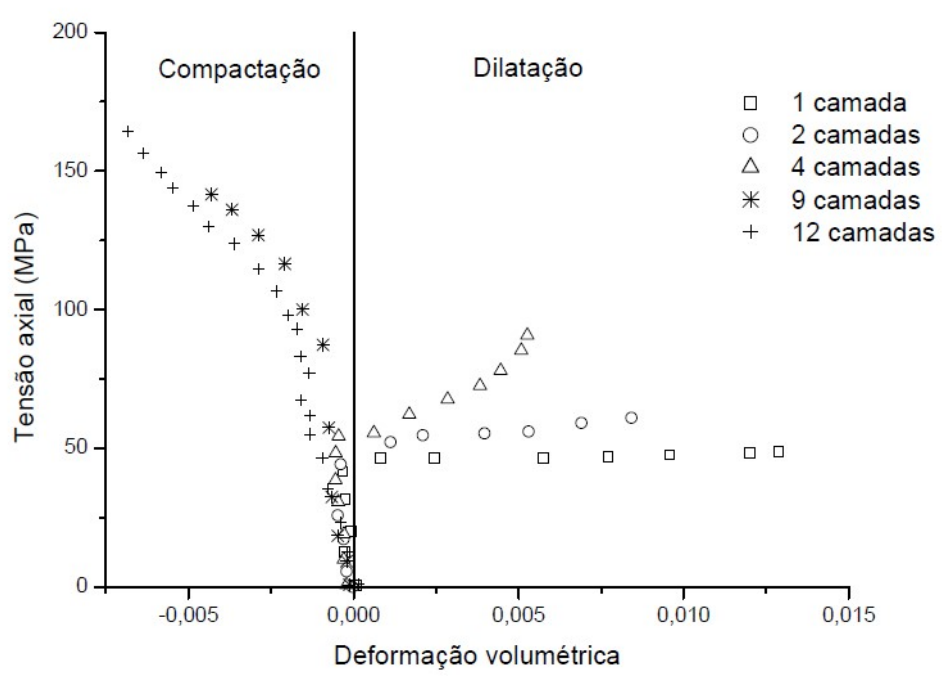

Figura 5. Comportamento das deformações volumétricas no confinamento com PRF Fonte: Berthet et al. (2005)

Quanto aos estudos para previsão das curvas tensão-deformação do concreto confinado, podem ser citados modelos analíticos como o de Richart et al. (1928) e Mander et al. (1988), que foram propostos para representar o confinamento do concreto com aço. Posteriormente, modelos como Saaman, Mirmiran e Shahawy (1998), Lam e Teng (2003), entre outros foram propostos para o comportamento do concreto confinado com PRF. Modelos como os citados são chamados orientados ao projeto, segundo nomenclatura sugerida por Lam e Teng (2003). Segundo Ozbakkaloglu, Lim e Vincent (2013), esses modelos são na maioria construídos com fórmulas fechadas obtidas por análises de regressão e calibradas com experimentos, geralmente restritos a apenas um tipo de confinamento (ativo, passivo com aço ou passivo com PRF) e a precisão depende do tamanho e da confiabilidade da base de dados utilizada para o desenvolvimento do modelo. Já os modelos chamados orientados à análise, como o de Jiang e Teng (2007), utilizam procedimentos numéricos incrementais para estabelecer o comportamento do concreto confinado por meio de equilíbrio de tensão e deformação entre o concreto e o material confinante. Jiang e Teng (2007) afirmam que são mais versáteis e capazes de descrever o comportamento do concreto confinado com diferentes materiais. Por outro lado, também indicaram que dependendo da relação deformação axial e lateral adotada os modelos podem representar com precisão o comportamento tensão-deformação do concreto, mas ainda assim apresentam limitações na determinação da tensão e deformação últimas, principalmente para baixos níveis de confinamento. 
2.1.3 Comportamento do concreto sob carregamento triaxial cíclico

Assim como outros autores, Li e Wu (2016) observaram que a envoltória da curva tensão-deformação do carregamento cíclico triaxial é bem próxima da curva tensãodeformação do carregamento triaxial monotônico sob a mesma pressão de confinamento, conforme observado em Figura 6, em que os corpos-de-prova foram submetidos a carregamento cíclico e monotônico, sob pressão lateral de confinamento de $15 \mathrm{MPa}$.

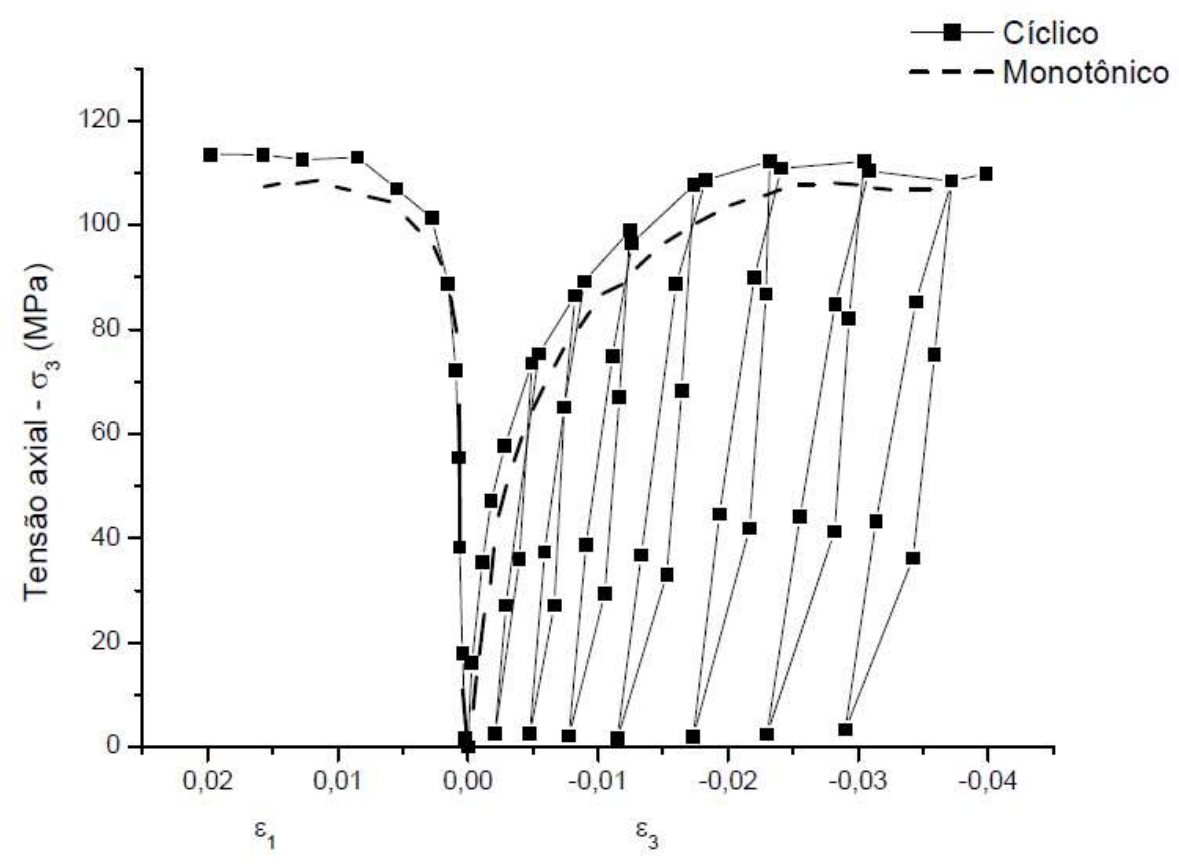

Figura 6. Curvas tensão - deformação para concreto confinado ativamente sob carregamentos monotônicos e cíclicos.

Fonte: Li e Wu (2016)

Uma quantidade menor de estudos se dedicou ao comportamento do concreto confinado com PRF sob compressão cíclica, se comparada a quantidade de estudos dedicada a carregamentos monotônicos. Alguns exemplos desses estudos são os de Lam et al. (2006) e Ozbakkaloglu e Akin (2012). E poucos modelos analíticos para previsão do comportamento sob carregamentos cíclicos foram propostos, sendo Shao et al. (2006) e Lam e Teng (2003) dois exemplos.

Lam et al. (2006) comparou o comportamento do concreto confinado com PRF sob compressão cíclica e monotônica e concluiu que os ciclos de carregamento/descarregamento tem pouco efeito na curva envoltória tensão-deformação, mas tem um efeito cumulativo na deformação permanente e na deterioração do material, como verificado na Figura 7, que 
indica a comparação entre uma amostra de concreto confinado com uma camada de CFRP, submetida a carregamento monotônico (linha pontilhada) e cíclico (linha contínua).

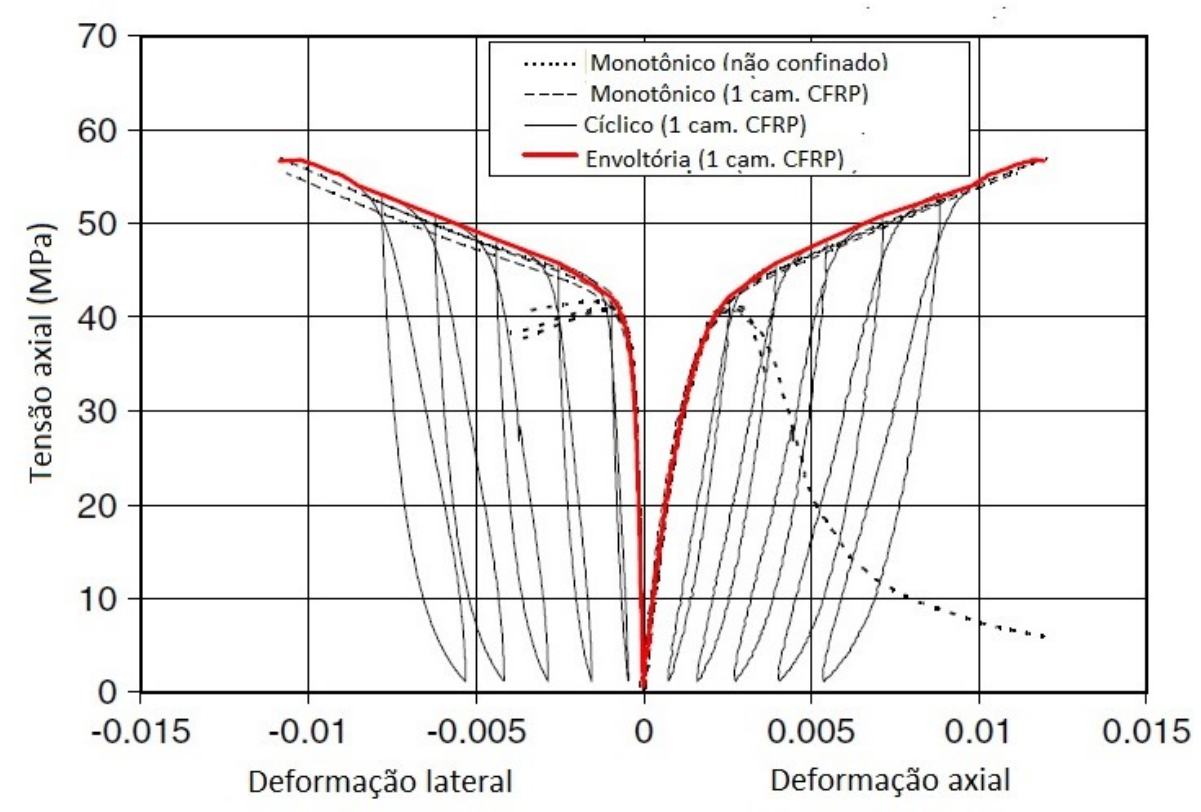

Figura 7. Curvas tensão - deformação para concreto confinado com PRF sob carregamentos monotônicos e cíclicos

Fonte: Lam et al. (2006)

\subsection{Confinamento}

O concreto pode ser submetido a um estado multiaxial de compressão através de confinamento passivo ou ativo, sendo que o confinamento passivo pode ocorrer por diferentes materiais, como o aço ou PRF. Estudos como o de Lim e Ozbakkaloglu (2014a) demonstram que fatores como tipo de confinamento e história de carregamento influenciam o comportamento do concreto sob confinamento. Além disso, Grassl (2004) constatou que o tipo e a rigidez do material confinante também afetam esse comportamento.

\subsubsection{Confinamento ativo e passivo}

O confinamento ativo consiste na existência de uma pressão de confinamento independente do desenvolvimento de deformações laterais que pode ser exercida por fluidos ou por materiais como fios de ligas metálicas com memória de forma ("Shape Memory Alloy" - SMA), como indicado nos estudos de Park et al. (2011). Nesse caso, a intensidade da 
pressão lateral independe da deformação lateral do concreto e pode permanecer constante com acréscimo de carregamento axial e com a expansão radial. Já no confinamento passivo, a tensão de confinamento surge com o desenvolvimento das deformações laterais a partir da atuação do carregamento axial. Outra situação de confinamento possível seria a atuação desses dois tipos de confinamento simultaneamente por meio do uso de protensão nas camisas de confinamento, por exemplo. Nesse caso, uma tensão inicial de confinamento é aplicada, caracterizando um confinamento ativo, porém, com a evolução da deformação lateral ocorre acréscimo de pressão de confinamento devido atuação da camisa, caracterizando um confinamento passivo.

O confinamento passivo pode ser explicado conforme esquema da Figura 8: ao aplicar uma tensão axial $\left(\sigma_{33}\right)$ em um elemento circular de concreto ocorrerá o encurtamento axial e uma expansão radial se o concreto estiver livre para se deslocar nessa direção. Com a utilização de uma parede fina envolvendo o elemento de concreto, a deformação lateral será restringida, desenvolvendo uma pressão de confinamento $\left(\sigma_{r}\right)$. O confinamento passivo pode ocorrer pelo uso de camisas de PRF, camisas de aço ou pela própria armadura transversal.
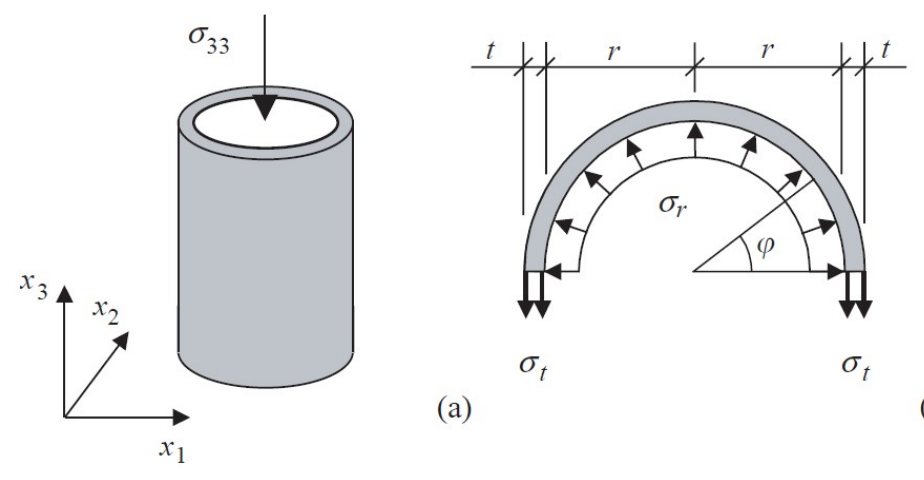

(a)

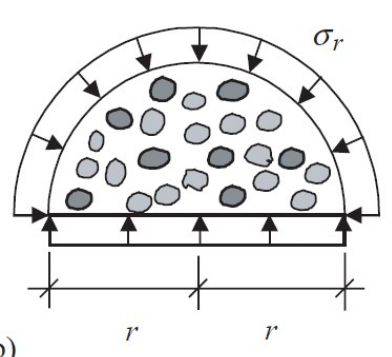

(b)

Figura 8. Efeito do confinamento passivo a) no material confinante b) no concreto. Fonte: Grassl (2004)

Considerando o equilíbrio de forças na direção $x_{1}$ ou $x_{2}$, conforme indicado na Figura 8, a pressão lateral $\left(\sigma_{r}\right)$ é dada pela Eq. (1), para a situação de confinamento uniforme.

$$
\sigma_{r}=\frac{E_{f} \cdot t \cdot \varepsilon_{t}}{r}
$$

Onde: $E_{f}, t, \varepsilon_{t}$ são o módulo de elasticidade, espessura e deformação tangencial do material confinante, respectivamente, e $r$ é o raio do cilindro de concreto.

A diferença entre comportamento do concreto sob confinamento ativo e passivo gerou opiniões diferentes entre os autores. Richart et al. (1928) mostrou acréscimo de resistência 
semelhantes em ensaios de confinamento ativo e passivo utilizando barras de aço espirais. Imran e Pantazopoulou (1996) verificaram que o comportamento de deformação do concreto era dependente do caminho de carregamento, porém, a resistência do concreto não era alterada significativamente.

Segundo experimentos de Ozbakkaloglu, Gholampour e Lim (2016) os confinamentos ativo e passivo apresentaram comportamentos diferentes para mesma pressão de confinamento. A Figura 9 mostra a comparação entre curvas de tensão-deformação axial obtidas em concreto não confinado, confinado ativamente e confinados com PRF, com resistência do concreto não confinado de $128 \mathrm{MPa}$. O comportamento do concreto confinado ativamente confinado é caracterizado pela tensão de pico $\left(f_{c c}^{*}\right)$ e a correspondente deformação axial $\left(\varepsilon_{c c}^{*}\right)$. Observa-se que a forma das curvas tensão-deformação depende do tipo de confinamento (ativo ou passivo). No confinamento ativo, verifica-se uma curva com ramo ascendente parabólico até atingir a tensão de pico $\left(f_{c c}^{*}\right)$ seguida de um ramo descendente, com inclinação variável dependente do nível de confinamento. No confinamento passivo (com PRF) a pressão de confinamento $\left(f_{l}\right)$ cresce gradualmente com o desenvolvimento das deformações laterais $\left(\varepsilon_{l}\right)$. Na Figura 9 verifica-se que para a mesma deformação axial o concreto confinado com PRF (com resistência última lateral $f_{l u, a}$ ) apresenta menor resistência que o concreto confinado ativamente e essa diferença aumenta com o nível de confinamento. Isso indicaria, portanto, que as relações tensão-deformação do concreto dependem do histórico de carregamento.

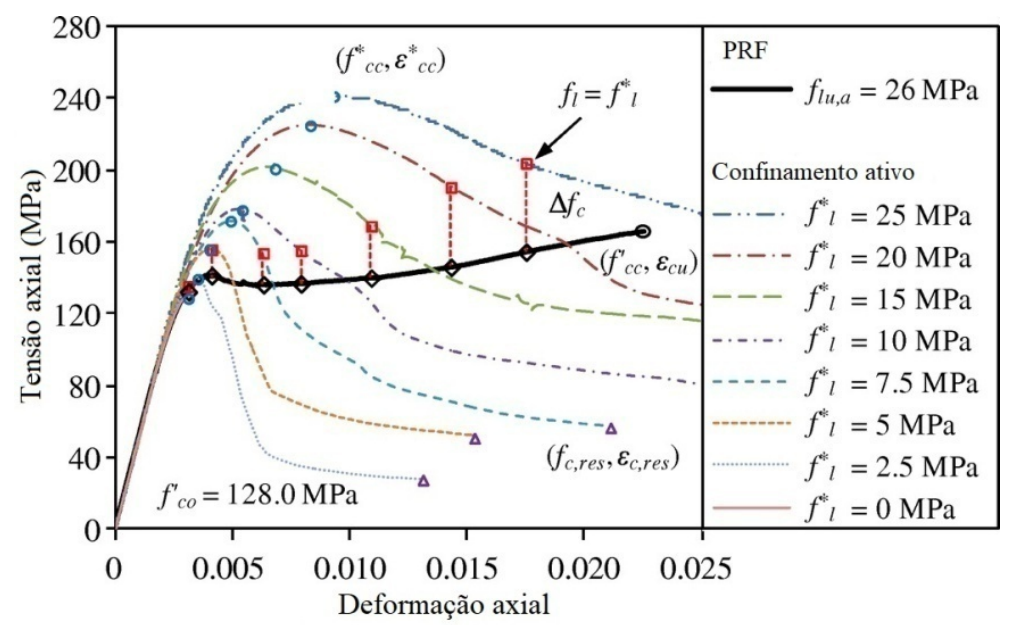

Figura 9. Comparação entre curvas tensão axial- deformação axial entre concretos confinados ativamente ou por PRF. Fonte: Ozbakkaloglu, Gholampour e Lim (2016) 
Li e Wu (2016) também compararam o comportamento do concreto confinado ativamente e por PRF e concluíram que as tensões de confinamentos $\mathrm{f}_{1}$ e $\mathrm{f}_{1}^{*}$ referentes ao confinamento passivo e ativo, respectivamente, são semelhantes para as mesmas deformações axiais, como demonstrado na Figura 10a que apresenta a relação entre essas tensões nos pontos de intersecção das duas curvas deformação lateral - deformação axial. Já na Figura 10b apresenta-se que a resistência do concreto confinado com PRF pode ser considerada entre 0,8 e 0,9 vezes a resistência do concreto confinado ativamente para os mesmos pontos analisados na Figura 10a, ou seja, para tensões de confinamento semelhantes, ocorre diferença significativa na resistência do material quando compara-se confinamento ativo e passivo. Portanto, assim como outros estudos, os resultados confirmam que dada uma deformação axial, deformação lateral e tensão de confinamento, a tensão axial depende do caminho de carregamento.

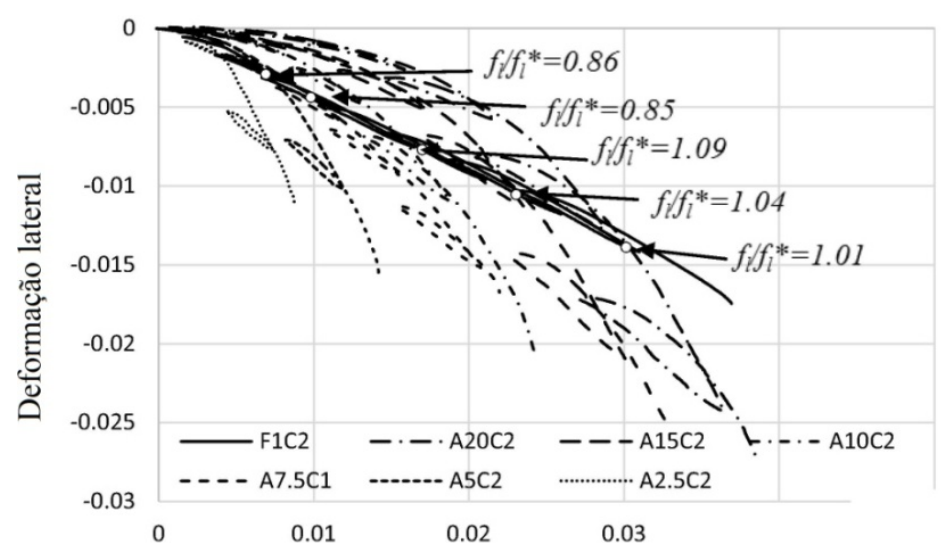

a) Curva deformação lateral - deformação axial

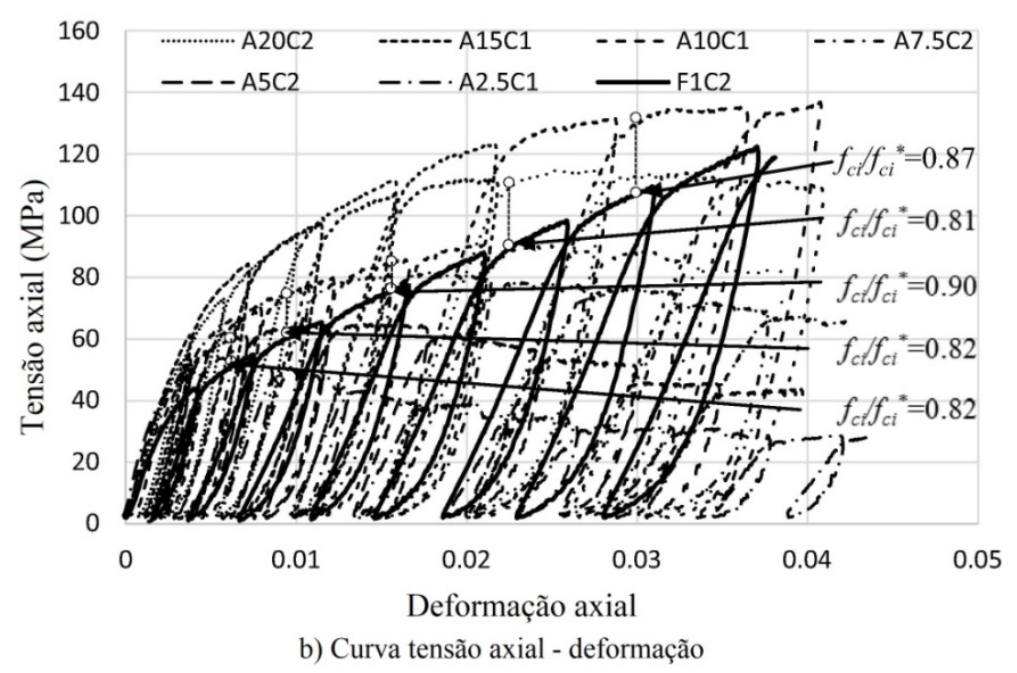

Figura 10. Comparação entre curvas tensão axial- deformação axial entre concretos confinados ativamente ou por PRF. Fonte: $\mathrm{Li}$ e Wu (2016) 
Bazant e Tsubaki (1980) já afirmava que a aplicação de pressão lateral desde o início do carregamento reduz a microfissuração, o que explicaria a maior resistência do concreto obtida para confinamento ativo se comparado ao confinamento passivo, no qual a pressão de confinamento é nula inicialmente e cresce gradativamente com a evolução das deformações laterais, explicando também o aumento da diferença na relação entre a resistência nos dois confinamentos a medida que a pressão lateral do confinamento ativo aumenta.

Portanto, um modelo para previsão do comportamento submetido a diferentes tipos de confinamento deve considerar o seu histórico de carregamento, que é dependente do nível de confinamento.

\subsubsection{Material confinante}

Como materiais confinantes podem ser citados as camisas de aço, concreto, a própria armadura transversal e os compósitos. Os compósitos, mais especificamente os PRF, ganharam destaque como material confinante, principalmente pela sua elevada resistência e módulo de elasticidade. São formados por uma matriz polimérica como poliéster, epóxi ou fenol e fibras de alta resistência, que podem ser de vidro, carbono, aramida ou boro.

Durante muito tempo, os modelos para representação do comportamento do concreto confinado com armadura transversal foram utilizados também para confinamento com PRF, no entanto, como demonstrado por Saaman, Mirmiran e Shahawy (1998), os resultados mostraram-se contra a segurança, devido a diferença entre o comportamento do concreto confinado por aço e por PRF, que fica clara quando observa-se as curvas tensão-deformação de Grassl (2004) - Figura 11a. Segundo o autor, cilindros de concreto confinados com aço apresentam aumento da tensão lateral de confinamento até que a resistência ao escoamento do aço seja atingida, sendo que a partir disso, a pressão de confinamento permanece constante. Portanto, a resistência última do concreto geralmente é atingida para pressão de confinamento constante, o que aproxima esse comportamento do confinamento ativo. Em relação a deformação volumétrica, com o escoamento do aço, o concreto tende a uma expansão volumétrica, conforme indicado na Figura 11b. Em experimentos de cilindros de concreto confinados com Polímeros Reforçados com Fibras de Carbono (CFRP), o aumento da tensão lateral de confinamento ocorre gradualmente até a ruptura do concreto ou da camisa de CFRP, apresentando baixos níveis no início do carregamento e podendo alcançar altos níveis, dependendo da rigidez da camisa, para os quais ocorreria a tendência de compactação volumétrica, conforme indicado na Figura $11 \mathrm{~b}$. 

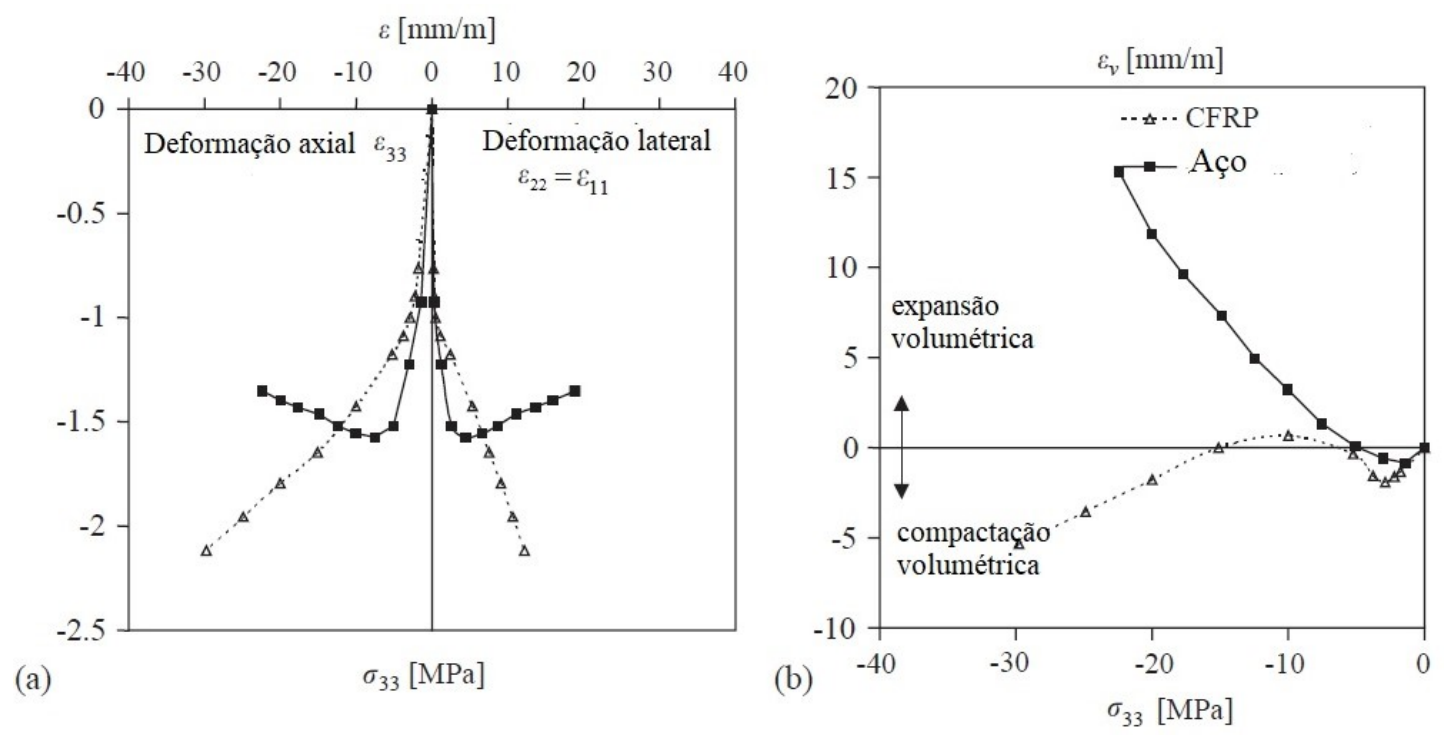

Figura 11. Influência do tipo de material de confinamento a) Tensão-deformação axial e lateral b) deformação volumétrica

Fonte: Grassl (2004)

\subsection{Fundamentos da teoria da plasticidade}

A teoria da plasticidade foi originalmente destinada a materiais metálicos, conforme descrito por Chen (1982). Esses trabalhos descrevem o comportamento plástico, que consiste no aparecimento de deformações irreversíveis quando retirada a solicitação a que o corpo foi submetido. Para os metais, essas deformações surgem quando as tensões excedem um limite chamado de tensão de escoamento $\left(\sigma_{y}\right)$. Com a evolução das deformações plásticas, também ocorre o aumento da tensão de escoamento, sendo que esse fenômeno é chamado de encruamento.

Embora haja semelhança entre o comportamento dos metais e o comportamento macroscópico do concreto devido ocorrência de deformações plásticas, segundo descrição de Nguyen (2005), o mecanismo de dissipação é completamente diferente. Em metais, as deformações plásticas são resultantes dos deslizamentos em nível microscópico ou, conforme afirmam Lemaitre e Chaboche (1994), as deformações permanentes são resultado do deslocamento relativo de átomos que permanecem após descarregamento. No concreto, Lemaitre e Chaboche (1994) explicam que para carregamentos superiores ao limite elástico, 
as microfissuras se espalham para a periferia dos agregados gerando as deformações permanentes, que aumentam consideravelmente para cargas maiores devido à perda de coesão e deslizamentos interfaciais entre argamassa e agregado.

Segundo Lubliner (1989) a plasticidade pode ser vista como tradução de uma realidade física, para sólidos cristalinos dúcteis, ou como aproximação de um comportamento sob certas circunstâncias, no caso do concreto. Por isso, muitos problemas relacionados ao comportamento desse material podem ser resolvidos com sucesso utilizando a plasticidade, como é o caso do concreto submetido predominantemente a compressão.

Em relação ao comportamento do concreto confinado, Karabinis e Rousakis (2002) demonstraram o potencial da teoria da plasticidade para descrever o comportamento tensãodeformação. Nesse sentido, muitos modelos constitutivos baseados na plasticidade, como Mirmiran et al. (2000), Grassl, Lundgren e Gylltoft (2002) e Papanikolaou e Kappos (2007) demonstraram boas representações do comportamento mecânico do concreto, inclusive sob estados multiaxiais de tensão.

Resumidamente, a seguir são apresentadas as premissas dos modelos convencionais de plasticidade, baseadas em uma relação constitutiva elástica, decomposição de deformação total em deformações elástica e plástica, definição de uma superfície de plastificação juntamente com uma lei de encruamento e uma regra de fluxo. Sendo que, segundo Han e Chen (1985), a aplicação da teoria clássica de plasticidade para materiais como o concreto, que apresenta características de amolecimento, exige modificações consideráveis das leis de evolução convencionais (para materiais metálicos). Cada um desses itens está explicado com mais detalhes a seguir.

\subsubsection{Decomposição de deformações}

A formulação clássica da plasticidade não pode abordar o regime de amolecimento, característico de materiais como o concreto, já que seria impossível distinguir os incrementos negativos de tensão que geram apenas descargas elásticas (referentes ao encruamento do material) dos que geram acréscimos de deformações plásticas (caso do trecho com amolecimento). Sendo assim, para esse tipo de comportamento, propõe-se a formulação baseada no espaço de deformações, definida a partir das premissas a seguir.

O tensor de tensões $(\boldsymbol{\varepsilon})$ é decomposto em uma parte elástica $\left(\boldsymbol{\varepsilon}^{\boldsymbol{e}}\right)$ e uma parte plástica $\left(\varepsilon^{p}\right)$, sendo que a parcela elástica está relacionada com o tensor de tensão $(\sigma)$ pelo tensor de quarta ordem de rigidez elástica D, conforme Lei de Hooke (Eq. (2)). O tensor de rigidez 
elástica D é definido pelo módulo de elasticidade do concreto $\left(E_{c}\right)$ e pelo coeficiente de Poisson $(v)$.

$$
\varepsilon=\varepsilon^{e}+\varepsilon^{p} ; \text { onde } \varepsilon^{e}=D^{-1}: \sigma
$$

Portanto, na Eq. (3), a o tensor de tensões $\boldsymbol{\sigma}$ pode ser determinado em função da deformação total e da parcela de deformação plástica, definindo a chamada formulação no espaço das deformações.

$$
\boldsymbol{\sigma}=\boldsymbol{D}: \varepsilon^{e}=\boldsymbol{D}:\left(\varepsilon-\varepsilon^{p}\right)
$$

\subsubsection{Funções de plastificação}

Conforme destacado por Chen (1982), o comportamento do concreto sob estados multiaxiais é dependente do estado de tensão a que está submetido, sendo que a representação da resistência só pode ser alcançada por meio de uma interação adequada de todos os fatores. Portanto, para definição dos critérios de ruptura foram considerados outros critérios, como o de plastificação e início da fissuração. A ruptura é definida como a capacidade máxima de carga do material. Para o concreto, a ruptura pode ser por tração ou compressão, caracterizada por fragilidade ou ductilidade, respectivamente. Como destacado por Chen (1982), o comportamento do concreto sob estado multiaxial de tensões não pode ser representado considerando critérios de ruptura de tração e compressão isoladamente. No entanto, o estudo está restringido a estados multiaxiais de compressão, já que se aborda o confinamento uniforme de elementos sob compressão centrada. Sendo assim, restringe-se a discussão em critérios de ruptura com características dúcteis.

A partir dessas considerações, para representação do comportamento do concreto sob estado multiaxial de compressão, define-se o critério de falha do material a partir do critério de plastificação, ou seja, estado de tensão limite do comportamento elástico, a partir do qual ocorre evolução das deformações plásticas caso seja retirado o carregamento. Quando o estado de tensão atinge a superfície de plastificação, verifica-se a expansão da superfície a medida que as deformações plásticas evoluem até atingir a superfície de ruptura, representando a capacidade máxima de carga do material. Esse fenômeno está ilustrado esquematicamente na Figura 12, onde a superfície inicial (plastificação) genérica atingida para um estado de tensão denominado $\sigma_{y}$ evolui gradativamente até o estado de tensão atual em função de um parâmetro de encruamento isotrópico $\mathrm{R}$, responsável por definir essa evolução. 


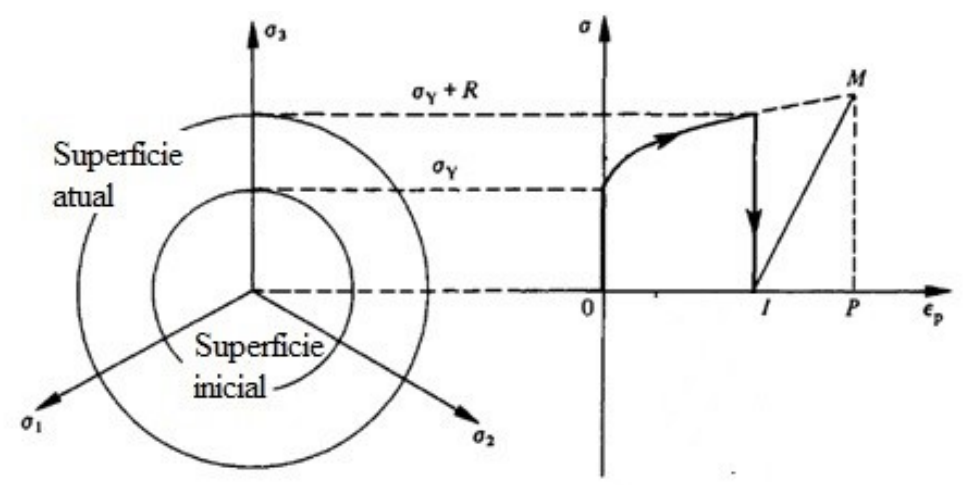

Figura 12. Representação da evolução de uma superfície de uma plastificação genérica no espaço de tensão.

Fonte: Lemaitre e Chaboche (1994)

\subsubsection{Definição da superfície de plastificação/ruptura no espaço das tensões principais}

A superfície de plastificação (f), descrita anteriormente, também pode ser representada no espaço tridimensional das tensões principais, apresentando a forma geral dada na Eq. (4).

$\mathrm{f}\left(\sigma_{1}, \sigma_{2}, \sigma_{3}\right) \leq 0$

A fim de fornecer uma explicação geométrica e física para essa superfície, essa pode ser definida em função dos invariantes de tensão. Sendo assim, o espaço de HaighWestergaard - espaço tridimensional em que os eixos são as tensões principais - é usado para definir a superfície de ruptura/plastificação, sendo que um estado de tensão é determinado por três componentes: hidrostáticas $(\xi)$, desviadoras $(\rho)$ e ângulo de Lode $(\theta)$, definidas nas Eqs. (5), (6) e (7) e com significado geométrico indicado na Figura 13.

$$
\begin{aligned}
& \xi=\frac{\mathrm{I}_{1}}{\sqrt{3}} \\
& \rho=\sqrt{2 \cdot J_{2}} \\
& \cos 3 \theta=\frac{3 \sqrt{3}}{2} \frac{J_{3}}{J_{2}^{\frac{3}{2}}}
\end{aligned}
$$

Onde $I_{1}, I_{2}$ e $I_{3}$ são os invariantes de tensão que são dados pelas Eqs. (8) a (10):

$$
\begin{aligned}
I_{1} & =\left|\sigma_{11}\right|+\left|\sigma_{22}\right|+\left|\sigma_{33}\right| \\
I_{2} & =\left|\begin{array}{ll}
\sigma_{22} & \sigma_{23} \\
\sigma_{32} & \sigma_{33}
\end{array}\right|+\left|\begin{array}{ll}
\sigma_{11} & \sigma_{13} \\
\sigma_{31} & \sigma_{33}
\end{array}\right|+\left|\begin{array}{ll}
\sigma_{11} & \sigma_{12} \\
\sigma_{21} & \sigma_{22}
\end{array}\right| \\
J_{3} & =\operatorname{Det}(\sigma)
\end{aligned}
$$

Os invariantes de tensão desviadora são definidos conforme Eqs. (11) a (13), sendo S o tensor de tensão desviadora.

$$
J_{1}=\left|S_{11}\right|+\left|S_{22}\right|+\left|S_{33}\right|
$$




$$
\begin{aligned}
& J_{2}=\left|\begin{array}{ll}
S_{22} & S_{23} \\
S_{32} & S_{33}
\end{array}\right|+\left|\begin{array}{ll}
S_{11} & S_{13} \\
S_{31} & S_{33}
\end{array}\right|+\left|\begin{array}{ll}
S_{11} & S_{12} \\
\sigma_{21} & S_{22}
\end{array}\right| \\
& J_{3}=\operatorname{Det}(S)
\end{aligned}
$$

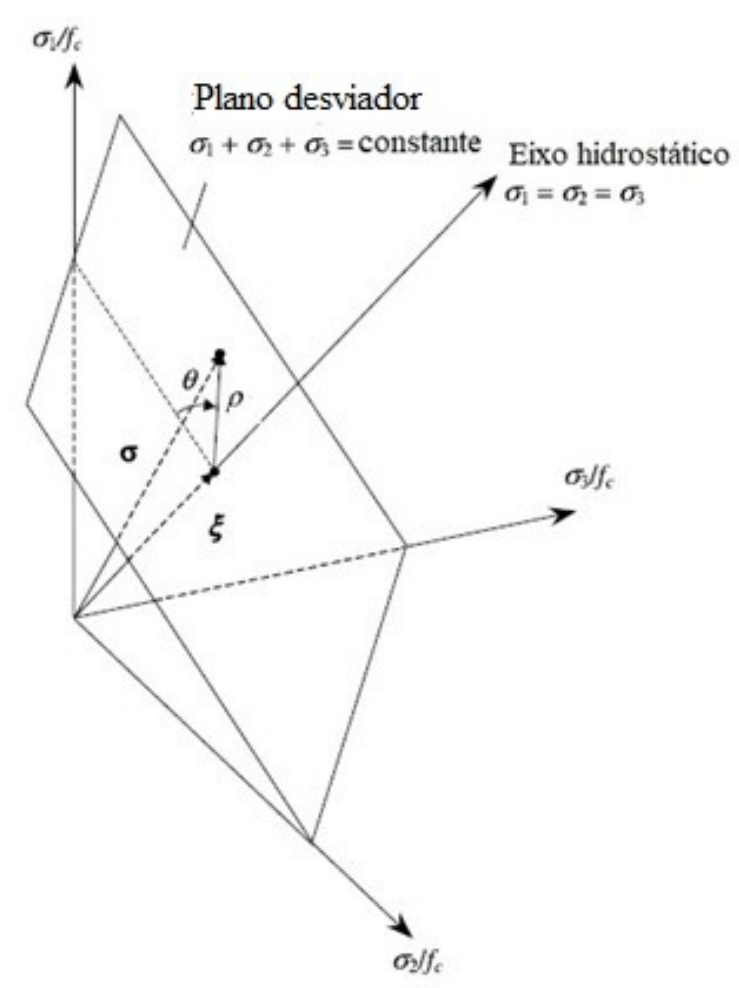

Figura 13. Significado geométrico das componentes no espaço de tensões de HaighWestergaard.

Fonte: Grassl, Lundgren e Gylltoft (2002)

A superfície de plastificação pode ser representada por meio de intersecções dessa superfície com os planos desviadores (planos ortogonais ao eixo hidrostático). A forma das superfícies no plano desviador para diferentes tensões hidrostáticas estão demonstradas na Figura 14a. Observa-se que a forma da seção transversal é variável no eixo hidrostático, sendo aproximadamente triangular para pequenas tensões de compressão e tração e tendendo a uma forma circular para maiores tensões de compressão. A superfície de ruptura também pode ser representada por meridianos no plano $\xi-\rho$, conforme Figura 14b. Os meridianos representam a intersecção da superfície de plastificação com os planos que contém o eixo hidrostático. Sendo assim, dois meridianos, que estão representados na Figura 14b, devem ser destacados: o meridiano de $60^{\circ}$ é o de compressão, que representa uma tensão de compressão uniaxial somada a uma pressão hidrostática (estados de compressão uniaxial e confinamento uniforme) e o meridiano de $0^{\circ}$ é o de tração, correspondente a uma tensão de tração uniaxial somada a uma pressão hidrostática (estado de tração uniaxial, por exemplo). 


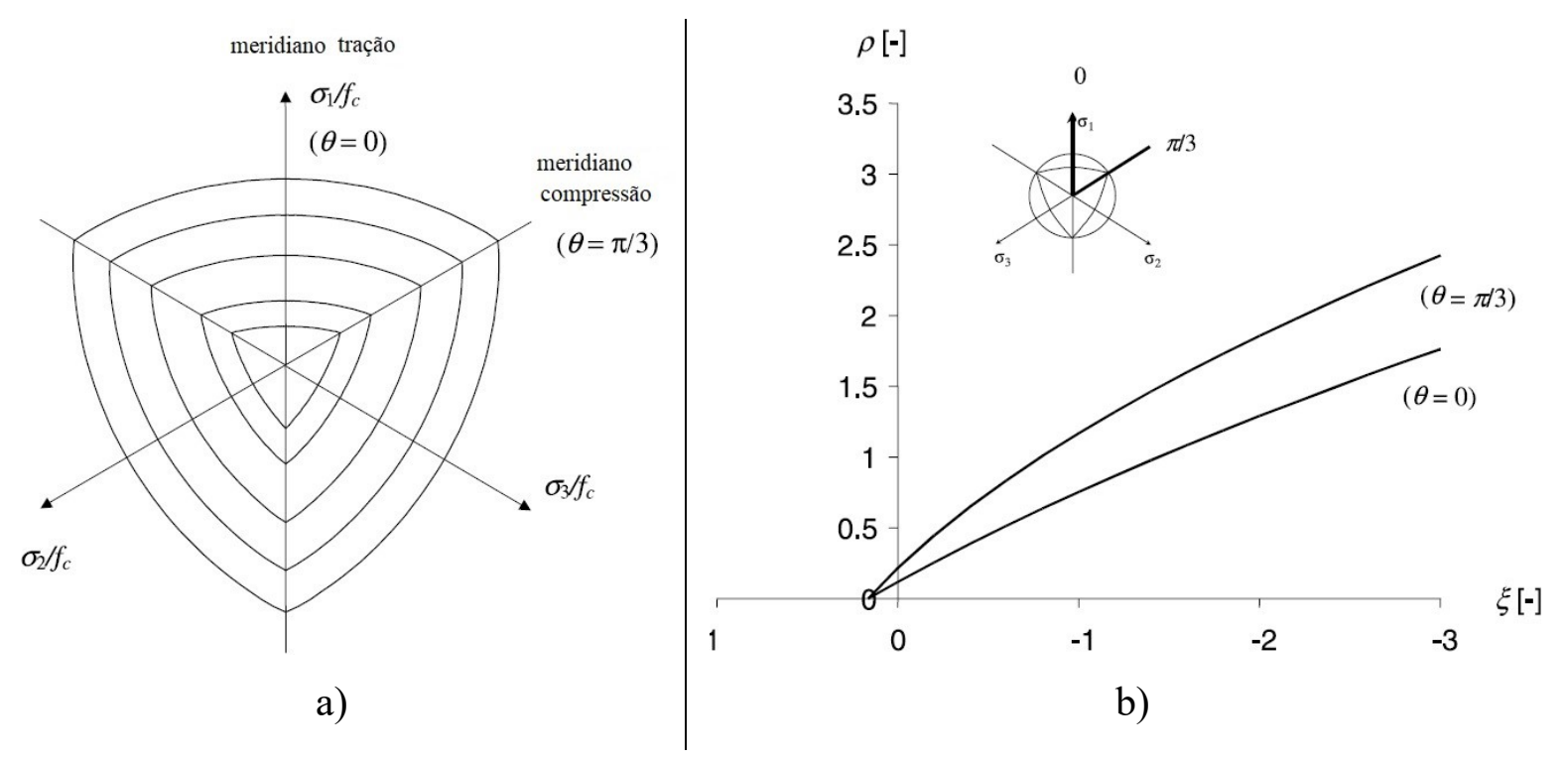

Figura 14. a) Forma da superfície de plastificação no plano desviadores para diferentes tensões hidrostáticas. b) Superfície de plastificação no plano $\xi-\rho$

Fonte: Grassl, Lundgren e Gylltoft (2002)

Chen (1982) cita inúmeras formas de superfície de ruptura, classificadas de acordo com o número de parâmetros. Como exemplo, tem-se a superfície de Tresca, Von Mises, Mohr-Coulomb e Drucker-Praguer. As duas últimas são aplicadas predominantemente a materiais granulares coesivos. Além dessas, outras superfícies mais complexas, com maior número de parâmetros, foram adotadas em inúmeros estudos para representação do comportamento do concreto.

\subsubsection{Encruamento por deformação}

Definida a superfície inicial de plastificação, a lei de encruamento determina como essa superfície evolui com o desenvolvimento das deformações plásticas. Lemaitre e Chaboche (1994) explicam que embora a maioria dos materiais apresente uma forte anisotropia induzida pelo encruamento, comumente utiliza-se um modelo de encruamento isotrópico como representação por simplicidade. Nesse caso, a evolução dessa superfície de plastificação é governada por apenas uma variável escalar que represente a história de carregamento.

Uma vez que o critério geral de plastificação (f), descrito anteriormente, é modificado com a evolução das deformações plásticas, conforme Eq. (14), pela função de encruamento isotrópico (q), que depende de um parâmetro de encruamento (k). 


$$
F=f(\xi, \rho, \theta)-q(k)
$$

O significado dessa função, conforme conceitos da plasticidade, é que para estado de tensão que resulte em um valor negativo para a função $(F<0)$ ocorre permanência no regime elástico. Um estado de tensão que resulte em função igual a zero e variação da função menor que zero $(F=0$ e $\partial F<0)$ corresponde a descarregamento elástico. Já para estado de tensão que resulte em função de carregamento igual a zero e variação da função maior que zero ( $\mathrm{F}=$ 0 e $\partial F>0$ ) ocorre evolução das deformações plásticas.

\subsubsection{Função potencial plástica}

Para completar a representação do comportamento, define-se como as deformações plásticas evoluem quando a superfície de plastificação é atingida. Segundo a teoria da plasticidade, as superfícies de plastificação e a relação tensão-deformação estão conectadas por uma lei de fluxo, responsável por definir a magnitude e direção dos incrementos de deformação plástica.

Portanto, a função potencial plástica é uma lei de fluxo responsável por caracterizar adequadamente a evolução e direção da deformação plástica, afetando diretamente a dilatação lateral do concreto, o que é essencial para descrever o comportamento do material. Essa função pode ser associativa ou não associativa. A função associativa é igual a função de plastificação e os incrementos de deformação plástica são calculados como demonstrado na Eq. (15).

$$
d \varepsilon_{i j}^{p}=\lambda \frac{\partial G}{\partial \sigma_{i j}}=\lambda \frac{\partial F}{\partial \sigma_{i j}}
$$

É amplamente aceito, como citado por Sfer et al. (2002), que uma regra de fluxo não associativa pode descrever melhor a capacidade de deformação do concreto que uma regra de fluxo associativa. Grassl e Jirásek (2006b) também afirmam que a utilização uma função potencial plástica não associativa é importante para descrever adequadamente a expansão volumétrica do concreto, principalmente para baixos níveis de confinamento. Nesse caso, uma função associativa superestima a expansão volumétrica afetando principalmente o comportamento do concreto confinado passivamente, já que superestima também sua resistência. 


\subsection{Fundamentos da teoria do dano}

O trabalho pioneiro que trouxe o conceito de Dano Contínuo e trata a evolução de um campo de defeitos como continuamente distribuídos foi introduzido por Kachanov (1958). Nesse trabalho foi considerada uma variável w, que assumiria valores de 1 (material sem defeitos) a 0 (material completamente destruído), sendo que a quantidade complementar $(\mathrm{D}=$ $1-$ w) é uma medida do estado de deterioração do concreto.

Segundo trabalho de Lemaitre e Chaboche (1994), o dano pode ser interpretado, microscopicamente, como o rompimento de ligações entre átomos que resulta em aumento das microfissuras. No nível da mesoescala, essas microfissuras podem ser representadas por uma área que corresponda à união de todas elas. Sendo assim, o dano isotrópico contínuo pode ser explicado, conforme ilustrado na Figura 15, tomando-se um Elemento Representativo de Volume (RVE), ou seja, suficientemente grande em relação às heterogeneidades do material e suficientemente pequeno para que as derivadas parciais das equações do contínuo sejam significativas, onde $\mathrm{S}$ a área de uma das faces do elemento definida por um plano com versor normal n. Nesse plano, $\bar{S}$ representa a área que oferece resistência, portanto, a área de defeitos $\left(\mathrm{S}_{0}\right)$ é dada pela Eq. (16).

$$
\mathrm{S}_{0}=\mathrm{S}-\overline{\mathrm{S}}
$$

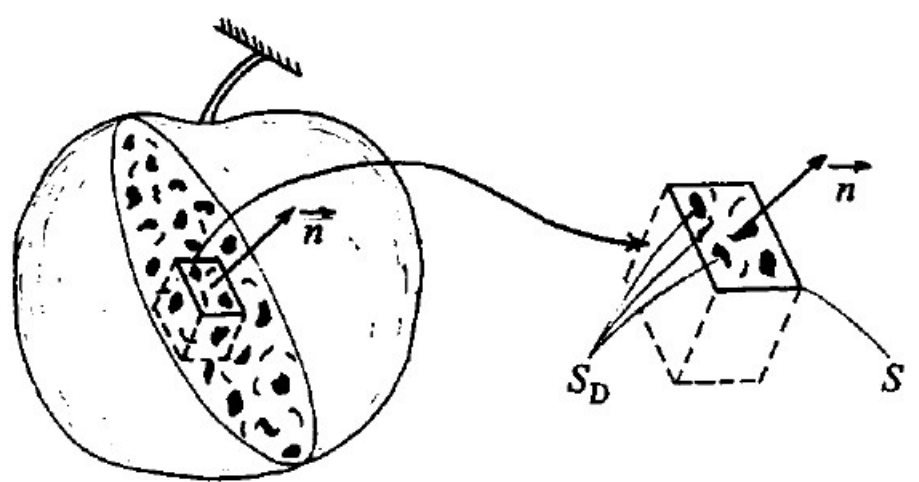

Figura 15. Elemento representativo de volume Fonte: Lemaitre e Chaboche (1994)

Define-se, portanto, a medida local de dano referente a direção $\vec{n}$, conforme Eq. (17).

$\mathrm{D}_{\mathrm{n}}=\lim _{\mathrm{S} \rightarrow 0} \mathrm{~S}_{0} / \mathrm{S}$

A hipótese de dano anisotrópico é correspondente a situação que as fissuras se desenvolvem preferencialmente em uma direção e os valores de D variam de acordo com a direção da normal $(\vec{n})$. Nesse caso, a variável de dano (D) teria natureza tensorial. Segundo 
Jirásek, Rolshoven e Grassl (2004) o dano induzido por fissuras é altamente anisotrópico, porém um modelo de dano isotrópico pode ser adotado para simplificações, já que os modelos anisotrópicos são muito complicados. Segundo Kachanov (1958), a hipótese de dano isotrópico corresponderia a assumir fissuras e cavidades com uma orientação distribuída uniformemente em todas as direções, ou seja, orientação uniforme independente da direção $\vec{n}$, permitindo a representação do dano por um escalar de dano D, conforme Eq. (18). Portanto, em modelos de dano isótropo, como o de Mazars (1986) supõe-se que a isotropia inicial é mantida.

$$
\mathrm{D}_{\mathrm{n}}=\mathrm{D} \quad \forall \vec{n}
$$

A definição da variável de dano conduz ao conceito de tensão efetiva $(\bar{\sigma})$, definido na Eq. (19), que é a tensão relacionada com a área que efetivamente resiste ao carregamento, ou seja, a área não danificada. Já a tensão nominal está relacionada com a área total $(\sigma=\mathrm{F} / \mathrm{S})$.

$$
\bar{\sigma}=\frac{\mathrm{F}}{\bar{S}}
$$

Onde a área que oferece resistência $(\bar{S})$ é dada em função do escalar dano D pela Eq. (20).

$$
\bar{S}=\mathrm{S}-\mathrm{S}_{0}=\mathrm{S}(1-\mathrm{D})
$$

Portanto, a tensão efetiva, para o caso unidimensional, é dada pela Eq. (21).

$$
\bar{\sigma}=\frac{\sigma}{1-\mathrm{D}}
$$

Da plasticidade, tem-se que o tensor de deformações pode ser decomposto em duas parcelas, elástica e plástica. Dessa forma, a relação tensão-deformação pode ser escrita conforme Eq. (22):

$$
\sigma=E\left(\varepsilon-\varepsilon^{p}\right)
$$

Onde $\boldsymbol{E}$ é o tensor da rigidez elástica. A tensão efetiva é definida a partir da rigidez elástica inicial $\left(\boldsymbol{E}_{\mathbf{0}}\right)$, conforme Eq. (23), onde $\boldsymbol{E}_{\mathbf{0}}$ o tensor de rigidez elástica inicial.

$$
\bar{\sigma}=E_{0}\left(\varepsilon-\varepsilon^{p}\right)
$$

Portanto, aplicando a definição de dano explicada anteriormente, o tensor de tensões nominais é escrito em função da rigidez inicial e do escalar de dano, conforme Eq. (24).

$$
\boldsymbol{\sigma}=(1-D) \boldsymbol{E}_{\mathbf{0}}\left(\boldsymbol{\varepsilon}-\boldsymbol{\varepsilon}^{\boldsymbol{p}}\right)
$$

E conclui-se que $\boldsymbol{E}=(1-D) \boldsymbol{E}_{\mathbf{0}}$ e D representa a degradação da rigidez elástica do material. 


\subsection{Plasticidade e dano}

Sabe-se que um modelo constitutivo é um modelo mecânico-matemático que descreve o comportamento tensão-deformação do material. Segundo Soon (1987) o avanço do método dos elementos finitos associado a técnicas numéricas permitiram o aumento da capacidade de cálculo de estruturas confinadas, embora uma boa representação dessas estruturas depende do modelo constitutivo utilizado. Devido à complexidade do concreto, a obtenção de um modelo constitutivo completo se torna difícil. Baseado nessa ideia, muitos autores deram muitas contribuições para representação da não linearidade do concreto baseando-se na plasticidade, mecânica do dano ou ambos.

Alguns autores como Menétrey e Willam (1995), Grassl, Lundgren e Gylltoft (2002) e Papanikolaou e Kappos (2007) usaram apenas a plasticidade para representar o comportamento do concreto. Outros, como Mazars (1986) e Ortiz (1985) usaram o dano mecânico com o conceito de perda de rigidez elástica.

Historicamente, a plasticidade é acoplada ao dano para representar o comportamento do concreto, como pode ser verificado em Lee e Fenves (1998), Grassl e Jirásek (2006a) e Grassl et al. (2013) acoplaram plasticidade e dano isotrópico no mesmo modelo. Isso se deve ao fato de que, segundo Lee e Fenves (1998), a formação de microfissuras no concreto é representada, na plasticidade clássica, por uma função de amolecimento que represente macroscopicamente esse processo. Porém, a microfissuração causa degradação da rigidez, que só pode ser adequadamente representada pela teoria de dano. Ou seja, a não linearidade do comportamento do concreto sob compressão pode ser representada baseando-se em conceitos de plasticidade, dano ou ambos. Quando os parâmetros são adotados adequadamente, diferentes modelos de plasticidade são capazes de prever o comportamento do concreto sob carregamentos monotônicos. Porém, quando se trata de carregamentos cíclicos, somente a incorporação do dano é capaz de representar a perda de rigidez do material nos descarregamentos.

A Figura 16 exemplifica a combinação de plasticidade e dano. No item a, está identificada a capacidade da teoria do dano de descrever a degradação da rigidez do material. No item b, demonstra-se a possibilidade de previsão da evolução das deformações plásticas por meio da plasticidade, sem capturar a perda de rigidez elástica em situações de descarregamento. Portanto, a combinação de plasticidade e dano, destacada no item c, é capaz de descrever o comportamento do concreto em relação às deformações permanentes e perda 
de rigidez elástica, permitindo representar adequadamente carregamento monotônicos e cíclicos.

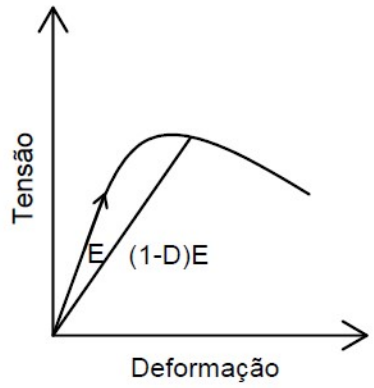

a)

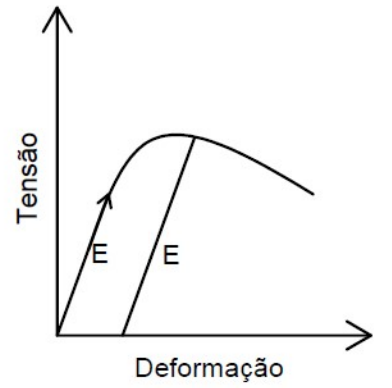

b)

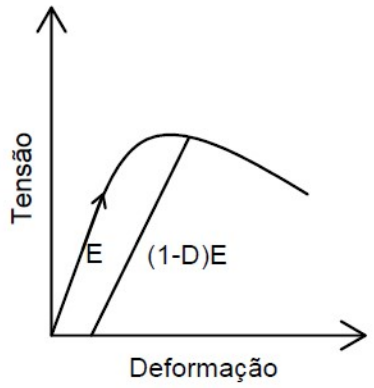

c)

Figura 16. Comportamento tensão-deformação baseado no princípio do dano (a), plasticidade (b), plasticidade e dano (c).

Fonte: Jason et al. (2006)

Quanto à forma de acoplar dano e plasticidade, podem ser citados dois tipos de modelos, conforme explicado por Heinze e Galvan (2016). O primeiro deles consiste no desacoplamento entre degradação da rigidez e deformações plásticas, por meio do conceito de tensões efetivas, que são corrigidas pela variável de dano isotrópico. Como exemplos desse tipo de modelos podem ser citados, tais como Grassl e Jirasek (2006a), Omidi et al. (2013) e $\mathrm{Wu}$ et al. (2006). O segundo tipo de modelo, ou fortemente acoplados, utiliza a degradação das propriedades elásticas para calcular deformações plásticas. Esses modelos acoplados baseiam-se em tensões nominais e apresentam como característica algoritmos complexos susceptíveis a instabilidades. Como exemplo, podem ser citados os modelos de Salari et al. (2004) e Shao et al. (2006).

No primeiro tipo o crescimento do dano é dado em função das deformações plásticas e a evolução das deformações plásticas não depende da evolução do dano. Segundo Vu et al. (2017), uma interpretação física desse tipo de modelo é que a plasticidade pode ser considerada como um mecanismo ativo de deformação e dissipação de energia, e o dano seria o mecanismo passivo, ou seja, só ocorre após a ocorrência de deformação plástica. Segundo Lee e Fenves (1998), ao incorporar a degradação da rigidez em um modelo de plasticidade, a utilização de modelos de danos descritos em termos de tensão efetiva apresentam vantagens consideráveis, pois permitem desacoplar o dano das relações constitutivas do modelo de plasticidade simplificando as equações de evolução. 


\section{MODELO CONSTITUTIVO}

Este capítulo apresenta todas as funções, critérios e considerações que permitiram a elaboração do modelo constitutivo para previsão do comportamento do concreto confinado, com base na teoria da plasticidade e dano. Também são apresentados os critérios utilizados para calibração do modelo. Destaca-se que as equações do modelo foram rearranjadas para permitir a utilização de um processo incremental explícito de implementação. O número de parâmetros do modelo foram reduzidos se comparado a modelos existentes, a fim de facilitar o processo de calibração e conseqüentemente, a utilização prática do modelo.

\subsection{Modelo de plasticidade}

O modelo constitutivo é composto basicamente por uma superfície de plastificação derivada da superfície de ruptura de Mohr-Coulomb, funções de encruamento diferentes para o ramo ascendente e descendente e deformação plástica desviadora como parâmetro de encruamento.

\subsubsection{Superfície de plastificação}

Para descrever o comportamento do concreto confinado foi adotada a superfície de ruptura de Mohr Coulomb. Essa superfície depende de dois parâmetros independentes, apresenta meridianos lineares (ou seja, as intersecções da superfície de ruptura com o plano que contém o eixo hidrostático são retas) e seção transversal no plano desviador apresenta forma hexagonal, como demonstrado na Figura 17. 

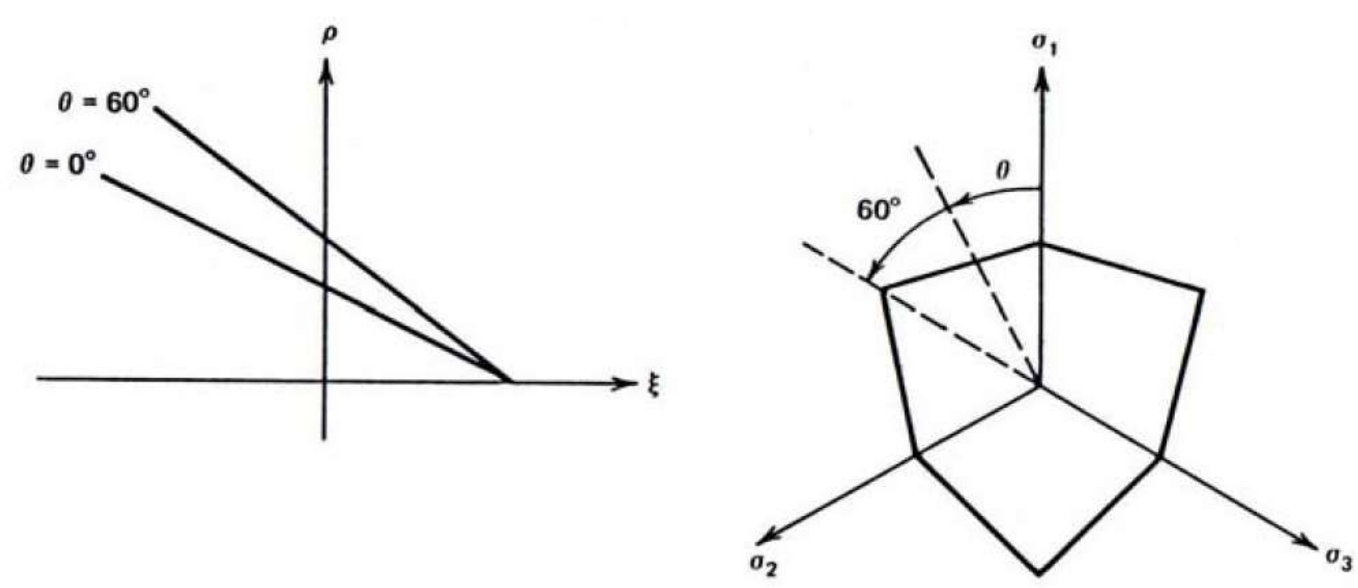

Figura 17. Envoltória de Mohr-Coulomb no plano $\xi$ - $\rho$ e no plano desviador. Fonte: Chen (1982)

Adotou-se essa superfície devido sua simplicidade, pois envolve apenas dois parâmetros. Conforme citado por Yu et al. (2010), envoltórias como de Mohr-Coulomb e Ducker Prager, que dependem de dois parâmetros e apresentam meridianos lineares, são capazes de capturar o aumento da capacidade na resistência a tensões cisalhantes com o aumento da pressão hidrostática. Portanto, esse tipo de superfície é capaz representar o comportamento do concreto uniformemente confinado, que apresenta esse tipo de comportamento com o aumento das tensões hidrostáticas.

A envoltória de Mohr-Coulomb depende de um ângulo de atrito interno $(\phi)$ e de um parâmetro denominado coesão (c) e pode ser escrita conforme Eq. (25).

$\tau=c-\sigma \cdot \tan \phi$

sendo $\tau$ a tensão de cisalhamento e $\sigma$ a tensão normal atuante. A envoltória de MohrCoulomb, em função das tensões normais e de cisalhamento, está demonstrada na Figura 18.

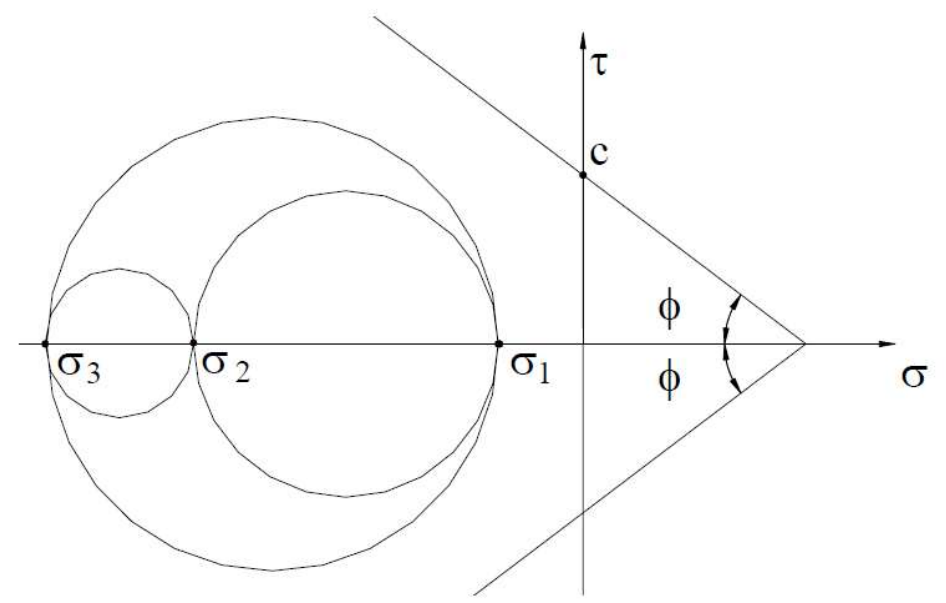

Figura 18. Envoltória de Mohr-Coulomb no plano $\sigma-\tau$ Fonte: Carrazedo (2002) 
A envoltória de Mohr-Coulomb também pode ser escrita em função das tensões principais, conforme Eq. (26):

$\sigma_{1} \cdot \frac{(1+\operatorname{sen} \phi)}{2 \cdot c \cdot \cos \phi}-\sigma_{3} \cdot \frac{(1-\operatorname{sen} \phi)}{2 \cdot c \cdot \cos \phi}=1$

Sendo $\sigma_{1}>\sigma_{2}>\sigma_{3}$.

A Eq. (26) indica que a envoltória é definida sem consideração do efeito da tensão principal intermediária $\left(\sigma_{2}\right)$, o que seria uma fonte de erro para o estado de compressão biaxial, por exemplo, pois não consideraria o acréscimo de resistência do material devido ao acréscimo de tensão de compressão nesse estado de tensão. No entanto, no estado de compressão triaxial uniforme a independência da tensão intermediária não é prejudicial para representação do comportamento do confinamento uniforme, pois as duas tensões de confinamento são iguais $\left(\sigma_{1}=\sigma_{2}\right)$.

$\mathrm{O}$ parâmetro c pode ser definido em função da resistência última do concreto não confinado $\left(f_{c 0}\right)$ quando a Eq. (26) é simplificada para o estado uniaxial, ou seja, quando se assume $\sigma_{1}=0$ e $\sigma_{3}=f_{c 0}$. Dessa forma, o parâmetro c fica definido pela Eq. (27). Conseqüentemente, no caso de confinamento uniforme, a Eq. (26) pode ser escrita em função da pressão lateral $\left(f_{l}\right)$, da resistência do concreto confinado $\left(f_{c c}\right)$ e da resistência do concreto não confinado $\left(f_{c 0}\right)$, como descrito na Eq. (28).

$$
\begin{aligned}
& c=f_{c 0} \cdot \frac{(1-s e)}{2 \cdot \cos \phi} \\
& f_{c c}=f_{c 0}+f_{l} \cdot \frac{1+\operatorname{sen} \phi}{1-\operatorname{sen} \phi}
\end{aligned}
$$

Assumindo o valor de $37^{\circ}$ para o ângulo de atrito, como recomendado por Shehata et al. (2001) e outros autores, a Eq. (28) pode ser reescrita resultando na Eq. (29), que indica uma relação linear entre o aumento da tensão de confinamento e tensão lateral.

$$
f_{c c}=f_{c 0}+4,02 \cdot f_{l}
$$

A envoltória de Mohr-Coulomb também pode ser escrita em termos dos invariantes de tensão, conforme Eq. (30).

$f(\xi, \rho, \theta)=\frac{\xi}{\sqrt{3}} \cdot \operatorname{sen} \phi+\frac{3 \cdot \rho}{2} \cdot \operatorname{sen}\left(\theta+\frac{\pi}{3}\right)+\frac{\rho}{\sqrt{6}} \cdot \cos \left(\theta+\frac{\pi}{3}\right) \cdot \operatorname{sen} \phi-\mathrm{c} \cdot \cos \phi \quad$ Eq. (30)

Para o caso particular de confinamento uniforme, em que $\theta=60^{\circ}$ (meridiano de compressão), a função pode ser simplificada, resultando na Eq. (31).

$$
f(\xi, \rho, \theta)=\frac{\xi \cdot \operatorname{sen} \phi}{\sqrt{3} \cdot \cos \phi}+\frac{3 \cdot \rho}{2 \cdot \sqrt{6} \cdot \cos \phi}+\frac{\rho \cdot \operatorname{sen} \phi}{2 \cdot \sqrt{6} \cdot \cos \phi}-\mathrm{c}
$$


onde a tensão hidrostática $(\xi)$ e a tensão desviadora $(\rho)$ são dadas pelas Eqs. (32) e (33), respectivamente.

$$
\begin{aligned}
& \xi=\frac{\mathrm{I}_{1}}{\sqrt{3} f_{c}} \\
& \rho=\frac{\sqrt{2 \cdot J_{2}}}{f_{c}}
\end{aligned}
$$

sendo $I_{1} \quad$ o primeiro invariante de tensão e $J_{2}$ o segundo invariante de tensão desviadora.

\subsubsection{Parâmetro de encruamento}

Papanikolaou e Kappos (2007) descrevem que o processo de encruamento e amolecimento do concreto são função do parâmetro de encruamento (k) que pode ser controlado pelo comprimento do vetor de deformação plástica ou pelo trabalho plástico, como adotado por Han e Chen (1985), por exemplo. Porém, essa consideração não descreve o aumento da capacidade de deformação do concreto sob compressão multiaxial. Portanto, outras técnicas foram sugeridas, com parâmetro de encruamento definido a partir da deformação plástica acumulada, como adotado por Imran e Pantazopoulou (2001), Grassl (2006a) e Farahmandpour (2017), por exemplo, descrevendo com maior ou menor eficácia a capacidade de deformação do material. A desvantagem citada, nesse caso, é a necessidade de definição de maior número de parâmetros que, em geral, representam significado físico fraco, dificultando a calibração.

Para superar essa desvantagem Grassl, Lundgren e Gylltoft (2002) adotaram a própria deformação plástica volumétrica como parâmetro de encruamento, pois constataram similaridades nas curvas de tensão-deformação axial do concreto não confinado e confinado em relação a esse parâmetro. Papanikolaou e Kappos (2007) adotaram o mesmo parâmetro e indicaram que com a associação de uma função potencial plástica adequada, a capacidade de deformação do concreto confinado pode ser descrita adequadamente. Ainda assim, os modelos apresentam limitações quanto à previsão da deformabilidade do concreto, principalmente quanto se trata de confinamento com PRF.

Há ainda, autores como Chi et al. (2014) e Lu et al. (2016) que adotaram a deformação plástica desviadora como parâmetro de encruamento, que também foi adotada como parâmetro nesse trabalho. Nesse caso, também é necessário incluir na definição do parâmetro 
de encruamento uma relação com o nível de confinamento. Nesse sentido, o parâmetro de encruamento normalizado, conforme definido em Lu et al. (2016), é definido pela Eq. (34).

$$
k=\frac{\varepsilon_{d}^{p}}{\varepsilon_{d 0}^{p}}
$$

sendo $\varepsilon_{d 0}^{p}$ a deformação plástica desviadora correspondente ao pico de tensão e $\varepsilon_{d}^{p}$ a deformação plástica desviadora, definida conforme Eq. (35).

$$
\varepsilon_{d}^{p}=\sqrt{\frac{2}{3} e_{i j}^{p} e_{i j}^{p}}=\sqrt{\frac{2}{3}\left(\varepsilon_{i j}^{p}-\frac{1}{3} \varepsilon_{v}^{p} \delta_{i j}\right)\left(\varepsilon_{i j}^{p}-\frac{1}{3} \varepsilon_{v}^{p} \delta_{i j}\right)}
$$

Onde $e_{i j}^{p}$ é a parte desviadora do tensor de deformações, $\varepsilon_{v}^{p}$ é a deformação plástica volumétrica e $\delta_{i j}$ é o delta de Kronecker.

Como indicado na Eq. (34), a definição do parâmetro de encruamento exige a definição da deformação desviadora de pico $\left(\varepsilon_{d 0}^{p}\right)$, sendo que verifica-se uma relação entre essa deformação e o estado de tensão, ou seja, o nível de confinamento do material, conforme demonstrado nos resultados experimentais de alguns estudos apresentados por Lu et al. (2016), na Figura 19. Os experimentos indicam uma relação linear entre a deformação desviadora correspondente ao pico de tensão (normalizada pela deformação desviadora correspondente ao pico de tensão do estado uniaxial $\varepsilon_{1, d 0}^{p}$ ) e a tensão de confinamento do material $\left(\sigma_{3}\right)$.

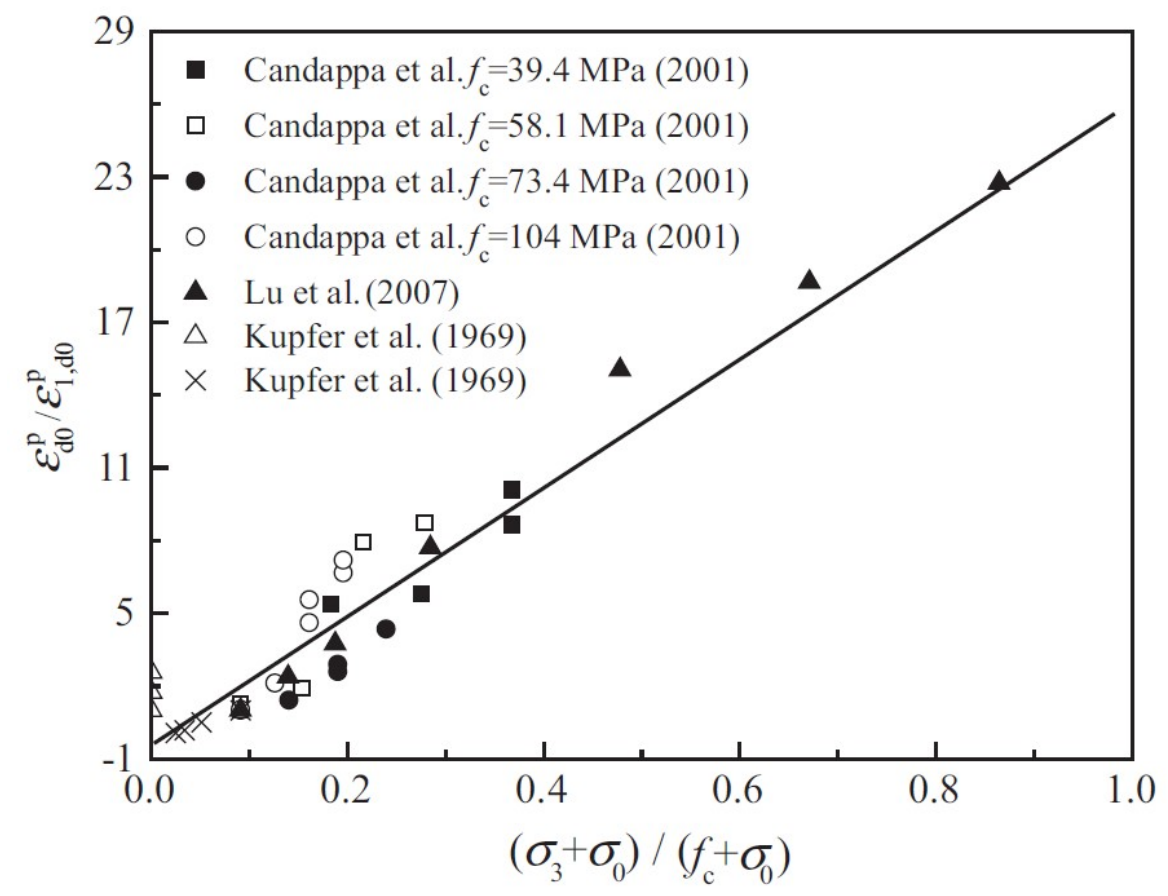

Figura 19. Relação entre deformações desviadoras de pico e tensão de confinamento.

Fonte: Lu et al. (2016) 
A partir desses resultados, Lu et al. (2016) definiram a relação linear da Eq. (36) entre as deformações plásticas desviadoras correspondentes ao pico de tensão $\left(\varepsilon_{d 0}^{p}\right)$ e a tensão de confinamento $\left(\sigma_{3}\right)$.

$$
\frac{\varepsilon_{d 0}^{p}}{\varepsilon_{1, d 0}^{p}}=28,12 \frac{\sigma_{3}+\sigma_{0}}{f_{c}+\sigma_{0}}-1,56
$$

Sendo $\varepsilon_{1, d 0}^{p}$ a tensão desviadora de pico na compressão uniaxial, $\sigma_{3}$ a tensão de confinamento, $f_{c}$ é a resistência última a compressão uniaxial e $\sigma_{0}$ a resistência última a tração (definida como $1 / 10$ da resistência a compressão do concreto).

A Figura 21 apresenta uma calibração dessa relação linear utilizando resultados existentes na literatura dos estudos de Candappa, Sanjayan e Setunge (2001), Lahlou et al. (1992) e Imran e Pantazopoulou (1996), que resultou em uma relação linear semelhante a obtida por Lu et al. (2016), conforme demonstrado na Eq. (37).

$$
\frac{\varepsilon_{d 0}^{p}}{\varepsilon_{1, d 0}^{p}}=33,27 \frac{\sigma_{3}+\sigma_{0}}{f_{c}+\sigma_{0}}-1,76
$$

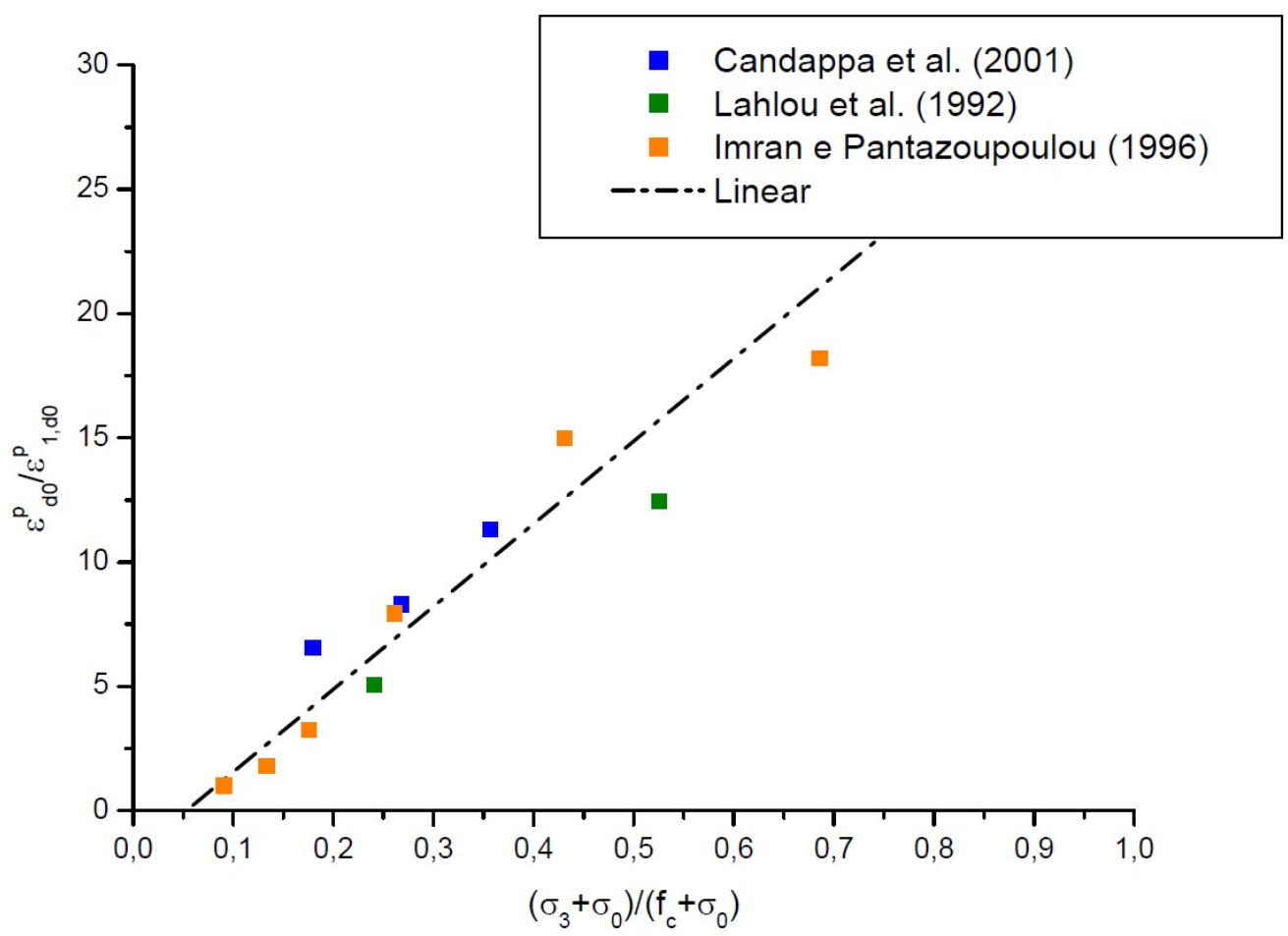

Figura 20. Relação entre deformações desviadoras de pico e tensão de confinamento.

Fonte: Autora (2018)

Considerando a semelhança nos coeficientes que definem a relação linear analisando experimentos de diferentes autores, adota-se a relação linear apresentada por Lu et al. (2016) para definição do parâmetro de encruamento do modelo proposto. 


\subsubsection{Função de encruamento}

As funções de encruamento $\left(\mathrm{q}_{\mathrm{h}}\right)$ e amolecimento $\left(\mathrm{q}_{\mathrm{s}}\right)$ são responsáveis por modificar a forma e o tamanho da função de plastificação a medida que as deformações plásticas evoluem, e consequentemente, modificam a resposta do material. A Eq. (38) indica a modificação de uma função de plastificação genérica por uma função de encruamento $(q(k))$.

$$
f_{p}(\sigma, k)=\sigma-q(k)
$$

Para a envoltória de Mohr-Coulomb, a função de plastificação fica definida conforme Eq. (39).

$$
f_{p}(\sigma, k)=\sigma_{1} \cdot \frac{(1+\operatorname{sen} \phi)}{f_{c 0} \cdot(1-\operatorname{sen} \phi)}-\frac{\sigma_{3}}{f_{c 0}}-q(k)
$$

Ou ainda, a função de plastificação pode ser definida em função dos invariantes de tensão, conforme Eq. (40).

$$
f_{p}(\xi, \rho, \phi, k)=\frac{2 \cdot \xi \cdot \operatorname{sen} \phi}{\sqrt{3} \cdot(1-\operatorname{sen} \phi)}+\frac{\rho \cdot(3+\operatorname{sen} \phi)}{\sqrt{6} \cdot(1-\operatorname{sen} \phi)}-q(k)
$$

No modelo proposto, a função de encruamento é dividida em duas funções, uma relativa ao ramo ascendente $\left(q_{h}(k)\right)$ e a outra relativa ao ramo descendente ou pós-pico $\left(q_{s}(k)\right)$ da curva tensão-deformação. Para o trecho ascendente, adotou-se a função cúbica utilizada por Grassl (2006a), demonstrada na Eq. (41). Destaca-se que a função de encruamento referente ao ramo descendente assume valor unitário.

$$
q_{h}(k)=q_{h 0}+\left(1-q_{h 0}\right)\left(a \cdot k^{3}+b \cdot k^{2}+c \cdot k\right)
$$

Os parâmetros $\mathrm{a}, \mathrm{b}$ e c são definidos em função de um único parâmetro $\left(\beta_{1}\right)$, que é responsável por modificar a inclinação inicial do trecho ascendente da função de encruamento. Além disso, essa função depende do limite elástico, representado pelo parâmetro $q_{h 0}$, que representa a relação entre a tensão limite do comportamento elástico e a resistência última do concreto sob carregamento uniaxial $\left(q_{h 0}=\frac{\sigma_{3 l i m}}{f_{c}}\right)$. Os parâmetros a, b e c estão definidos nas Eqs. (42) a (44), respectivamente.

$$
\begin{aligned}
& a=\frac{\beta_{1}}{1-q_{h 0}}-2 \\
& b=\frac{-2 \cdot \beta_{1}+3 \cdot\left(1-q_{h 0}\right)}{1-q_{h 0}} \\
& c=\frac{\beta_{1}}{1-q_{h 0}}
\end{aligned}
$$


Para o ramo descendente, adotou-se a função utilizada por Lu et al. (2016), que está indicada na Eq. (45). Destaca-se que a função de encruamento referente ao ramo ascendente assume valor unitário no trecho pós-pico.

$$
q_{s}(k)=\frac{k}{\beta_{2}(k-1)^{2}+k}
$$

A Figura 21 mostra a influência do parâmetro $\beta_{1}$ no trecho ascendente da função de encruamento. E a Figura 22 mostra a influência do parâmetro $\beta_{2}$ no trecho descendente da função de encruamento.

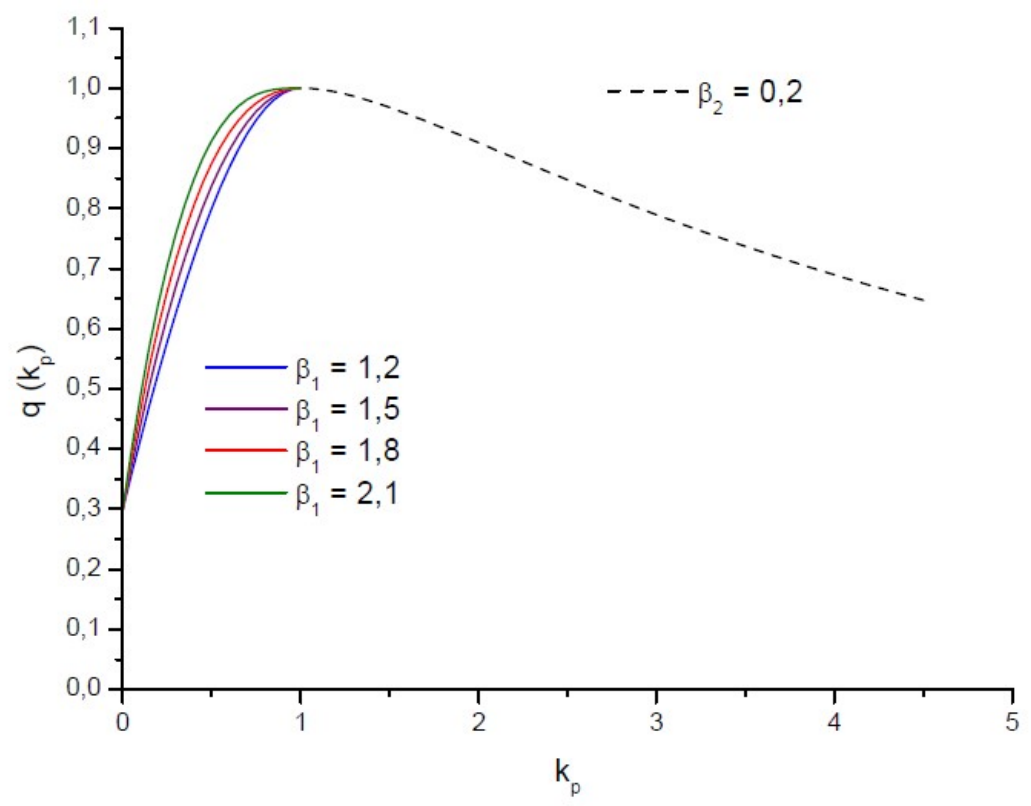

Figura 21. Influência do parâmetro $\beta_{1}$ no trecho ascendente da função de encruamento. Fonte: Autora (2018)

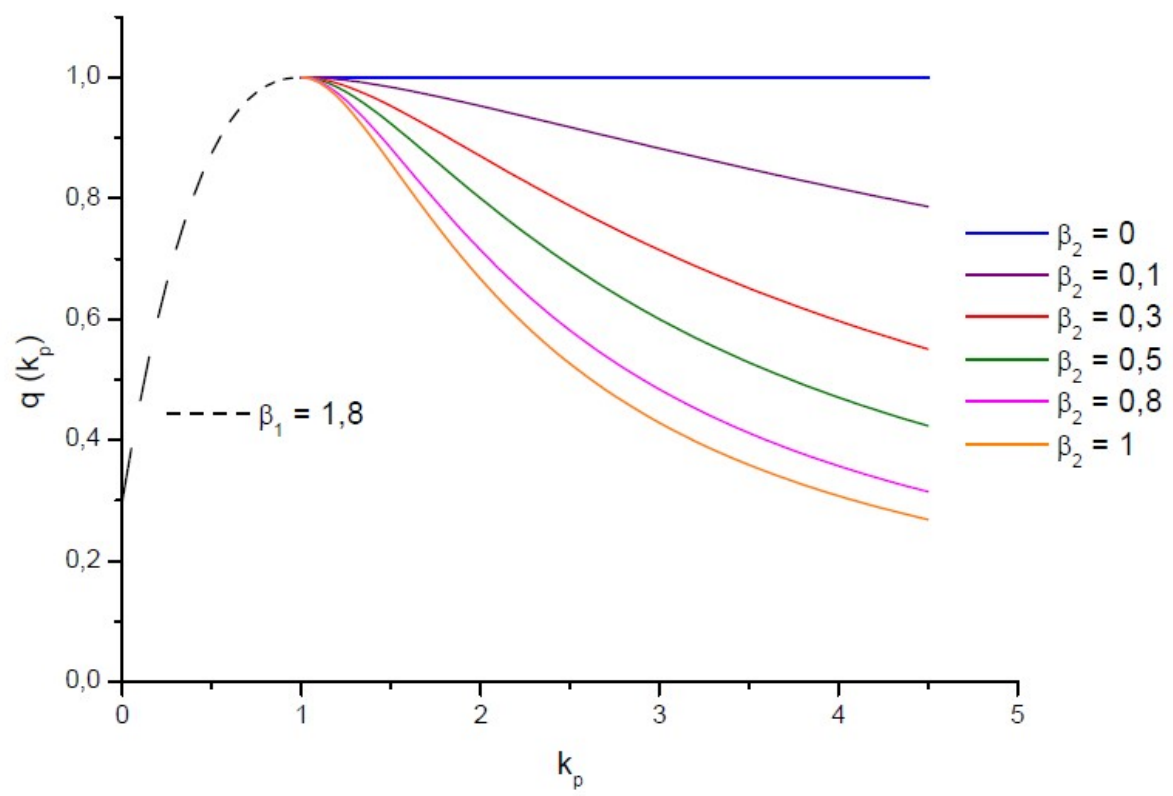

Figura 22. Influência do parâmetro $\beta_{2}$ no trecho descendente da função de encruamento. Fonte: Autora (2018) 
Para o confinamento passivo há dificuldade em definir o ponto da transição do ramo ascendente e descendente da função de encruamento $\left(q_{h}=q_{s}=1\right)$ a partir da curva tensãodeformação, devido ao aspecto da curva tensão-deformação que não apresenta pico bem definido, pois apresenta geralmente comportamento bilinear. Portanto, nesse caso, não é possível extrair a deformação desviadora para esse ponto de transição dos resultados experimentais, como foi feito com os experimentos de confinamento ativo. Essa análise seria importante para definição do parâmetro de encruamento no confinamento passivo a fim de analisar a regra de evolução da deformação desviadora de pico, assim como feito anteriormente. Como simplificação para essa limitação, considera-se plausível a hipótese de utilização da própria deformação plástica desviadora da compressão uniaxial como a deformação referente ao "pico" ( $\left.\varepsilon_{d 0}^{p}\right)$ para definir o parâmetro de encruamento $\left(\mathrm{k}=\varepsilon_{d}^{p} / \varepsilon_{d 0}^{p}\right)$. Isso se justifica pelas observações de experimentos de confinamento com PRF, nos quais percebe-se que a evolução da tensão de confinamento é lenta devido às características de deformabilidade do concreto e rigidez dos compósitos, fazendo com que essa transição ocorra para pequenas tensões de confinamento. Destaca-se que essa aproximação se torna menos eficiente a medida que a rigidez da camisa aumenta, já que o nível de confinamento, assim como as deformações plásticas desviadoras na transição das funções de encruamento aumentam, se afastando do parâmetro normalizador adotado, referente a compressão uniaxial.

Considerando a hipótese citada anteriormente, as funções de encruamento propostas e a função de plastificação baseada em Mohr-Coulomb foram geradas curvas para a função de encruamento baseadas nos dados experimentais obtidos por Raiz (2014), no Laboratório do Departamento de Estruturas. Os resultados estão indicados na Figura 23, na qual se observa-se que, considerando essa hipótese, o comportamento das funções de encruamento é semelhante para diferentes materiais e níveis de confinamento, com valores de pico da função muito próximos ao parâmetro de encruamento unitário. Portanto, justifica-se a aproximação utilizada para o confinamento passivo de que a deformação desviadora referente à transição do trecho ascendente para o descendente é igual aproximadamente a deformação desviadora no pico da compressão uniaxial $\left(\varepsilon_{d 0}^{p} \approx \varepsilon_{1, d 0}^{p}\right)$. 


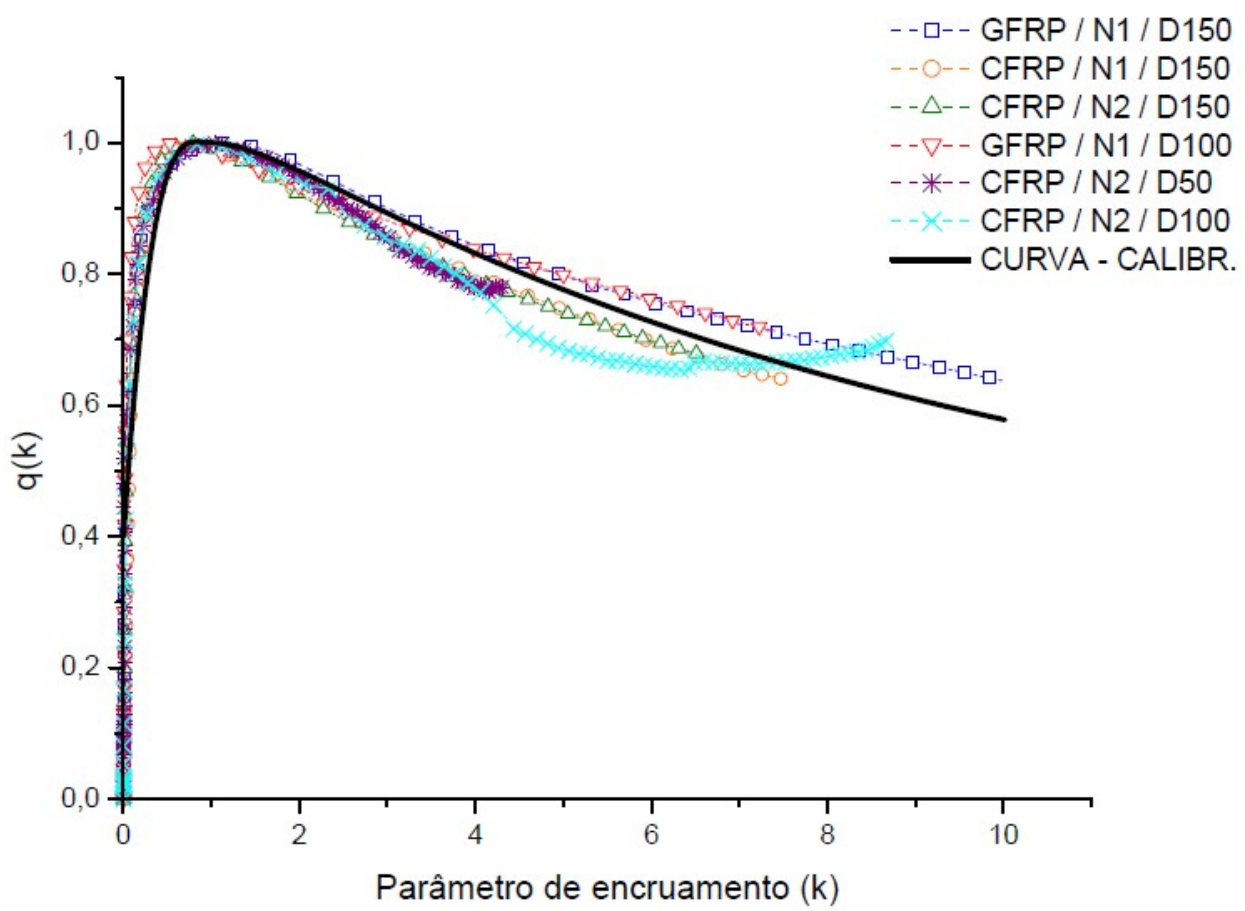

Figura 23. Funções de encruamento geradas para conjunto de dados experimentais de confinamento passivo de Raiz (2014)

Fonte: Autora (2018)

A partir dessas curvas referentes às funções e hipóteses adotadas para o modelo, geradas a partir dos dados experimentais, também foram estabelecidos alguns limites para os parâmetros que definem as funções de encruamento. O parâmetro $q_{h 0}$ que representa a relação entre a tensão axial referente ao limite elástico e a resistência última na compressão uniaxial apresenta valores definidos no intervalo de 0,3 e 0,4 , conforme consagrado em muitos estudos sobre o comportamento do concreto sob compressão uniaxial. O parâmetro $\beta_{1}$ que define a inclinação do trecho ascendente deve ser limitado ao intervalo 1,8 e 2,2, a fim de que a função cúbica gere uma boa representação da forma da função nesse trecho. E finalmente, o parâmetro $\beta_{2}$ pode variar de 0 a 1, conforme indicado por Lu et al. (2016), porém a calibração com resultados experimentais de confinamento passivo, que foi extrapolada para o confinamento ativo, indicou que o intervalo entre 0,01 e 0,1 é mais adequado para a representação do comportamento do concreto confinado. Portanto, os intervalos sugeridos para cada parâmetro estão resumidos nas Eqs. (46) a (48).

$$
\begin{aligned}
& 0,3<q_{h 0}<0,4 \\
& 1,8<\beta_{1}<2,2 \\
& 0,01<\beta_{2}<0,1
\end{aligned}
$$




\subsubsection{Função potencial plástica}

Neste trabalho, a função potencial plástica consiste de uma função não associativa, ou seja, diferente da função de plastificação. Essa função baseia-se no modelo de Grassl, Lundgren e Gylltoft (2002), mas também foi utilizada por autores como Papanikolaou e Kappos (2007) e Carrazedo et al. (2013) nos seus modelos de plasticidade. A função polinomial adotada é dada pela Eq. (49).

$$
g=A\left(\frac{\rho}{q_{h}(k) \cdot \sqrt{q_{s}(k)}}\right)^{n}+B \frac{\rho}{q_{h}(k) \cdot \sqrt{q_{s}(k)}}+\frac{\xi}{q_{h}(k) \cdot \sqrt{q_{s}(k)}}
$$

Sendo que Papanikolaou e Kappos (2007) sugerem $n=3$, diferentemente dos outros autores citados anteriormente que adotaram $n=2$.

Os coeficientes A e B são constantes do material calibrados a partir das deformações e tensões de pico do estado de compressão uniaxial e triaxial. Para a calibração, assume-se a hipótese de Pantazopoulou e Mills (1995) de que a deformação volumétrica próxima a ruína do concreto sob compressão uniaxial é nula. Essa hipótese depende das propriedades do concreto e como mostrado por estudos, como Imran e Pantazopoulou (1996), pode não ser confirmada. Nesse sentido, estudos como o de Grassl (2004) indicaram que a atribuição de valores não nulos para a deformação volumétrica de pico influencia principalmente na deformabilidade lateral, mas não na resistência do concreto. Essa aproximação afetaria mais a representação do confinamento passivo que a do ativo. No entanto, ainda pode ser considerada uma boa aproximação e, portanto, é adotada como hipótese.

Outra hipótese necessária para calibração, como explicado por Grassl, Lundgren e Gylltoft (2002), é a de que a deformação plástica volumétrica referente ao pico de tensão na compressão uniaxial é a mesma para todos os estados de tensões. A terceira hipótese assumida para a calibração é a de que a inclinação da deformação plástica total é igual ao gradiente da função potencial plástica, permitindo fazer a associação da Eq. (50). Essa hipótese está representada esquematicamente na Figura 24, com uma representação genérica das funções de plastificação (f) e potencial plástica $(\mathrm{g})$.

$$
\psi=\tan \psi=\frac{\rho^{\prime}}{\xi^{\prime}}=-\frac{d \xi}{d \rho}
$$




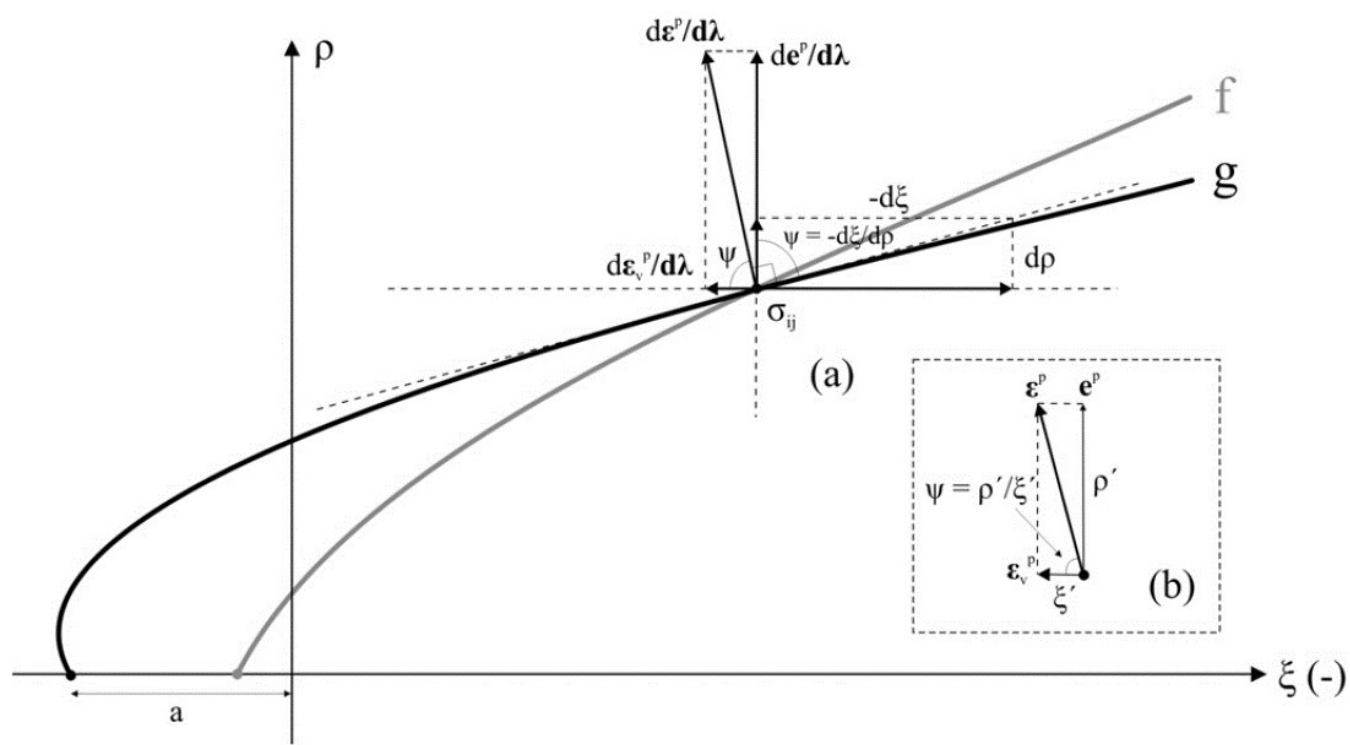

Figura 24. Direção $\psi$ dos vetores deformação plástica incremental (a) e total (b) para uma função potencial plástica genérica não associativa.

Fonte: Papanikolaou e Kappos (2007)

Substituindo a Eq. (49) na Eq. (50), e assumindo valor unitário para a função de encruamento, já que se trata da calibração para o pico de tensão uniaxial e triaxial, obtém-se a Eq. (51).

$$
\psi=-\frac{d \xi}{d \rho}=n A \rho^{n-1}+B
$$

Os coeficientes são calibrados a partir de dois carregamentos: uniaxial e triaxial. Sendo que $\rho_{1}$ e $\psi_{1}$ são o comprimento normalizado do vetor de tensão desviadora e inclinação do vetor deformação plástica, respectivamente, para o pico de tensão no carregamento uniaxial e $\rho_{2}$ e $\psi_{2}$ são os mesmos parâmetros para o pico de tensão do confinamento ativo uniforme. Dessa forma, resolvendo o sistema com duas equações (resultantes dos estados uniaxial e triaxial de tensão), obtém-se como solução os dois coeficientes (A e B), conforme Eqs. (52) e (53).

$$
\begin{aligned}
& A=\frac{\psi_{1}-\psi_{2}}{\mathrm{n} \cdot\left(\rho_{1}{ }^{n-1}-\rho_{2}{ }^{n-1}\right)} \\
& B=\psi_{1}-n \cdot \rho_{1}^{n-1} \cdot \frac{\psi_{1}-\psi_{2}}{\mathrm{n} \cdot\left(\rho_{1}{ }^{n-1}-\rho_{2}{ }^{n-1}\right)}
\end{aligned}
$$

Os comprimentos normalizados do vetor de tensão desviadora no pico de tensão da compressão uniaxial e confinamento ativo são dados pelas Eqs. (54) e (55), respectivamente.

$$
\rho_{1}=\frac{\sqrt{2 \cdot J_{2}}}{f_{c}}=\sqrt{\frac{1}{3}\left[\left(\sigma_{1}-\sigma_{2}\right)^{2}+\left(\sigma_{2}-\sigma_{3}\right)^{2}+\left(\sigma_{1}-\sigma_{3}\right)^{2}\right]}=\sqrt{2 / 3}
$$




$$
\rho_{2}=\sqrt{2 / 3} \frac{\left(\sigma_{1 c c}-\sigma_{3 c c}\right)}{f_{c}}
$$

Para compressão uniaxial e confinamento ativo, as inclinações do potencial plástico no pico de tensão são dadas pelas Eqs. (56) e (57), respectivamente.

$$
\begin{aligned}
& \psi_{1}=\frac{\sqrt{\frac{1}{3}\left[\left(\varepsilon_{1}^{p}-\varepsilon_{2}^{p}\right)^{2}+\left(\varepsilon_{2}^{p}-\varepsilon_{3}^{p}\right)^{2}+\left(\varepsilon_{3}^{p}-\varepsilon_{1}^{p}\right)^{2}\right]}}{\frac{\varepsilon_{1}^{p}+\varepsilon_{2}^{p}+\varepsilon_{3}^{p}}{3}}=\sqrt{2} \frac{\varepsilon_{3 p u}-\varepsilon_{1 p}}{\varepsilon_{v p 0}} \\
& \psi_{2}=\sqrt{2} \frac{\varepsilon_{3 p c}-\varepsilon_{1 p c}}{\varepsilon_{v p 0}}
\end{aligned}
$$

sendo que as deformações e tensões necessárias para definição das tensões desviadoras e inclinações são calculadas a seguir, considerando as hipóteses adotadas anteriormente.

Na compressão uniaxial, a deformação plástica axial no pico de tensão $\left(\varepsilon_{3 p u}\right)$ é dada pela Eq. (58). Sendo $E_{c}$ o módulo de elasticidade, $v_{c}$ o coeficiente de Poisson e $f_{c}$ a resistência última e $\varepsilon_{c}$ a deformação última do concreto na compressão uniaxial, respectivamente.

$$
\varepsilon_{3 p u}=-\varepsilon_{c}+\frac{f_{c}}{E_{c}}
$$

A deformação plástica lateral no pico de tensão é dada pela Eq. (59).

$$
\varepsilon_{1 p u}=\varepsilon_{1 u}-v_{c} \cdot \frac{f_{c}}{E_{c}}
$$

Se a deformação lateral no pico de tensão não for conhecida, assume-se a hipótese de deformação volumétrica nula explicada anteriormente, resultando em $\varepsilon_{1 u}=\varepsilon_{c} / 2$, que substituído na Eq. (59) resulta a Eq. (60).

$$
\varepsilon_{1 p u}=\frac{\varepsilon_{c}}{2}-v_{c} \cdot \frac{f_{c}}{E_{c}}
$$

Portanto, a deformação volumétrica no pico de tensão é dada pela Eq. (61).

$$
\varepsilon_{v p 0}=2 \varepsilon_{1 p u}+\varepsilon_{3 p u}
$$

Sendo assim, define-se a deformação plástica volumétrica no pico de tensão para a compressão uniaxial conforme Eq. (63).

$$
\varepsilon_{v p}=\frac{f_{c}}{E_{c}\left(1-2 v_{c}\right)}
$$

A calibração da função potencial plástica também depende de um caso triaxial de tensão, o que exige algumas considerações. A tensão axial última $\left(\sigma_{3 c c}\right)$ para um estado de confinamento ativo uniforme com determinada pressão lateral $\sigma_{1 c c}$ é dada pela Eq. (63), a partir do critério de resistência de Mohr-Coulomb. 


$$
\sigma_{3 c c}=f_{c}+4,02 \cdot \sigma_{1 c c}
$$

A deformação axial no pico de tensão é estimada pela Eq. (64) sugerida por Candappa, Sanjayan e Setunge (2001).

$$
\varepsilon_{3 c c}=\varepsilon_{c}\left(1-\frac{20 \sigma_{1 c c}}{f_{c}}\right)
$$

Subtraindo a deformação elástica da deformação total, calcula-se a deformação plástica referente ao pico do caso triaxial conforme Eq. (65).

$$
\varepsilon_{3 p}=\varepsilon_{3 c c}-\left(\frac{1}{E_{c}}\right)\left(\sigma_{3 c c}-2 v_{c} \sigma_{1 c c}\right)
$$

Então a deformação plástica lateral é dada pela Eq. (66), assumindo a hipótese de que as deformação volumétricas de pico são iguais para os casos uniaxial e triaxial.

$$
\varepsilon_{1 p c}=\frac{\varepsilon_{v p 0}-\varepsilon_{3 p}}{2}
$$

A partir disso, as inclinações da função potencial plástica para compressão uniaxial e confinamento ativo no pico de tensão podem ser calculadas e, finalmente, obtém-se os coeficientes A e B da função de plastificação. A representação esquemática do processo para determinação dos coeficientes da função potencial plástica está demonstrada na Figura 25.

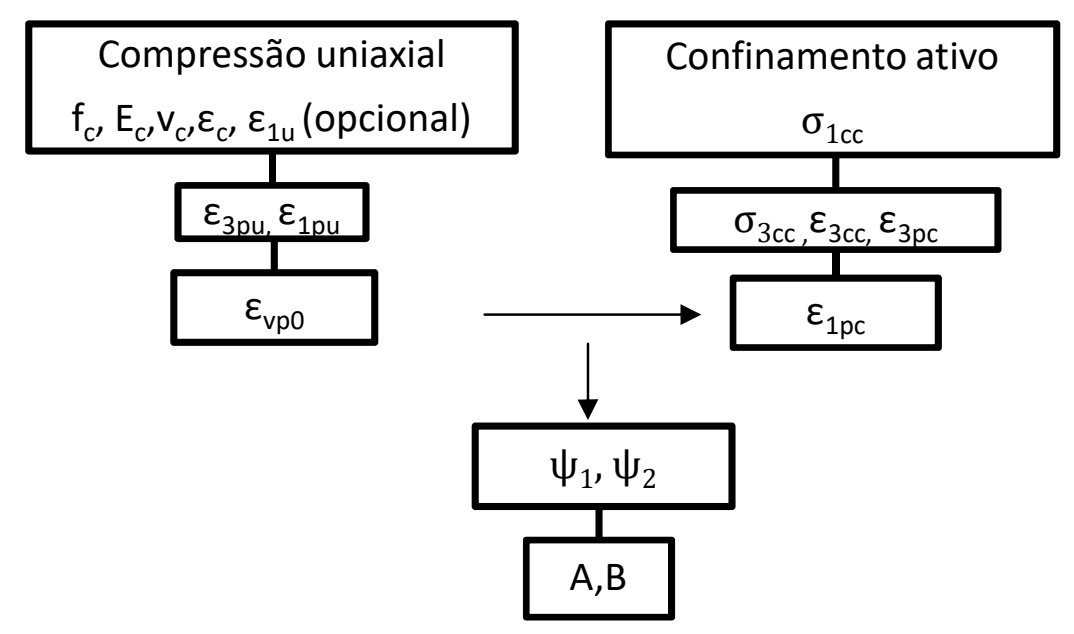

Figura 25. Representação esquemática do procedimento para calibração da função potencial plástica.

Fonte: Autora (2018)

Como parâmetro de entrada para a calibração dos coeficientes da função de plastificação tem-se, portanto, apenas a tensão lateral utilizada para o confinamento ativo $\left(\sigma_{1 c c}\right)$. Sendo que essa tensão pode ser adotada igual ou aproximadamente o valor da pressão lateral para o confinamento ativo em questão e com valores baixos para o confinamento 
passivo, aproximadamente igual a - 5,0 MPa. Porém, Papanikolaou e Kappos (2007) afirmam, com base em estudo paramétrico, que a função potencial plástica cúbica atende às expectativas para representação da evolução das deformações plásticas independentemente da tensão de confinamento utilizada para calibração, já que a seleção arbitrária da tensão não afeta significativamente os resultados.

Adotado esse processo de calibração, assume-se uma modificação na função potencial plástica para a representação do concreto confinado passivamente, devido a impossibilidade de representar a taxa de evolução das deformações plásticas no confinamento ativo e passivo por meio da função genérica. A utilização de uma função potencial plástica idêntica para representação do comportamento do concreto confinado ativa e passivamente mostra-se ineficiente, como demonstrado por muitos autores que sugeriram modificações nessas funções, como Yu et al. (2010), Bao (2013), entre outros. Isso se deve ao fato de que as taxas de dilatação (relação entre deformações plásticas lateral e axial) nos dois confinamentos são muito diferentes. Piscesa et al. (2016) explica que para o confinamento ativo a taxa de dilatação plástica está fortemente relacionada com a pressão de confinamento e tende a um limite de -0,5. Já no confinamento passivo, a taxa de dilatação depende tanto do nível de confinamento quanto da rigidez do material confinante. A variação dessa taxa para o confinamento passivo também é maior, já que assume um intervalo de $-2,5$ a $-0,3$ ou -0,2 (que são os valores do coeficiente de Poisson da camisa de PRF). Nesse sentido, Piscesa et al. (2016) propôs uma modificação da função potencial plástica a partir de um vasto conjunto de dados experimentais, indicado na Figura 26, na qual está demonstrada a tendência da relação entre deformações plásticas laterais e axiais para o confinamento passivo em função do nível de confinamento e rigidez do material confinante. 


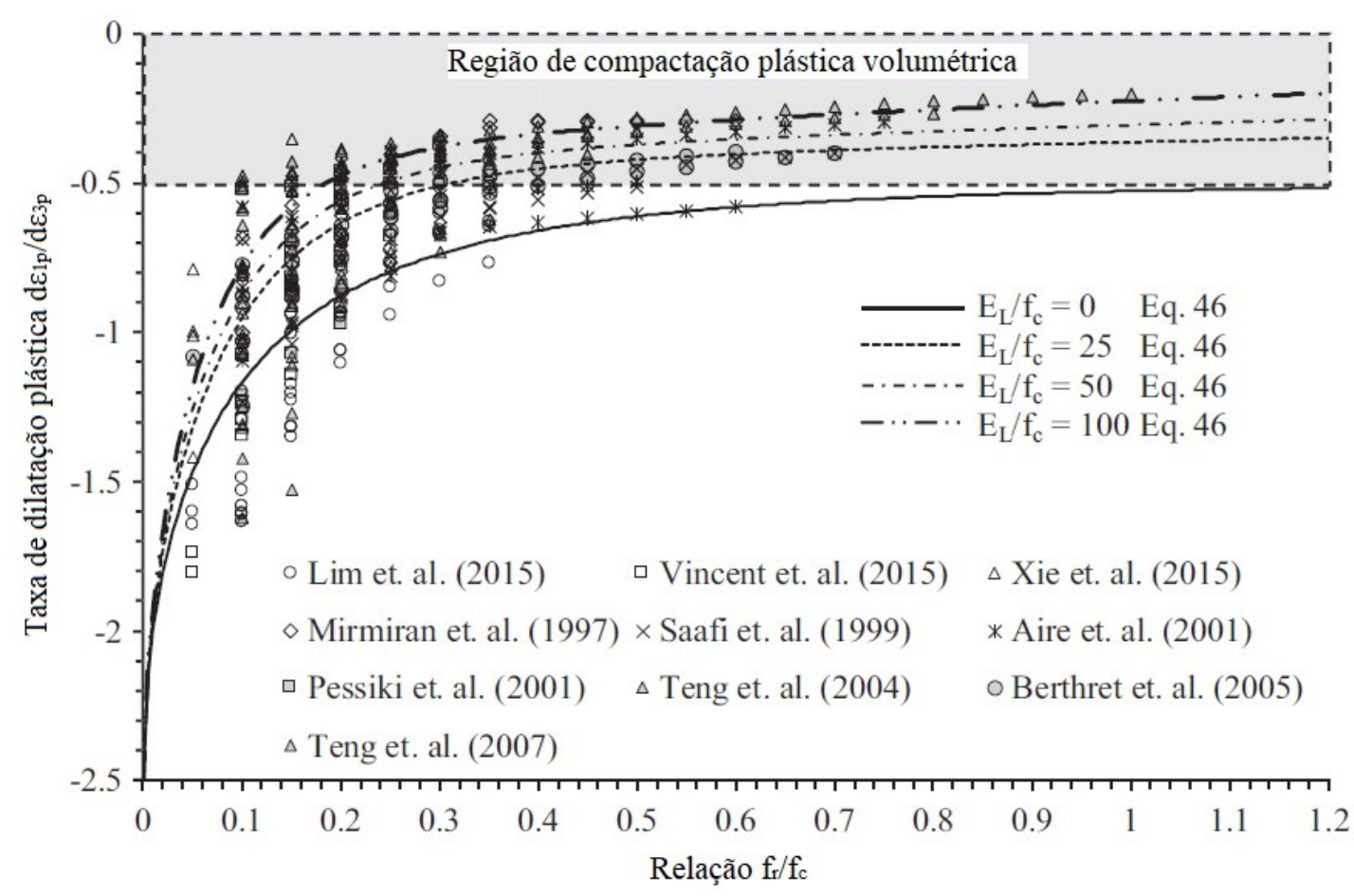

Figura 26. Taxa de dilatação plástica para confinamento passivo segundo resultados experimentais

Fonte: Piscesa et al. (2016)

Sendo assim, Piscesa et al. (2016) propôs a Eq. (67) para representação da evolução da taxa de dilatação do confinamento passivo $(\beta)$.

$$
\beta=\beta_{0}+\left(\beta_{\text {core }}-\beta_{0}\right) \tanh \left(a_{4}\left(\frac{f_{r}}{f_{c}}\right)^{b_{4}}\right)
$$

Sendo que os coeficientes da Eq. (67) estão definidos nas Eqs. (68) e (69).

$$
\begin{aligned}
& a_{4}=2,5+0,25 \sqrt{E_{l} / f_{c}} \\
& b_{4}=0.0915 \sqrt{f_{c}} \exp \left(-0,0192 \sqrt{\frac{E_{l}}{f_{c}} \frac{f_{r}}{f_{c}}}\left\langle f_{c}-73\right\rangle\right.
\end{aligned}
$$

Sendo $f_{r}$ a tensão lateral de confinamento e $E_{l}$ a rigidez do material confinante. Os parâmetros $\beta_{0}$ e $\beta_{\text {core }}$ são derivados dos valores de dilatação plástica para confinamento nulo e limite da compactação plástica volumétrica, e estão indicados na Eq. (70).

$$
\beta_{0}=-2,5 ; \beta_{\text {core }}=-0,5+0,0275 \sqrt{\frac{E_{l}}{f_{c}} \frac{f_{r}}{f_{c}}} \leq \mu_{P R F}
$$

A modificação da função potencial plástica ocorre pela consideração de um parâmetro $\alpha_{p 0}$ que acompanha a pressão hidrostática na função original, conforme apresentado na Eq. (71). 


$$
g=A\left(\frac{\rho}{q_{h}(k) \cdot \sqrt{q_{s}(k)}}\right)^{n}+B \frac{\rho}{q_{h}(k) \cdot \sqrt{q_{s}(k)}}+\frac{\alpha_{p 0} \cdot \xi}{q_{h}(k) \cdot \sqrt{q_{s}(k)}}
$$

Piscesa et al. (2016) propôs uma função semelhante $(n=2$ e desconsideração da parcela linear da tensão desviadora $\rho$ ) para o confinamento passivo, sendo que em estudo posterior, Piscesa et al. (2017), sugeriu que o parâmetro $\alpha_{p 0}$ fosse adotado igual a 1 para o confinamento ativo, sem prejuízo para a representação do comportamento. Portanto, adotouse a mesma estratégia para o modelo proposto. Sendo assim, a função potencial plástica foi mantida igual à original para o confinamento ativo, já que $\alpha_{p 0}$ é considerado igual a 1 . O processo utilizado para calibração dos coeficientes A e B também é mantido, até mesmo para o confinamento passivo, já que é derivado de estados de tensão uniaxial e triaxial.

Para determinação do parâmetro $\alpha_{p 0}$, primeiramente define-se a taxa de dilatação, que é obtida pelo gradiente de função potencial plástica em relação às tensões principais, conforme indicado na relação da Eq. (72). Sendo que os gradientes da função potencial plástica em relação às tensões principais $\sigma_{1}$ (lateral) e $\sigma_{3}$ (axial) estão indicados nas Eqs. (73) e (74), respectivamente. Finalmente, temos que o parâmetro $\alpha_{p 0}$ é dado pela Eq. (75).

$$
\begin{aligned}
& \beta=\frac{d \varepsilon_{1}^{p}}{d \varepsilon_{3}^{p}}=\frac{d \varepsilon_{2}^{p}}{d \varepsilon_{3}^{p}}=\frac{d \lambda \dot{g}_{1}}{d \lambda \dot{g}_{3}}=\frac{d \lambda \dot{g}_{2}}{d \lambda \dot{g}_{3}} \\
& g_{1}=\frac{\sqrt{2}}{\sqrt{3}} \frac{A \cdot\left(\sigma_{1}-\sigma_{3}\right)^{2}}{\left(f_{c} \cdot q_{h} \cdot \sqrt{\left.q_{s}\right)}\right.}+\frac{\sqrt{3}}{\sqrt{2}} \frac{B}{\left(f_{c} \cdot q_{h} \cdot \sqrt{\left.q_{s}\right)}\right.}+\frac{\alpha_{p 0}}{\sqrt{3}\left(f_{c} \cdot q_{h} \cdot \sqrt{\left.q_{s}\right)}\right.} \\
& g_{3}=\frac{-2 \sqrt{2}}{\sqrt{3}} \frac{A \cdot\left(\sigma_{1}-\sigma_{3}\right)^{2}}{\left(f_{c} \cdot q_{h} \cdot{\sqrt{q_{s}}}^{3}\right.}-\frac{2 \sqrt{3}}{\sqrt{2}} \frac{B}{\left(f_{c} \cdot q_{h} \cdot \sqrt{\left.q_{s}\right)}\right.}+\frac{\alpha_{p 0}}{\sqrt{3}\left(f_{c} \cdot q_{h} \cdot \sqrt{\left.q_{s}\right)}\right.} \\
& \alpha_{p 0}=\frac{(1+2 \beta)}{(\beta-1)}\left[\sqrt{2} \frac{A \cdot\left(\sigma_{1}-\sigma_{3}\right)^{2}}{\left(f_{c} \cdot q_{h} \cdot{\sqrt{q_{s}}}^{2}\right.}+\frac{3 \sqrt{2}}{2} B\right]
\end{aligned}
$$

Dessa forma, o parâmetro $\alpha_{p 0}$ é utilizado para modificar a função potencial plástica original a fim de melhorar a representação da taxa de dilatação do confinamento passivo, que é essencial para determinação da resistência e deformação última do concreto confinado passivamente. 


\subsection{Modelo de dano}

Para representação da degradação da rigidez do concreto foi adotado um modelo de dano isotrópico por meio da utilização de uma variável escalar de dano. No modelo proposto, todo o modelo de plasticidade baseia-se no conceito de tensões efetivas, conforme já explicado anteriormente, e o definido a partir das deformações plásticas derivadas do modelo de plasticidade. Neste modelo, especificamente, o dano foi completamente desacoplado do modelo de plasticidade, influenciando de forma independente a perda de rigidez, diferentemente de alguns modelos de plasticidade e dano baseados em tensões efetivas, como o de Grassl et al. (2006a), que consideram que o trecho ascendente da curva tensãodeformação é definido pela plasticidade e o trecho pós-pico é definido pela plasticidade e dano. Neste modelo definiu-se que a plasticidade define toda a curva envoltória tensãodeformação (inclusive o trecho pós-pico) e o dano é responsável apenas pela representação da degradação da rigidez nos ciclos de carregamento e descarregamento. Optou-se por essa alternativa para facilitar a calibração do modelo já que a definição de dano e plasticidade juntos dificulta a compreensão da parcela resultante de cada um dos mecanismos na curva tensão-deformação do material.

Autores como Frantziskonis (1986) e Farahmandpour (2017) assumem que a evolução do dano na compressão ocorre devido principalmente ao deslizamento ao longo das superfícies das microfissuras, o que está relacionado com as deformações plásticas desviadoras. Portanto, para o concreto sob compressão, define-se o parâmetro de dano $\left(\dot{\gamma}^{d}\right)$ é definida em função das deformações plásticas desviadoras, assim como o parâmetro de encruamento do modelo de plasticidade. A Eq. (76) apresenta a definição do parâmetro de dano, sendo $e^{p}$ as deformações plásticas desviadoras e $\varepsilon_{1, d 0}^{p}$ a deformação desviadora de pico na compressão uniaxial, que é adotada como normalizadora do parâmetro tanto para o confinamento ativo quanto para o passivo, diferentemente do parâmetro de encruamento, onde essa deformação assume valores diferentes para os dois tipos de confinamento.

$$
\dot{\gamma}^{d}=\left(\sqrt{\frac{2}{3} e^{p}: e^{p}}\right) / \varepsilon_{1, d 0}^{p}
$$

O critério de dano deste modelo é o mesmo adotado por Farahmandpour (2017) que se inspirou em trabalhos anteriores, como o de Mazars (1986) e Lee e Fenves (1998). A função de dano $\left(F_{c}\right)$ está demonstrada na Eq. (77). Considerando que para ocorrer a evolução do 
dano, a função de dano deve atender as seguintes condições: $F_{c} \leq 0, \dot{\gamma}^{d} \geq 0, F_{c} \dot{\gamma}^{d}=0$. A partir disso, define-se variável de dano $\omega$, responsável por penalizar a rigidez elástica do material.

$$
F_{c}=X_{d}\left(1-\exp \left(-A_{c} \cdot \gamma_{d}\right)-\omega \leq 0\right.
$$

Sendo que $A_{c}$ é um parâmetro que controla a taxa de evolução do dano e $X_{d}$ é um coeficiente relacionado com a dependência entre evolução do dano e nível de confinamento. A lei de evolução do parâmetro $X_{d}$ foi motivada por ensaios experimentais, como o de Li et al. (2015), e está demonstrada na Eq. (78). Esse coeficiente permite, por exemplo, reduzir o valor do dano a medida que o nível de confinamento aumenta.

$$
X_{d}=\left(1+a_{2}\left(\frac{\left\langle-\xi-\frac{f_{c}}{3}\right\rangle}{\frac{f_{c}}{3}}\right)\right)^{-1}
$$

Definida a variável de dano $(\omega)$, a rigidez elástica do concreto é corrigida conforme Eq. (79).

$$
E_{d}=(1-\omega) \cdot E
$$

\subsection{Modelo incremental explícito}

Antes de desenvolver as equações do modelo objetivando um processo incremental explícito de implementação, é necessário definir as convenções utilizadas para as tensões e deformações em um cilindro de concreto sob confinamento uniforme. Define-se que a tensão axial $\sigma_{3}$ e a deformação axial $\varepsilon_{3}$ são causadas por aplicação de carregamento de compressão no eixo longitudinal do cilindro de diâmetro D. Enquanto as tensões laterais $\sigma_{1}$ e $\sigma_{2}$, assim como as deformações laterais $\varepsilon_{1}$ e $\varepsilon_{2}$ são iguais, no caso específico de confinamento uniforme. 


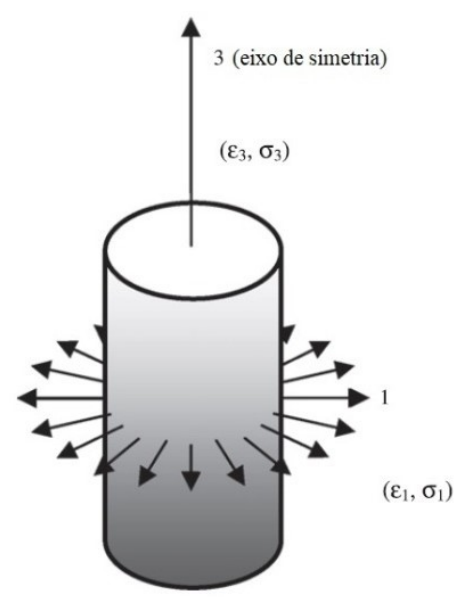

Figura 27. Convenção para um cilindro confinado. Fonte: Carrazedo et al. (2013)

3.3.1 Limite do comportamento elástico

O primeiro passo do processo de implementação é definir o limite do comportamento elástico. Nessa fase, a relação entre tensões e deformação lateral $\left(\varepsilon_{1}\right)$ é definida pela Lei de Hooke, conforme Eq. (80).

$$
\varepsilon_{1}=\frac{\left[\sigma_{1}-v_{c} \cdot\left(\sigma_{2}+\sigma_{3}\right)\right]}{E_{c}}
$$

A partir da deformação lateral $\left(\varepsilon_{1}\right)$ define-se a tensão lateral de confinamento conforme Eq. (81).

$$
\sigma_{1}=\sigma_{0}-E_{l} \varepsilon_{1}
$$

sendo $\sigma_{0}$ o nível inicial de confinamento gerado por confinamento ativo ou por protensão da camisa (assume valor negativo de acordo com a orientação adotada).

A rigidez lateral da camisa $\left(E_{l}\right)$ é dada pela Eq. (82).

$E_{l}=\frac{2 \cdot n_{j} \cdot E_{j} \cdot t_{j}}{D}$

sendo $n_{j}, E_{j}, t_{j}$ o número de camadas, o módulo de elasticidade longitudinal e a espessura da camisa, respectivamente.

Substituindo a Eq. (80) na Eq. (81), substituindo a tensão $\sigma_{2}$ por $\sigma_{1}$ e rearranjando, obtém-se a Eq. (83) para a tensão lateral de confinamento.

$\sigma_{1}=\frac{\left[E_{c} \cdot \sigma_{0}+v_{c} \cdot E_{l} \cdot \sigma_{3}\right]}{E_{c}+E_{l} \cdot\left(1-v_{c}\right)}$

Simplificando obtém-se a Eq. (84).

$\sigma_{1}=k_{1}+k_{2} \cdot \sigma_{3}$

sendo $k_{1}$ e $k_{2}$ dados pelas Eqs. (85) e (86). 


$$
\begin{aligned}
& k_{1}=\frac{E_{c} \cdot \sigma_{0}}{E_{c}+E_{l} \cdot\left(1-v_{c}\right)} \\
& k_{2}=\frac{v_{c} \cdot E_{l}}{E_{c}+E_{l} \cdot\left(1-v_{c}\right)}
\end{aligned}
$$

Então é possível reescrever a função de plastificação em função de $\sigma_{3}$, conforme Eq. (87).

$$
f_{p}=a \cdot \sigma_{3}+b
$$

onde a e b são dados nas Eqs. (88) e (89).

$$
\begin{gathered}
a=\frac{1+\operatorname{sen} \phi}{1-\operatorname{sen} \phi} \cdot k_{2}-1 \\
b=\frac{1+\operatorname{sen} \phi}{1-\operatorname{sen} \phi} \cdot k_{1}-q_{0}
\end{gathered}
$$

Considerando que até o limite elástico as deformações plásticas não evoluem, considera-se a função de plastificação nula, permitindo o cálculo da deformação axial correspondente ao limite elástico $\left(\sigma_{3 l i}\right)$, conforme demonstrado na Eq. (90).

$$
\sigma_{3 \lim }=-\frac{b}{a}
$$

Consequentemente $\sigma_{1 l i}, \varepsilon_{3 l i m}$ e $\varepsilon_{1 \text { lim }}$ podem ser calculadas pelas Eqs. (91) a (93), respectivamente.

$$
\begin{aligned}
\sigma_{1 l i} & =\frac{\left[E_{c} \cdot \sigma_{0}-v_{c} \cdot E_{l} \cdot \sigma_{3 l i}\right]}{E_{c}+E_{l} \cdot\left(v_{c}-1\right)} \\
\varepsilon_{3 l i m} & =\frac{\left[-2 \cdot v_{c} \cdot \sigma_{1 l i m}+\sigma_{3 l i m}\right]}{E_{c}} \\
\varepsilon_{1 \mathrm{lim}} & =\frac{\left[\sigma_{1 \mathrm{lim}}\left(1-v_{c}\right)-v_{c} \cdot \sigma_{3 \mathrm{lim}}\right]}{E_{c}}
\end{aligned}
$$

\subsubsection{Resposta elasto-plástica}

Assume-se a hipótese de que durante o desenvolvimento das deformações plásticas $(\Delta \lambda>0)$ a função de plastificação permanece igual a zero, conforme Eq. (94), atendendo as condições de consistência que garante a evolução das deformações plásticas $(\dot{f} \leq 0 ; \Delta \lambda \geq$ $0 ; \Delta \lambda \cdot \dot{f}=0)$.

$$
\dot{f}=\frac{\partial f}{\partial \sigma_{i}} \dot{\sigma}_{l}+\frac{\partial f}{\partial q} \dot{q}=0
$$


Essa consideração, escrita em função de incrementos de tensão está demonstrada na Eq. (95).

$$
\Delta f=f_{1} \cdot \Delta \sigma_{1}+f_{2} \cdot \Delta \sigma_{2}+f_{3} \cdot \Delta \sigma_{3}+\frac{\partial f}{\partial q} \cdot \Delta q=0
$$

Sendo $f_{1}=\frac{\partial f}{\partial \sigma_{1}}, f_{3}=\frac{\partial f}{\partial \sigma_{3}}$ e $f_{2}=\frac{\partial f}{\partial \sigma_{2}}=0$ (para função de ruptura de Mohr-Coulomb).

Com a lei de Hooke, determina-se o incremento de deformação elástica pela Eq. (96).

$$
\Delta \varepsilon_{1 e}=\frac{\Delta \sigma_{1}\left(1-v_{c}\right)-v_{c} \Delta \sigma_{3}}{E_{c}}
$$

Sendo a deformação elástica igual a diferença entre deformação total e deformação plástica, obtém-se a Eq. (97).

$$
\Delta \varepsilon_{1 e}=\Delta \varepsilon_{1}-\Delta \varepsilon_{1 p}=\frac{\Delta \sigma_{1}\left(1-v_{c}\right)-v_{c} \Delta \sigma_{3}}{E_{c}}
$$

No confinamento passivo os incrementos de deformação e tensão são proporcionais ao $E_{l}$ e o incremento de deformação plástica está relacionado com o multiplicador plástico $(\Delta \lambda)$ e com a derivada da função potencial plástica, portanto a Eq. (97) pode ser reescrita conforme Eq. (98), onde a obtenção de uma resposta precisa depende da divisão da análise em pequenos incrementos $\Delta \lambda$, logo o multiplicador plástico deve assumir valores muito pequenos.

$$
-\frac{\Delta \sigma_{1}}{E_{l}}-\Delta \lambda \cdot g_{1}=\frac{\Delta \sigma_{1}\left(1-v_{c}\right)-v_{c} \Delta \sigma_{3}}{E_{c}}
$$

Rearranjando a Eq. (98) obtém-se os incrementos de tensão lateral por meio da Eq. (99).

$$
\Delta \sigma_{1}=\frac{\frac{v_{c} \Delta \sigma_{3}}{E_{c}}-\Delta \lambda \cdot g_{1}}{\frac{E_{l}\left(1-v_{c}\right)+E_{c}}{E_{c} E_{l}}}
$$

E substituindo $\Delta \sigma_{1}$ na Eq. (98), obtém-se os incrementos de tensão axial $\Delta \sigma_{3}$ por meio da Eq. (100).

$$
\Delta \sigma_{3}=\frac{\frac{f_{1} \cdot \Delta \lambda \cdot g_{1} \cdot v_{c} \cdot E_{c} \cdot E_{l}}{E_{l}\left(1-v_{c}\right)+E_{c}}-\frac{\partial f}{\partial q} \cdot \Delta q}{\frac{f_{1} \cdot v_{c} \cdot E_{l}}{E_{l}\left(1-v_{c}\right)+E_{c}}+f_{3}}
$$

Conhecendo o incremento de deformação axial $\left(\Delta \sigma_{3}\right)$, calcula-se os incrementos de tensão lateral $\left(\Delta \sigma_{1}\right)$ pela Eq. (99), assim como os incrementos de deformação elástica $\left(\Delta \varepsilon_{1 e} \mathrm{e}\right.$ $\left.\Delta \varepsilon_{3 e}\right)$ pelas Eqs. (101) e (102).

$$
\Delta \varepsilon_{1 e}=\frac{\Delta \sigma_{1}\left(1-v_{c}\right)-v_{c} \Delta \sigma_{3}}{E_{c}}
$$


$\Delta \varepsilon_{3 e}=\frac{\Delta \sigma_{3}-2 v_{c} \Delta \sigma_{1}}{E_{c}}$

Como as deformações plásticas são dadas pelas Eqs. (103) e (104), os incrementos de deformação total podem ser calculados pelas Eqs. (105) e (106).

$$
\begin{aligned}
& \Delta \varepsilon_{3 p}=\Delta \lambda \cdot g_{3} \\
& \Delta \varepsilon_{1 p}=\Delta \lambda \cdot g_{1} \\
& \Delta \varepsilon_{3}=\Delta \varepsilon_{3 p}+\Delta \varepsilon_{3 e} \\
& \Delta \varepsilon_{1}=\Delta \varepsilon_{1 p}+\Delta \varepsilon_{1 e}
\end{aligned}
$$

Reforçando que é importante que $\Delta \lambda$ assuma valores pequenos para que o processo incremental explícito não seja prejudicado.

Então a deformação plástica desviadora é calculada conforme Eq. (107).

$$
\Delta \varepsilon_{d}^{p}=\frac{2}{3}\left(\Delta \varepsilon_{1 p}-\Delta \varepsilon_{3 p}\right)
$$

Os incrementos do parâmetro de encruamento são dados pela Eq. (108).

$$
\Delta k=\frac{\Delta \varepsilon_{d}^{p}}{\varepsilon_{d 0}^{p}}
$$

Ressaltando que para o confinamento passivo $\Delta \varepsilon_{\mathrm{d} 0}^{\mathrm{p}}$ é igual a $\varepsilon_{1, \mathrm{~d} 0}^{\mathrm{p}}$, que é a tensão desviadora de pico na compressão uniaxial, dada pela Eq. (109), onde $\varepsilon_{1 u p}$ e $\varepsilon_{3 u p}$ são as deformações plásticas lateral e axial de pico na compressão uniaxial. Para o confinamento ativo, $\Delta \varepsilon_{\mathrm{d} 0}^{\mathrm{p}}$ é dado pela Eq. (110).

$$
\begin{aligned}
& \varepsilon_{d 0}^{p}=\varepsilon_{1, d 0}^{p}=\frac{2}{3}\left(\varepsilon_{1 u p}-\varepsilon_{3 u p}\right) \\
& \varepsilon_{d 0}^{p}=\left(28,12 \frac{\sigma_{3}+\sigma_{0}}{f_{c}+\sigma_{0}}-1,56\right) \varepsilon_{1, d 0}^{p}
\end{aligned}
$$

Finalmente, o incremento da função de encruamento é calculado pela Eq. (111).

$$
\Delta q=\frac{\partial f}{\partial k} \Delta k
$$




\subsubsection{Derivadas}

As derivadas da função de plastificação em relação às tensões principais são dadas pelas Eqs. (112) e (113).

$$
\begin{aligned}
& f_{1}=\frac{(1+\operatorname{sen} \phi)}{f_{c} \cdot(1-\operatorname{sen} \phi)} \\
& f_{3}=\frac{-1}{f_{c}}
\end{aligned}
$$

As derivadas da função potencial plástica em relação às tensões principais são dadas pelas Eqs. (114) e (115).

$$
\begin{aligned}
& g_{1}=\frac{\sqrt{2}}{\sqrt{3}} \frac{A \cdot\left(\sigma_{1}-\sigma_{3}\right)^{2}}{\left(f_{c} \cdot q_{h} \cdot{\sqrt{q_{s}}}^{3}\right.}+\frac{\sqrt{3}}{\sqrt{2}} \frac{B}{\left(f_{c} \cdot q_{h} \cdot \sqrt{\left.q_{s}\right)}\right.}+\frac{\alpha_{p 0}}{\sqrt{3}\left(f_{c} \cdot q_{h} \cdot \sqrt{\left.q_{s}\right)}\right.} \\
& g_{3}=\frac{-2 \sqrt{2}}{\sqrt{3}} \frac{A \cdot\left(\sigma_{1}-\sigma_{3}\right)^{2}}{\left(f_{c} \cdot q_{h} \cdot{\sqrt{q_{s}}}^{3}\right.}-\frac{2 \sqrt{3}}{\sqrt{2}} \frac{B}{\left(f_{c} \cdot q_{h} \cdot \sqrt{\left.q_{s}\right)}\right.}+\frac{\alpha_{p 0}}{\sqrt{3}\left(f_{c} \cdot q_{h} \cdot \sqrt{\left.q_{s}\right)}\right.}
\end{aligned}
$$

As derivadas da função de plastificação em relação a função de encruamento no ramo ascendente e descendente são dadas pelas Eqs. (116) e (117) respectivamente.

$$
\begin{gathered}
\frac{\partial f}{\partial q_{h}}=-1 \\
\frac{\partial f}{\partial q_{s}}=-1
\end{gathered}
$$

As derivadas da função de encruamento em relação ao parâmetro de encruamento no ramo ascendente e descendente são dadas pelas Eqs. (118) e (119), respectivamente.

$$
\begin{aligned}
& \frac{\partial q_{h}}{\partial k}=\frac{\partial f}{\partial q_{h}}=\left(1-q_{h 0}\right)\left(3 \cdot a \cdot k^{2}-2 \cdot b \cdot k+c\right) \\
& \frac{\partial q_{s}}{\partial k}=\frac{1}{\beta_{2}(k-1)^{2}+k}-\frac{k *\left(2 \beta_{2}(k-1)+1\right)}{\left(\beta_{2}(k-1)^{2}+k\right)^{2}}
\end{aligned}
$$

\subsubsection{Estratégia de implementação}

Primeiramente, define-se os parâmetros de entrada do modelo que são as propriedades do concreto $\left(\mathrm{f}_{\mathrm{c}}, \mathrm{E}_{\mathrm{c}}, v_{c}, \varepsilon_{\mathrm{c}}, \varepsilon_{1 \mathrm{u}}\right)$, as propriedades do material confinante $\left(\mathrm{n}_{\mathrm{j}}, \mathrm{t}_{\mathrm{j}}, \mathrm{E}_{\mathrm{j}}, \mathrm{D}, \sigma_{0}\right)$ e os parâmetros das funções de plasticidade e dano do modelo: parâmetros da função de plastificação de Mohr-Coulomb $(\phi)$, função de encruamento $\left(\mathrm{q}_{\mathrm{h} 0}, \beta_{1}, \beta_{2}\right)$, função potencial plástica $\left(\sigma_{1 c c}\right)$ e função de dano $\left(\mathrm{A}_{\mathfrak{c}}, \mathrm{a}_{2}\right)$. Desses parâmetros, o valor sugerido para $\phi$ em 
diversos estudos, como em Shehata et al. (2001), é igual a $37^{\circ}$. Já a definição arbitrária da tensão de confinamento $\sigma_{1 \mathrm{cc}}$ utilizada para calibração da função potencial plástica praticamente não afeta os resultados obtidos, conforme analisado por Papanikolaou e Kappos (2007). Portanto, restam cinco (5) parâmetros que devem ser calibrados, cujos intervalos de valores foram propostos anteriormente neste trabalho.

A Figura 28 indica o fluxograma com o processo explícito e incremental do modelo. 


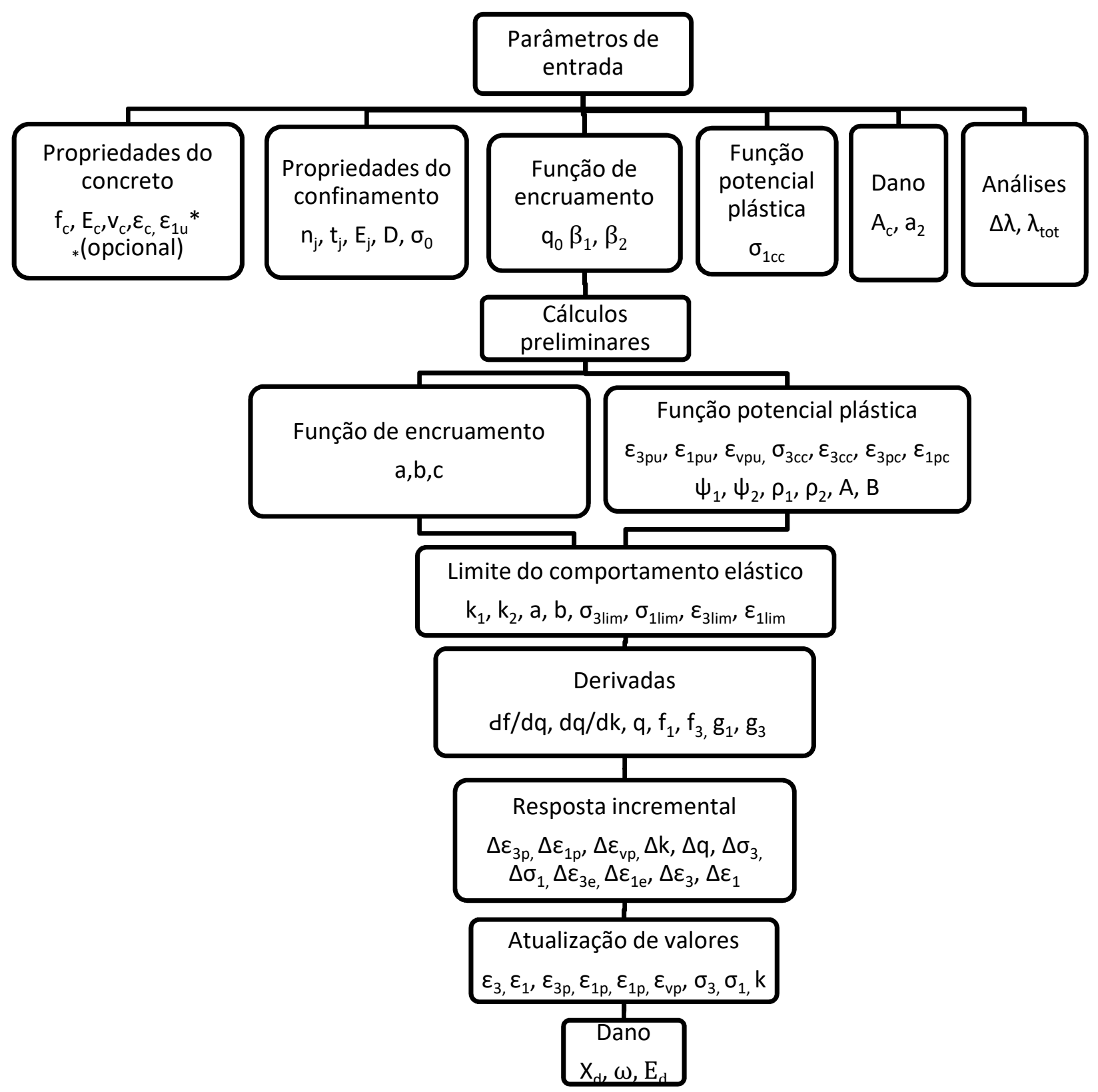

Figura 28. Fluxograma do processo incremental explícito Fonte: Autora (2018) 


\section{RESULTADOS E ANÁLISES}

\subsection{Bibliografias selecionadas}

Estão descritas brevemente as bibliografias selecionadas para comparação com os resultados gerados pelo modelo constitutivo proposto. Sendo que o conjunto de dados foi definido de forma que abrangesse diferentes tipos de fibras, número de camadas e espessuras de camisa para confinamento passivo e diferentes tensões laterais para o confinamento ativo. Destaca-se que as comparações estão limitadas, nesse estudo, a concretos de resistência normal, ou seja, resistência última à compressão entre 20 e $50 \mathrm{MPa}$. Também não foram analisados pilares de concreto com armadura.

\subsubsection{Confinamento passivo}

- Lam et al. (2006)

Lam et al. (2006) apresentam experimentos com cilindros $152 \mathrm{~mm}$ de diâmetro e 305 mm de altura com resistências últimas à compressão uniaxial de 38,9 e 41,1 MPa. Os ensaios foram realizados para 1 e 2 camadas de CFRP.

- Xiao e $W u$ (2000)

Xiao e Wu. (2000) apresentam experimentos com cilindros $152 \mathrm{~mm}$ de diâmetro e 305 mm de altura com resistência última à compressão uniaxial de $33,7 \mathrm{MPa}$. Os ensaios foram realizados para 12 e 3 camadas de CFRP. Os corpos-de-prova foram submetidos somente a ensaios monotônicos.

- Berthet et al.(2005)

Berthet et al. (2005) apresentam experimentos com cilindros $160 \mathrm{~mm}$ de diâmetro e $320 \mathrm{~mm}$ de altura com resistência última à compressão uniaxial de 25 e $40 \mathrm{MPa}$. Os ensaios foram realizados para 1, 2, 4, 9 e 12 camadas de CFRP e 2 camadas de GFRP. Os corpos-deprova foram submetidos somente a ensaios monotônicos. 
- Lim e Ozbakkaloglu (2015)

Lim e Ozbakkaloglu (2015) apresentam experimentos com cilindros $63 \mathrm{~mm}$ de diâmetro e $127 \mathrm{~mm}$ de altura com resistência última a compressão uniaxial de 51,6 MPa. Os ensaios foram realizados para 1 e 2 camadas de AFRP e GFRP, sendo que os corpos-de-prova foram submetidos somente a ensaios monotônicos.

- Ozbakkaloglu e Akin (2012)

Ozbakkaloglu e Akin (2012) apresentam experimentos com cilindros 152,5 mm de diâmetro e $305 \mathrm{~mm}$ de altura com resistência última a compressão uniaxial de $40 \mathrm{MPa}$. Os ensaios foram realizados para 2, 3, 4 e 6 camadas de AFRP e CFRP, sendo que os cilindros foram submetidos a ensaios cíclicos e monotônicos.

- Choi et al. (2009) - Confinamento passivo com camisa de aço

Choi et al. (2009) apresentam experimentos com cilindros $150 \mathrm{~mm}$ de diâmetro e 300 $\mathrm{mm}$ de altura com resistência última a compressão uniaxial de 26,8 MPa. Os ensaios foram realizados para camisas de aço com 1 e 1,5 mm de espessura.

\subsubsection{Confinamento ativo}

- Li e Wu (2016)

$\mathrm{Li}$ e $\mathrm{Wu}$ (2016) apresentam um programa experimental com cilindros de concreto de $54 \mathrm{~mm}$ de diâmetro e $108 \mathrm{~mm}$ de altura com resistência última a compressão uniaxial de 36,6 MPa. Os ensaios abrangem diferentes pressões de confinamento: 5MPa, $10 \mathrm{MPa}, 15 \mathrm{MPa}$ e $20 \mathrm{MPa}$. Para cada pressão de confinamento foram ensaiados quatro cilindros, sendo que os cilindros foram submetidos a ensaios cíclicos e monotônicos.

- Imran e Pantazopoulou (1996)

Imran e Pantazopoulou (1996) apresentam experimentos com cilindros de concreto de $54 \mathrm{~mm}$ de diâmetro e $108 \mathrm{~mm}$ de altura com resistência última a compressão uniaxial de 47,4 MPa. Os ensaios abrangem diferentes pressões de confinamento: 2,1 MPa, 4,3 MPa, 8,6 MPa, 17,2 MPa e 30,1 MPa. Todos os corpos-de-prova foram submetidos a carregamentos monotônicos.

- Lahlou et al. (1992)

Lahlou et al. (1992) apresentam um programa experimental com cilindros de concreto de $52 \mathrm{~mm}$ de diâmetro e $104 \mathrm{~mm}$ de altura com resistência última a compressão uniaxial de 46 
MPa. Os ensaios abrangem diferentes pressões de confinamento: 7,6 MPa e $22 \mathrm{MPa}$. Todos os corpos-de-prova foram submetidos a carregamentos monotônicos.

\subsubsection{Confinamento passivo com protensão}

- Janke et al.(2009)

Janke et al. (2009) apresentam experimentos com cilindros de concreto de $150 \mathrm{~mm}$ de diâmetro e $600 \mathrm{~mm}$ de altura com resistência última a compressão uniaxial de 42,5 MPa. Os ensaios abrangem corpos-de-prova confinados com 9 camadas de CFRP, sem e com protensão inicial de 2,1 MPa, além de corpos-de-prova confinados com camisas de aço de 0,8 $\mathrm{mm}$, sem e com protensão de 1,9 MPa.

\subsection{Confinamento passivo}

As curvas tensão-deformação resultantes do modelo proposto foram comparadas a resultados experimentais existentes na literatura para avaliar a precisão do modelo proposto. A Tabela 1 apresenta o resumo dos experimentos de corpos-de-prova cilíndricos confinados por PRF, que foram retirados da literatura para validação do modelo. Na Tabela 1 estão apresentadas as seguintes propriedades do concreto e do material confinante: resistência última e deformação de pico na compressão uniaxial do concreto ( $f_{c}$ e $\varepsilon_{c}$, respectivamente), módulo de elasticidade do concreto $\left(E_{c}\right)$, diâmetro do corpo-de-prova (D), tipo de carregamento (monotônico ou cíclico), tipo de fibra, número de camadas de PRF, espessura das camadas de PRF (e), módulo de elasticidade do material confinante ( $\left.\mathrm{E}_{\mathrm{PRF}}\right)$ e deformação lateral última de ruptura da camisa $\left(\varepsilon_{1 u l t}\right)$. 
Tabela 1. Resumo dos experimentos de confinamento passivo com as principais propriedades dos materiais.

\begin{tabular}{|c|c|c|c|c|c|c|c|c|c|c|}
\hline Experimentais & $\begin{array}{c}f_{c} \\
(\mathrm{MPa})\end{array}$ & $\varepsilon_{\mathrm{c}}$ & $\begin{array}{c}E_{c} \\
(G P a)\end{array}$ & $\begin{array}{c}\mathrm{D} \\
(\mathrm{mm})\end{array}$ & Tipo & $\begin{array}{c}\text { Tipo } \\
\text { de } \\
\text { fibra }\end{array}$ & $\begin{array}{c}\text { № } \\
\text { camadas }\end{array}$ & $\begin{array}{c}\mathrm{e} \\
(\mathrm{mm})\end{array}$ & $\begin{array}{l}E_{P R F} \\
(\mathrm{GPa})\end{array}$ & $\varepsilon_{1 \text { ult }}$ \\
\hline $\begin{array}{l}\text { Xiao e Wu } \\
\text { (2000) }\end{array}$ & 33,7 & 0,0024 & 20,3 & 152 & Monotônico & CFRP & 1,2 e 3 & 0,38 & 105 & 0,01 \\
\hline $\begin{array}{l}\text { Berthet et al. } \\
\text { (2005) }\end{array}$ & 40 & 0,002 & 25 & 160 & Monotônico & CFRP & $\begin{array}{c}1,2,4,9 \mathrm{e} \\
12\end{array}$ & 0,11 & 230 & 0,01 \\
\hline $\begin{array}{l}\text { Berthet et al. } \\
\text { (2005) }\end{array}$ & 25 & 0,0024 & 20 & 160 & Monotônico & $\begin{array}{l}\text { CFRP } \\
\text { GFRP }\end{array}$ & 1 e 2 & 0,165 & $\begin{array}{c}230 \\
74\end{array}$ & $\begin{array}{l}0,01 \\
0,015\end{array}$ \\
\hline $\begin{array}{l}\text { Lim et al. } \\
(2015)\end{array}$ & 51,6 & 0,002 & 28,4 & 63 & Monotônico & $\begin{array}{l}\text { AFRP } \\
\text { GFRP }\end{array}$ & 1 e 2 & 0,2 & $\begin{array}{c}128,5 \\
95,3\end{array}$ & $\begin{array}{r}0,0186 \\
0,020\end{array}$ \\
\hline $\begin{array}{l}\text { Lam e Teng } \\
\quad(2006)\end{array}$ & $\begin{array}{l}41,1 \\
38,9\end{array}$ & 0,0025 & $\begin{array}{l}25,3 \\
24,6\end{array}$ & 152 & Cíclico & CFRP & $\begin{array}{l}1 \\
2\end{array}$ & 0,165 & $\begin{array}{l}250 \\
247\end{array}$ & 0,01 \\
\hline $\begin{array}{l}\text { Ozbakkaloglu } \\
\text { e Akin (2012) }\end{array}$ & 38 & 0,0021 & 24,3 & 152,5 & Cíclico & AFRP & 2 e 3 & 0,2 & 120 & 0,017 \\
\hline
\end{tabular}

A Tabela 2 apresenta, para cada conjunto de experimentos, todos os parâmetros utilizados na calibração do modelo: ângulo de atrito $(\phi)$, relação do limite elástico $\left(\mathrm{q}_{0}\right)$, parâmetros da função de encruamento $\left(\beta_{1}\right.$ e $\left.\beta_{2}\right)$, tensão de confinamento para calibração da função potencial plástica $\left(\sigma_{1 c c}\right)$ e parâmetros de dano $\left(\mathrm{A}_{\mathrm{c}} \mathrm{e} \mathrm{a}_{2}\right)$.

Tabela 2. Parâmetros do modelo utilizados na comparação com experimentos

\begin{tabular}{cccccccc}
\hline Experimentais & $\phi$ & $\mathrm{q}_{0}$ & $\beta_{1}$ & $\beta_{2}$ & $\sigma_{1 c c}(\mathrm{MPa})$ & $\mathrm{A}_{c}$ & $\mathrm{a}_{2}$ \\
\hline Xiao e Wu (2000) & $37^{\circ}$ & 0,3 & 2,1 & 0,01 & -5 & - & - \\
Berthet et al. (2005) & $37^{\circ}$ & 0,3 & 2,1 & 0,01 & -5 & - & - \\
Berthet et al. (2005) & $37^{\circ}$ & 0,3 & 2,1 & 0,01 & -5 & - & - \\
Lim e Ozbakkaloglu (2015) & $37^{\circ}$ & 0,3 & 2,1 & 0,02 & -5 & - & - \\
Lam e Teng (2006) & $37^{\circ}$ & 0,3 & 2,1 & 0,02 & -5 & 0,1 & 0,3 \\
Ozbakkaloglu e Akin(2012) & $37^{\circ}$ & 0,3 & 2,1 & 0,02 & -5 & 0,1 & 0,3 \\
\hline
\end{tabular}


4.2.1 Confinamento com camisas de PRF - Monotônicos

A Figura 29 mostra a comparação entre curvas tensão-deformação do modelo com os resultados experimentais de Xiao e $\mathrm{Wu}(2000)$.

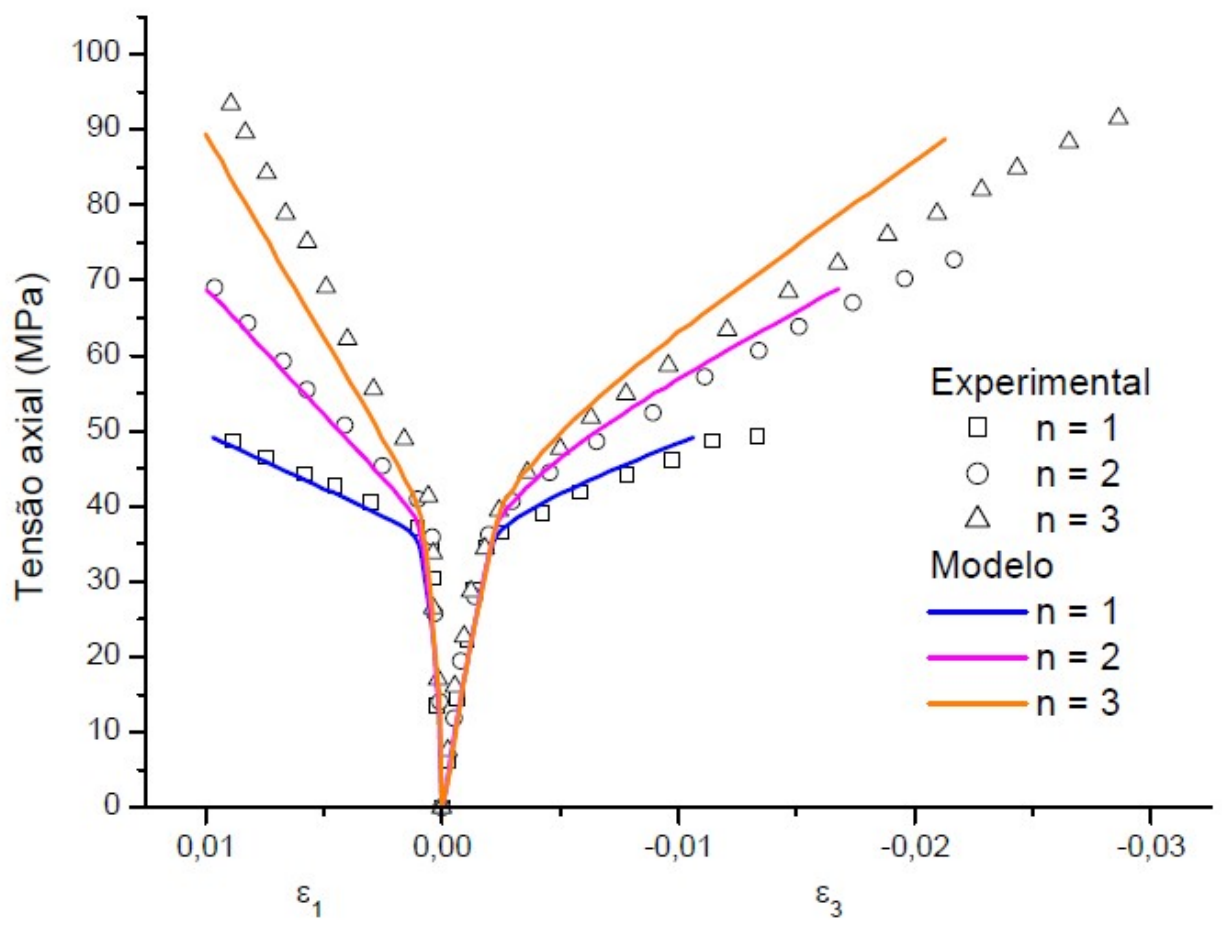

Figura 29. Comparação com experimentos de confinamento passivo de Xiao e Wu (2000)

A comparação demonstrada na Figura 29 indica uma boa previsão da resistência última do concreto confinado, principalmente para níveis mais baixos de confinamento, relacionados a menores quantidades de camisas de confinamento. Quanto à deformação última, também pode ser observada bastante proximidade entre os resultados experimentais e numéricos, principalmente considerando que muitos modelos não são capazes de representar o aumento significativo de ductilidade do concreto confinado passivamente com o acréscimo do número de camadas confinantes.

A Figura 30 apresenta as curvas tensão-deformação resultantes do modelo comparadas aos resultados experimentais de Berthet et al. (2005) com cilindros de 160x320 cm confinados por 1, 2, 4, 9 e 12 camadas de CFRP. Já a Figura 31 apresenta a comparação entre ensaios do mesmo autor, para concreto de resistência de $25 \mathrm{MPa}$, confinados por 1 e 2 camadas de CFRP e 2 camadas de GFRP. 


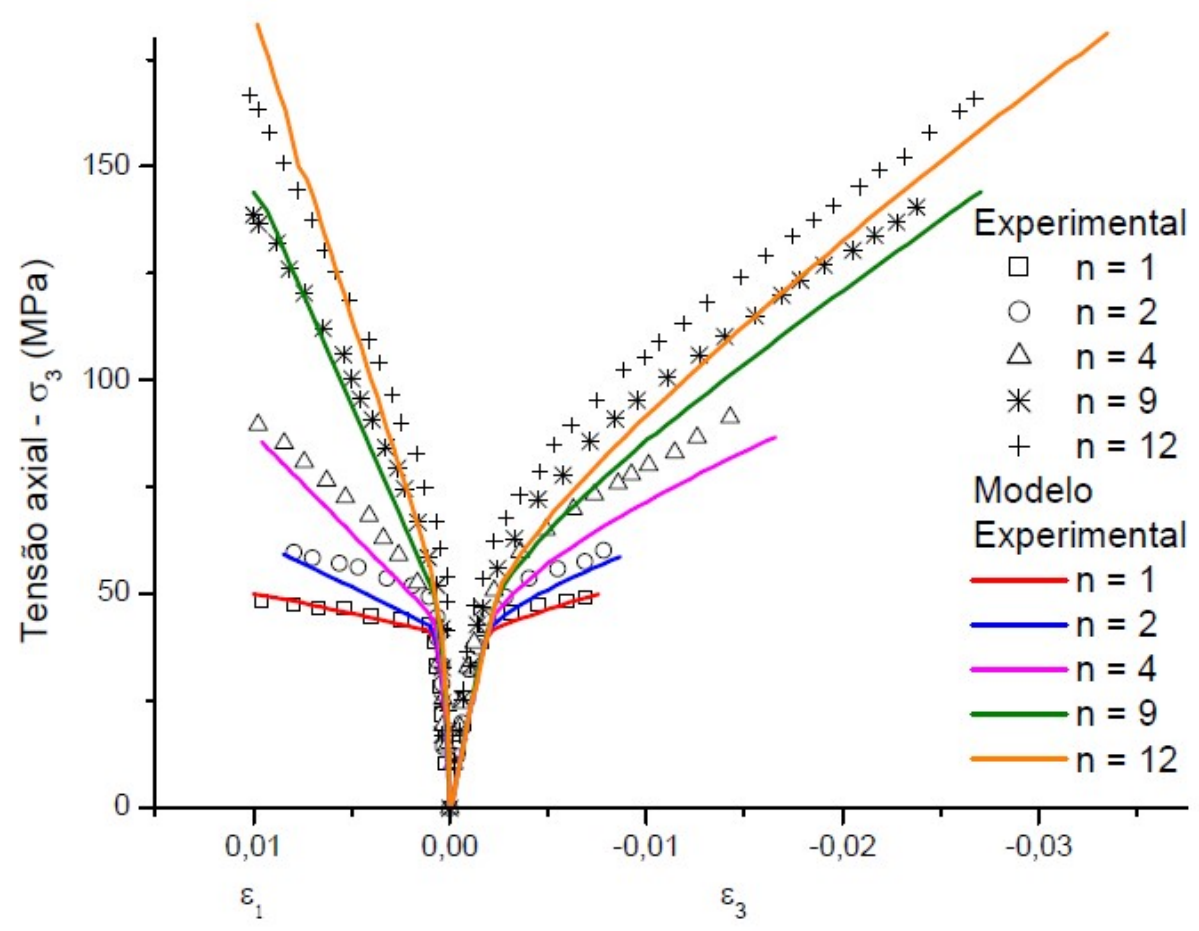

Figura 30. Comparação com experimentos de confinamento passivo de Berthet et al. (2005) para concreto de $40 \mathrm{MPa}$.

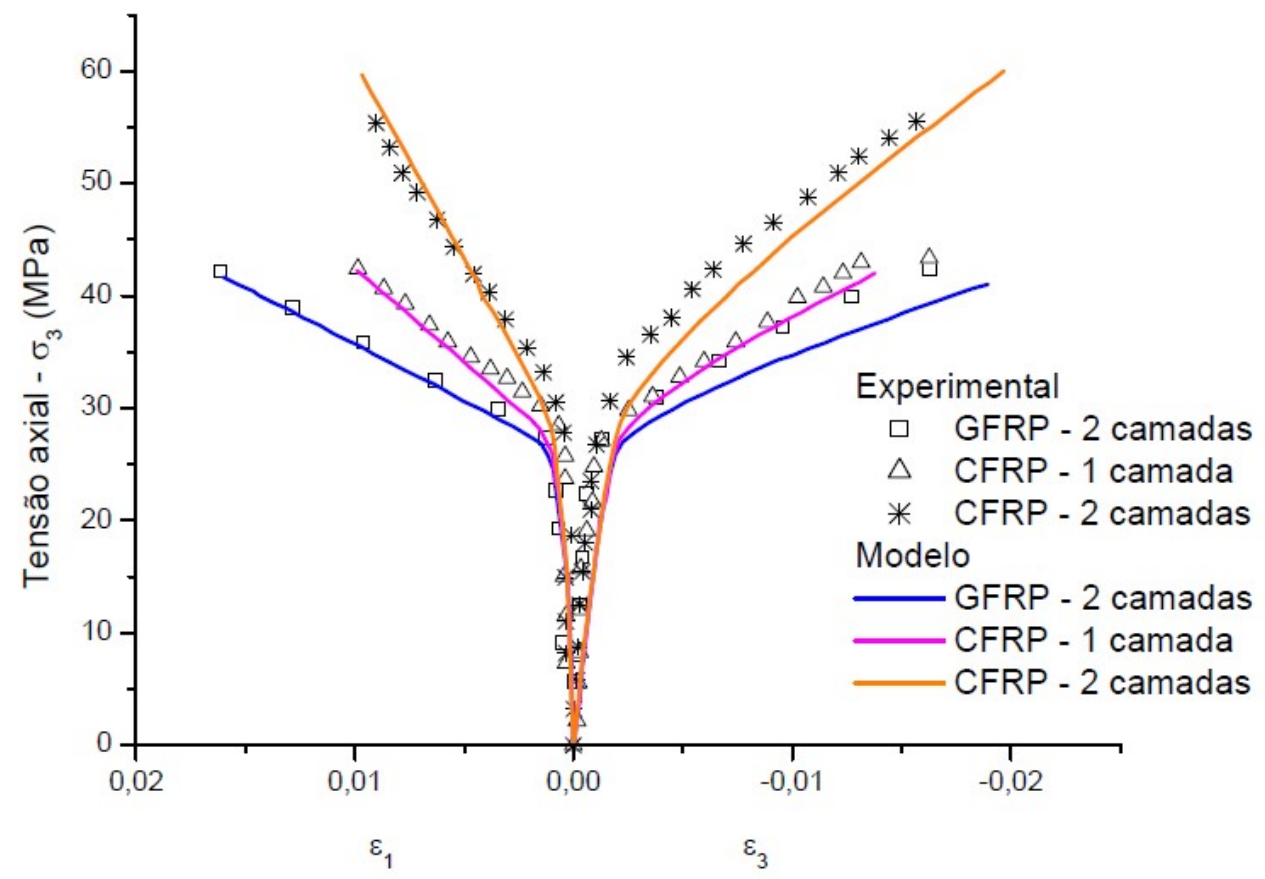

Figura 31. Comparação com experimentos de confinamento passivo de Berthet et al. (2005) para concreto de $25 \mathrm{MPa}$.

A comparação com os resultados experimentais de Berthetet al. (2005) também indica boa previsão da resistência e deformação última do concreto confinado. Porém, destaca-se que para níveis maiores de confinamento, representado por um número de camadas maior que 4, ocorre redução na precisão, com tendência a subestimar a resistência do concreto. 
A Figura 32 indica a evolução da deformação volumétrica para os ensaios de Berthet et al. (2005) para concreto de resistência a compressão uniaxial de $40 \mathrm{MPa}$, confinado por 1, 2, 4, 9 e 12 camadas de CFRP. Como observado experimentalmente, verifica-se que com o aumento do número de camisas, o concreto confinado apresenta mudança considerável de comportamento em relação à deformabilidade. Sendo que para menor número de camisas, o concreto apresenta inicialmente uma compactação volumétrica seguida por expansão volumétrica que evolui até a ruptura. A medida que o número de camisas aumenta, não observa-se mais dilatação volumétrica, mas sim uma compactação do material até a sua ruptura. Como demonstrado na comparação entre resultados experimentais e o modelo proposto, conclui-se que o modelo consegue prever com precisão a deformação volumétrica do concreto confinado passivamente, principalmente quando trata-se de menores número de camadas (1, 2 e 4 camadas). Para 9 e 12 camadas de CFRP, observa-se tendência a superestimar os níveis de compactação, no entanto, o modelo é capaz de capturar a compactação volumétrica e a forma da curva tensão-deformação volumétrica, representando com precisão o ponto de inversão de dilatação para compactação.

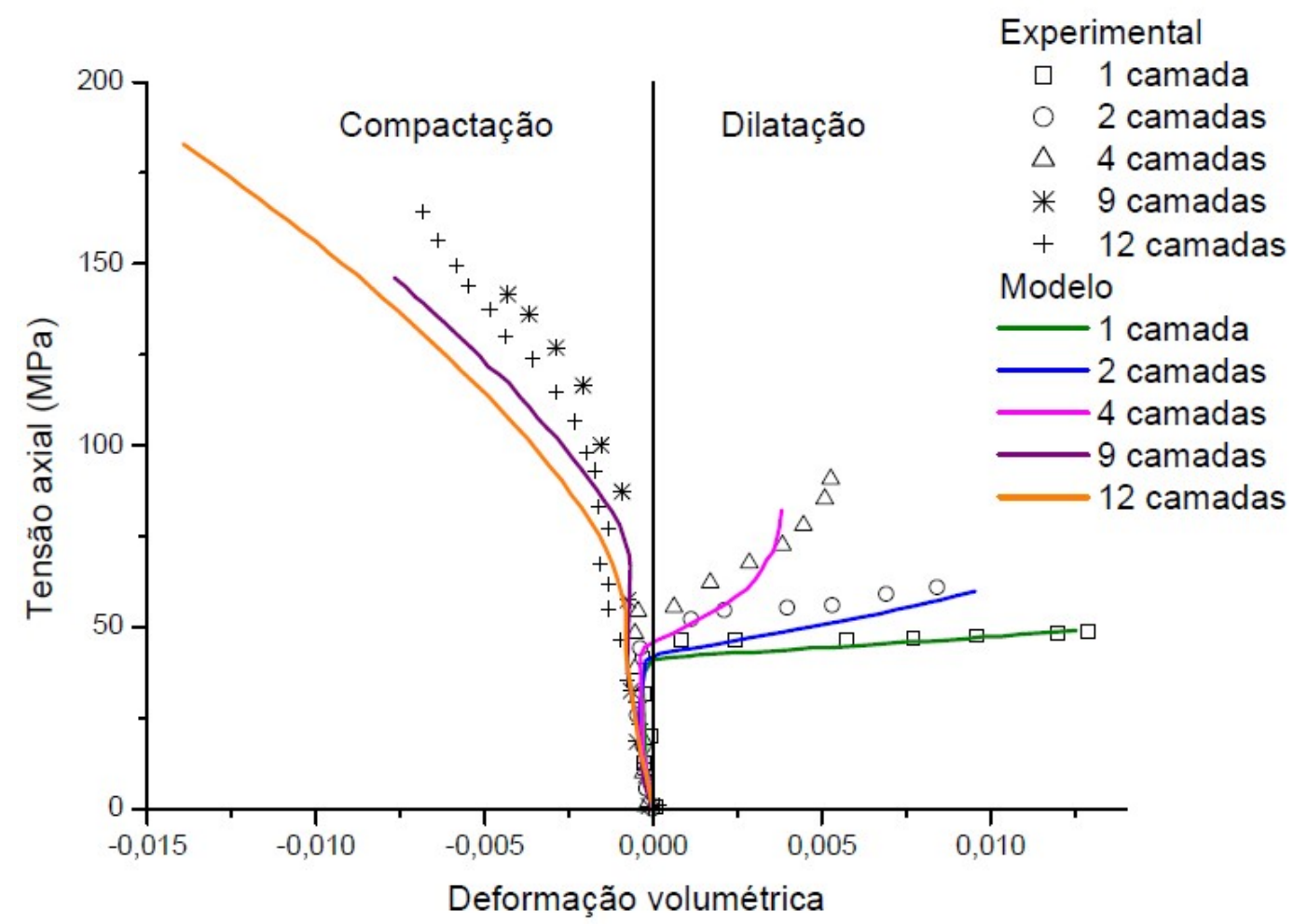

Figura 32. Comparação da deformação volumétrica para confinamento passivo com experimentos de Berthet et al. (2005) 
As Figuras 33 e 34 apresentam as curvas tensão-deformação resultantes do modelo para ensaios experimentais de Lim e Ozbakkaloglu (2015), que apresenta corpos-de-prova confinados com 1 e 2 camadas de GFRP e AFRP.

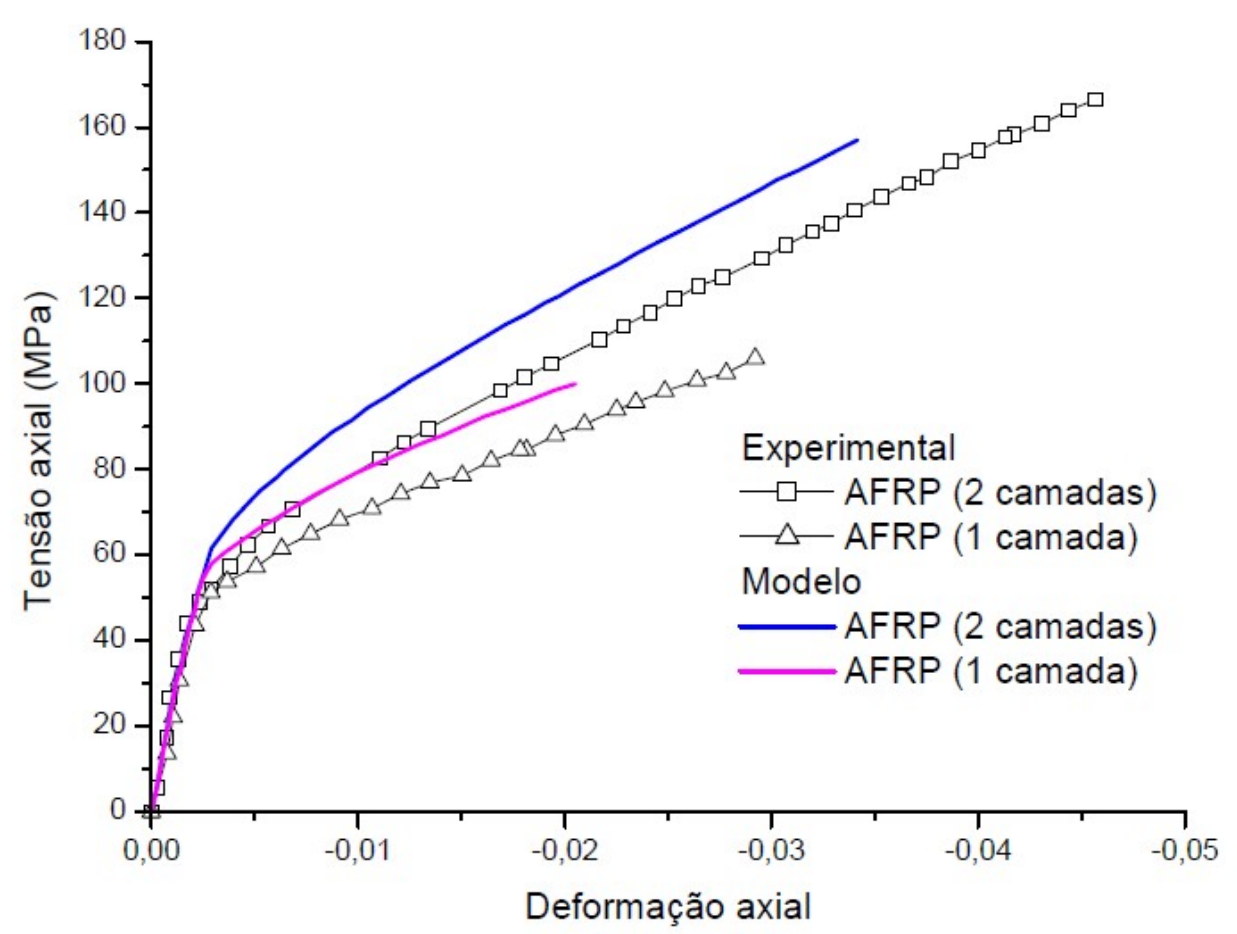

Figura 33. Comparação com experimentos de Lim e Ozbakkaloglu (2015) para confinamento com camisas de AFRP.

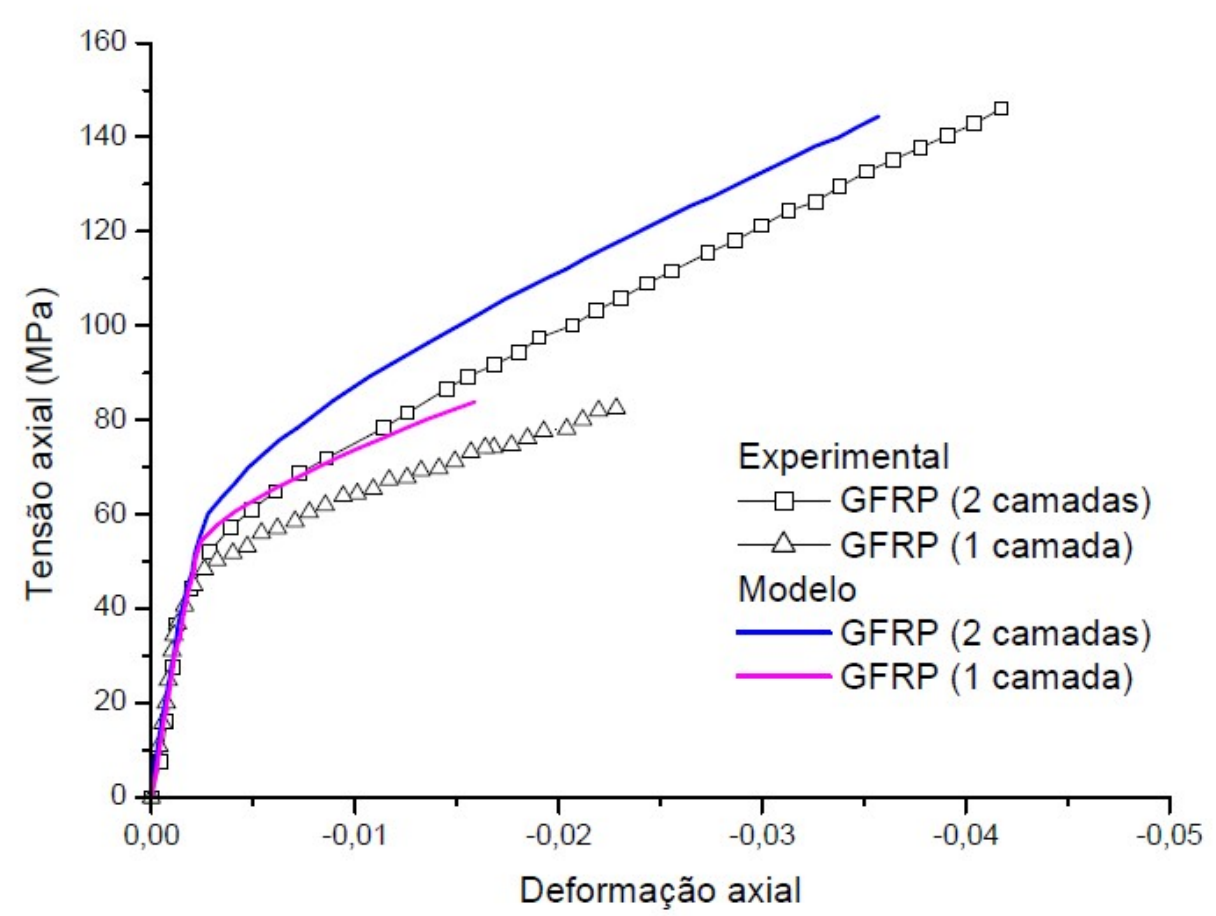

Figura 34. Comparação com experimentos de Lim e Ozbakkaloglu (2015) para confinamento com camisas de GFRP. 
Para esse conjunto de experimentos de Lim e Ozbakkaloglu (2015) observa-se uma maior discrepância entre os resultados do modelo proposto e os experimentais, se comparados aos resultados apresentados anteriormente, referentes a outros conjuntos de dados. Essa diferença pode ser percebida mais claramente na comparação entre deformação axial e lateral apresentada na Figura 35, na qual observa-se considerável afastamento entre as curvas experimentais e numéricas de deformação lateral x axial.

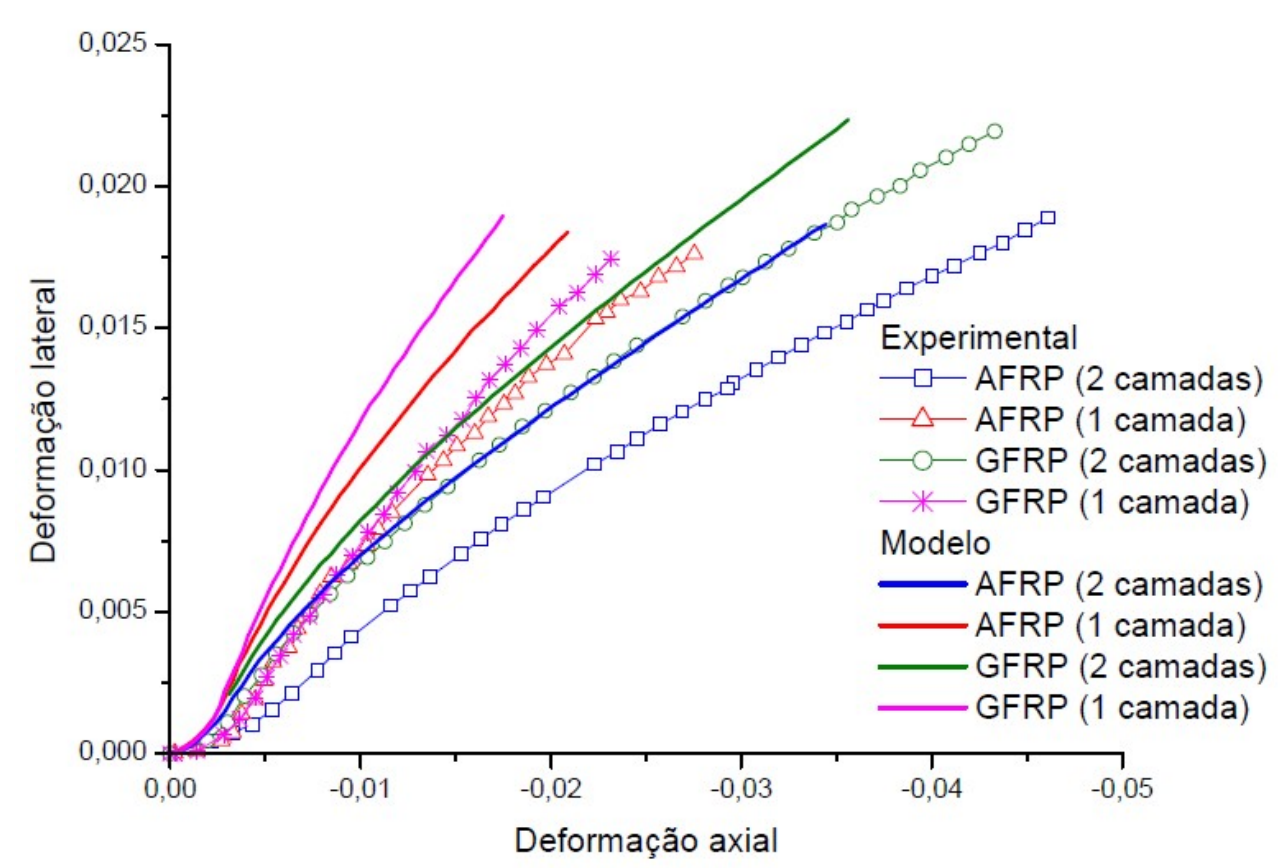

Figura 35. Comparação da relação deformação axial e lateral com experimentos de Lim e Ozbakkaloglu (2015)

\subsubsection{Confinamento com camisas de PRF - Cíclicos}

Em carregamentos cíclicos, observa-se a existência de laços de histerese resultantes da falta de coincidência entre os ramos de descarregamento e recarregamento. A formação desses laços depende não só da variável de dano, mas também da deformação por escorregamento. De forma simplifica, autores como Mazars (1986) assumem que a primeira variável está relacionada com o número e tamanho das fissuras e a segunda está relacionada com a forma das fissuras. Além disso, muitos estudos consideram plausível a hipótese de que só ocorre variação da forma das fissuras em um ciclo de descarregamento e recarregamento, ou seja, em um laço de histerese. Portanto, em um ciclo só ocorre variação da deformação por escorregamento, enquanto a variável de dano permanece constante. O modelo proposto, por simplificação, desconsidera os efeitos da deformação por escorregamento nos ciclos, 
adotando apenas a variável de dano para a descrição da evolução do dano. Dessa forma, os laços de histerese são desconsiderados, assumindo que o ramo de recarregamento (com forma aproximadamente linear) é representativo da rigidez elástica do material dentro do ciclo. Logo, todas as comparações realizadas para a análise da perda de rigidez elástica do material consideram os ramos de recarregamento como referência.

As Figuras 36 e 37 apresentam as comparações entre resultados do modelo para curvas tensão-deformação de corpos-de-prova confinados passivamente por 1 e 2 camadas de CFRP de Lam e Teng (2006), que foram submetidos a carregamento cíclico.

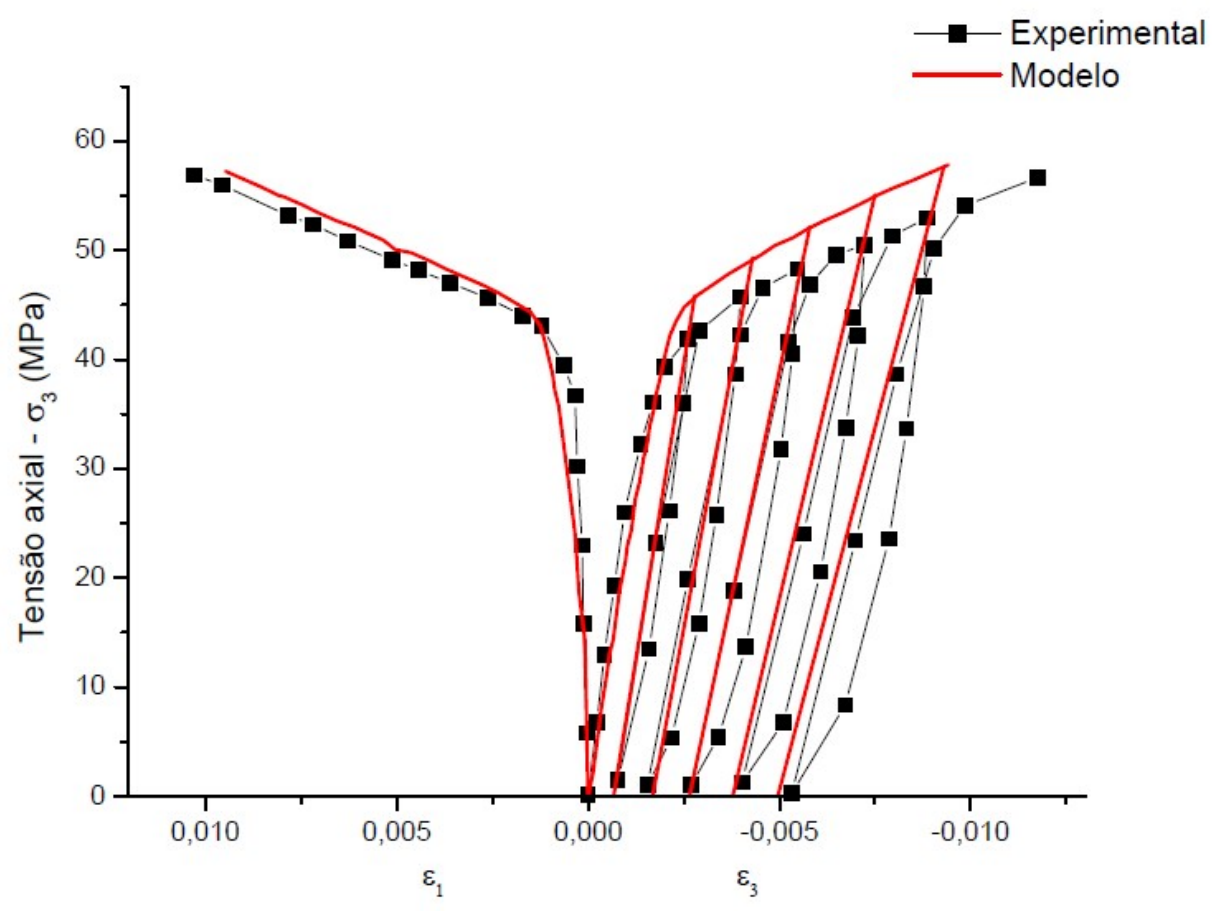

Figura 36. Comparação com experimentos de confinamento passivo de Lam e Teng (2006) para 1 camada de CFRP. 


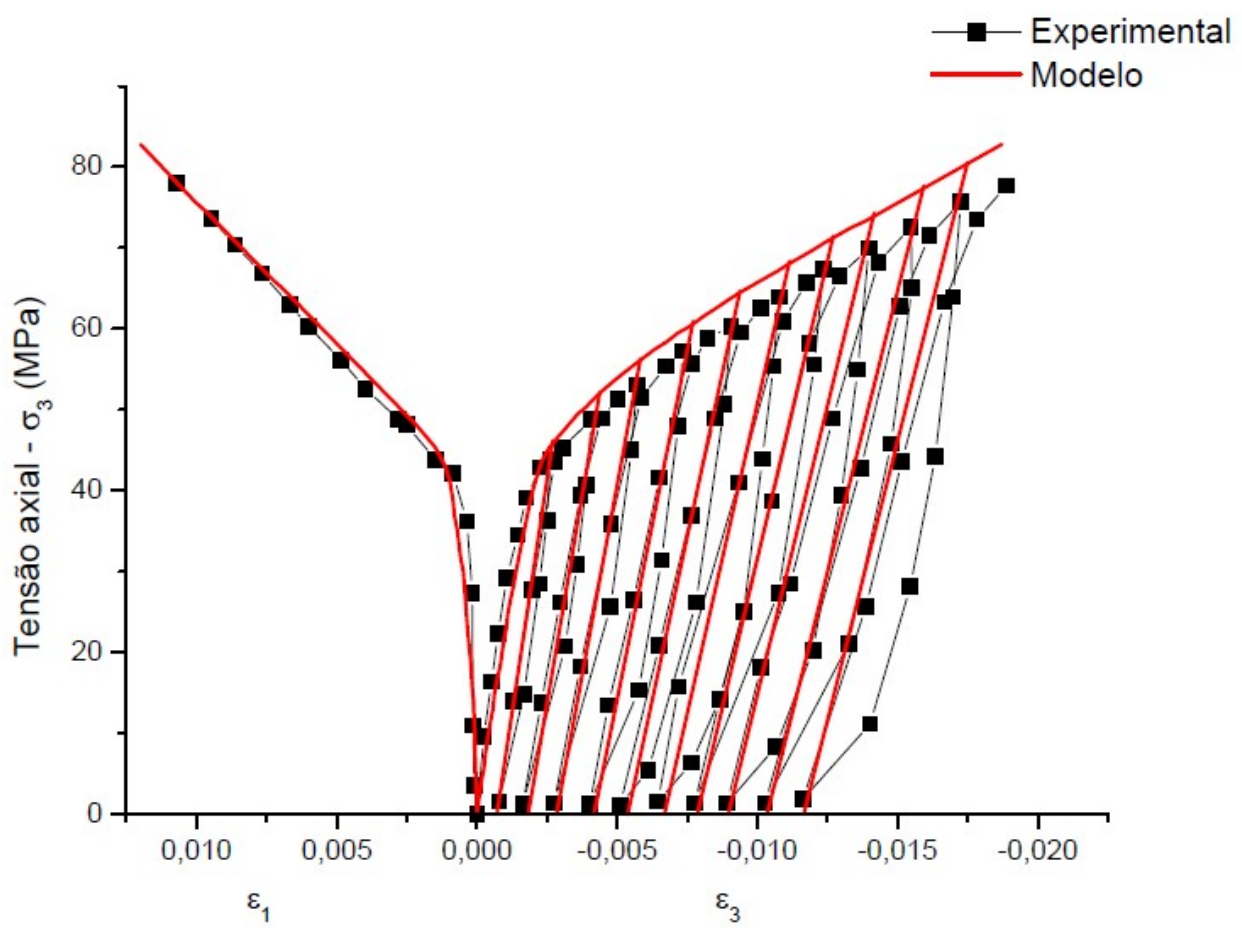

Figura 37. Comparação com experimentos de confinamento passivo de Lam e Teng (2006) para 2 camadas de CFRP.

Considerado as hipóteses e simplificações citadas inicialmente sobre os laços de histerese, observa-se, pela comparação com os resultados experimentais de Lam e Teng (2006), que a perda de rigidez do material nos ciclos é representada pelo modelo proposto. No entanto, destaca-se a necessidade de obtenção de outros resultados experimentais cíclicos para complementar a análise da evolução da perda de rigidez elástica, permitindo adequada calibração e validação do modelo.

Para carregamentos cíclicos, as curvas tensão-deformação do modelo também foram comparadas aos resultados experimentais de Ozbakkaloglu e Akin (2012) nas Figuras 38 e 39. 


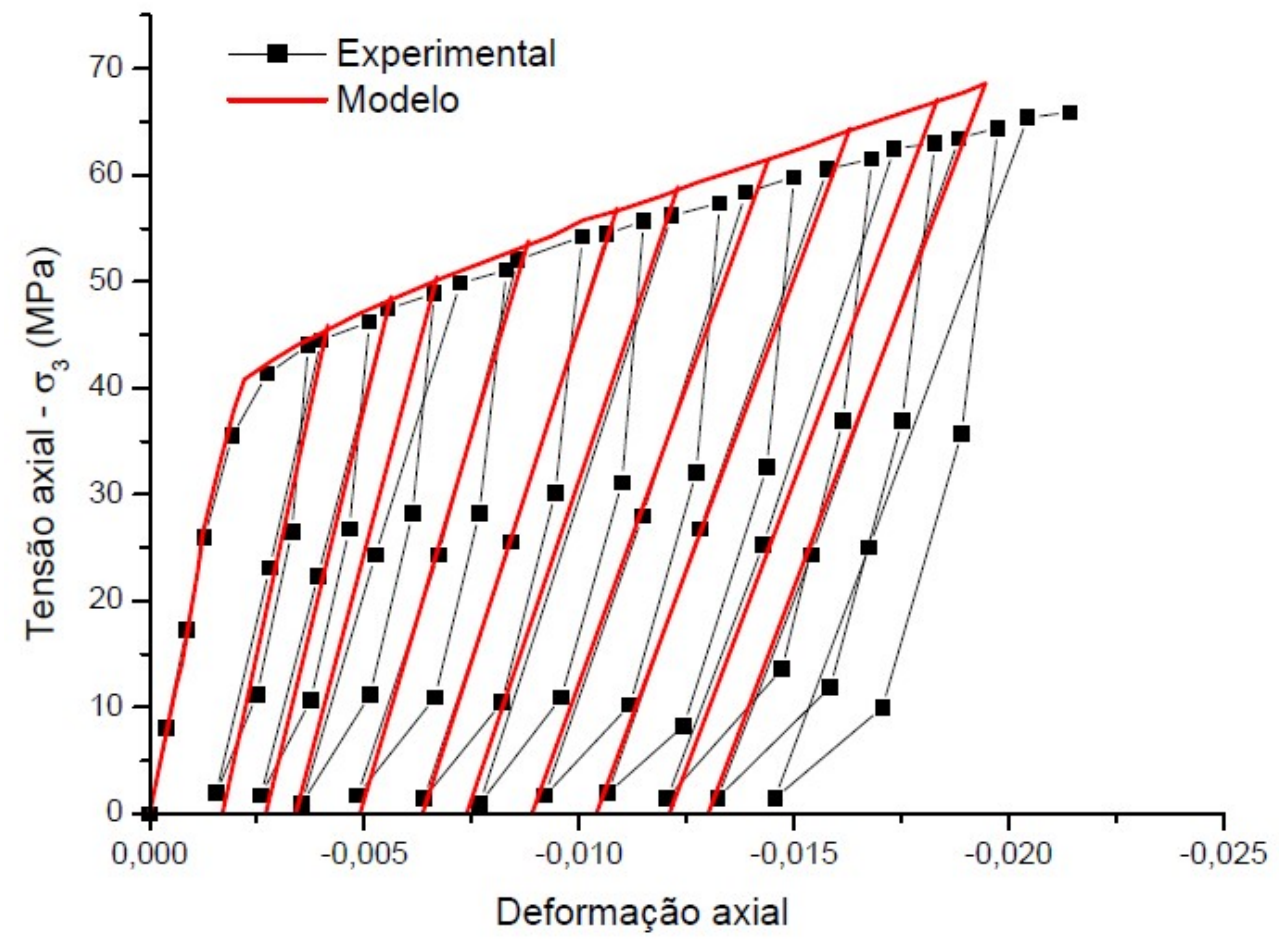

Figura 38. Comparação com experimentos de confinamento passivo de Ozbakkaloglu e Akin (2012) para 2 camadas de AFRP.

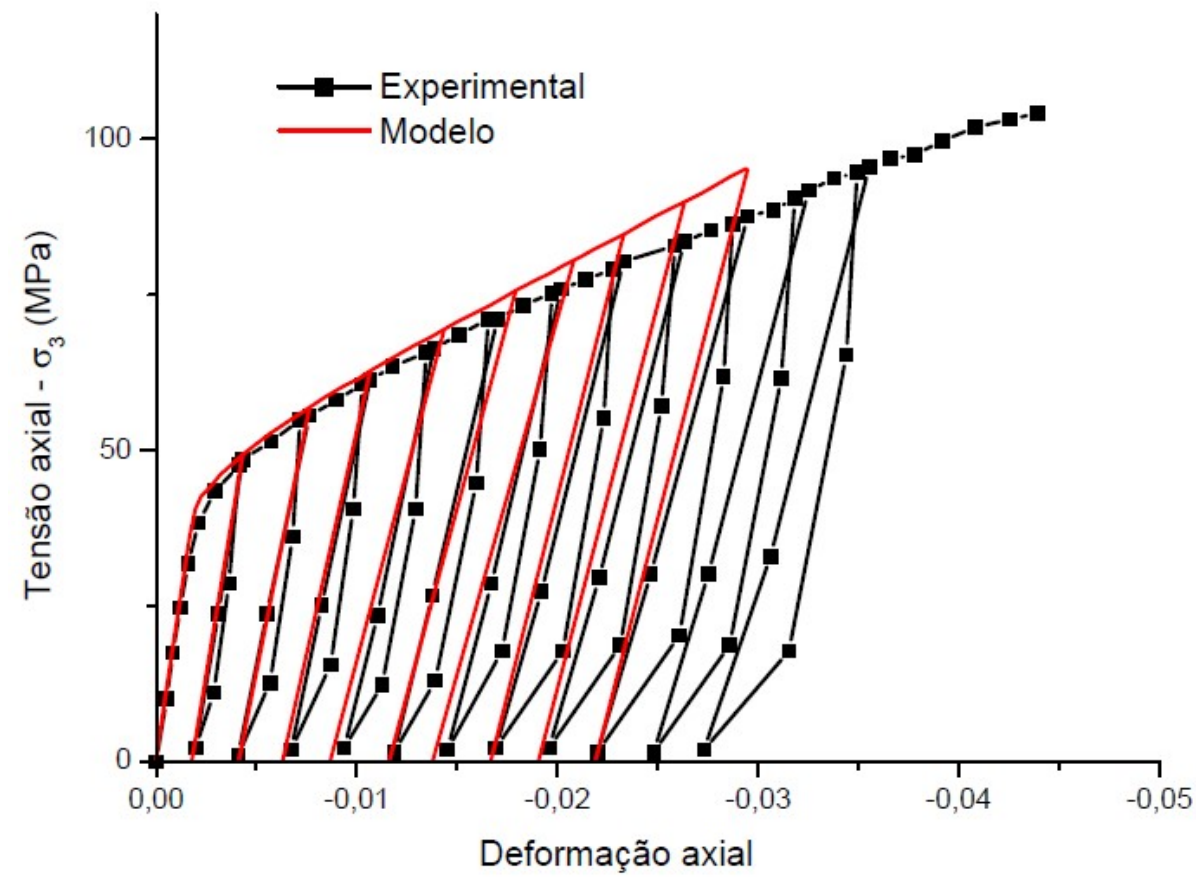

Figura 39. Comparação com experimentos de confinamento passivo de Ozbakkaloglu e Akin (2012) para 3 camadas de AFRP. 
A comparação com os resultados experimentais de Ozbakkaloglu e Akin (2012) também indica resultados semelhantes entre resultados experimentais e numéricos para a resistência e deformação última do concreto confinado. A evolução da perda de rigidez também é descrita pelo modelo.

A Tabela 3 indica o resumo da comparação entre as resistências e deformações últimas experimentais e resultantes do modelo proposto, assim como os respectivos erros calculados conforme Eq. (120).

$$
E(\%)=\left(\frac{\text { resultado experimental }}{\text { resultado modelo }}-1\right) \times 100
$$

Tabela 3. Resumo da comparação entre modelo proposto e resultados experimentais.

\begin{tabular}{|c|c|c|c|c|c|c|c|c|c|}
\hline Experimentais & $\begin{array}{c}f_{c} \\
(\mathrm{MPa})\end{array}$ & $\begin{array}{l}\text { Tipo } \\
\text { de } \\
\text { fibra }\end{array}$ & $\begin{array}{c}\text { № de } \\
\text { camadas }\end{array}$ & $\begin{array}{c}f_{c c} \\
(\mathrm{MPa}) \\
\text { EXP. }\end{array}$ & $\begin{array}{c}f_{c c} \\
\text { (MPa) } \\
\text { MOD. }\end{array}$ & $\begin{array}{c}\text { Erro } \\
\mathrm{f}_{\mathrm{cc}}(\%)\end{array}$ & $\begin{array}{r}\varepsilon_{c c} \\
\text { EXP. }\end{array}$ & $\begin{array}{c}\varepsilon_{c c} \\
\text { MOD. }\end{array}$ & $\begin{array}{l}\text { Erro } \\
\varepsilon_{c c} \\
(\%)\end{array}$ \\
\hline \multirow{3}{*}{$\begin{array}{l}\text { Xiao e Wu } \\
(2000)\end{array}$} & \multirow{3}{*}{33,7} & CFRP & 1 & 49,3 & 49,1 & 0,4 & 0,0133 & 0,0106 & 25,5 \\
\hline & & CFRP & 2 & 72,7 & 68,8 & 5,7 & 0,0217 & 0,0168 & 29,2 \\
\hline & & CFRP & 3 & 91,5 & 88,8 & 3,0 & 0,0286 & 0,0213 & 34,3 \\
\hline \multirow{5}{*}{$\begin{array}{l}\text { Berthet et al. } \\
\text { (2005) }\end{array}$} & \multirow{5}{*}{40} & CFRP & 1 & 49,3 & 50 & $-1,4$ & 0,0076 & 0,0075 & 1,3 \\
\hline & & CFRP & 2 & 60,2 & 58,8 & 2,4 & 0,0087 & 0,009 & $-3,3$ \\
\hline & & CFRP & 4 & 91,3 & 86,7 & 5,3 & 0,0143 & 0,0166 & $-13,9$ \\
\hline & & CFRP & 9 & 140,5 & 144 & $-2,4$ & 0,0238 & 0,027 & $-11,9$ \\
\hline & & CFRP & 12 & 165,8 & 181 & $-8,4$ & 0,027 & 0,0335 & $-19,4$ \\
\hline \multirow{3}{*}{$\begin{array}{l}\text { Berthet et al. } \\
\text { (2005) }\end{array}$} & \multirow{3}{*}{25} & CFRP & 1 & 43,4 & 42 & 3,3 & 0,0163 & 0,014 & 16,4 \\
\hline & & CFRP & 2 & 55,5 & 60 & $-7,5$ & 0,0157 & 0,019 & $-17,4$ \\
\hline & & GFRP & 2 & 42,5 & 41 & 3,7 & 0,0163 & 0,019 & $-14,2$ \\
\hline \multirow{4}{*}{$\begin{array}{l}\text { Lim et al. } \\
\text { (2014) }\end{array}$} & \multirow{4}{*}{51,6} & AFRP & 1 & 106 & 100 & 6,0 & 0,0292 & 0,0205 & 42,4 \\
\hline & & AFRP & 2 & 166,4 & 157 & 6,0 & 0,0457 & 0,0342 & 33,6 \\
\hline & & GFRP & 1 & 82,5 & 83,9 & $-1,7$ & 0,0228 & 0,0159 & 43,4 \\
\hline & & GFRP & 2 & 146,1 & 144,4 & 1,2 & 0,0418 & 0,0357 & 17,1 \\
\hline \multirow{2}{*}{$\begin{array}{l}\text { Lam e Teng } \\
\qquad(2006)\end{array}$} & \multirow{2}{*}{40} & CFRP & 1 & 56,6 & 57,8 & $-2,1$ & 0,0117 & 0,0095 & 23,2 \\
\hline & & CFRP & 2 & 77,7 & 82,8 & $-6,2$ & 0,0189 & 0,0187 & 1,1 \\
\hline \multirow{2}{*}{$\begin{array}{l}\text { Ozbakkaloglu } \\
\text { e Akin (2012) }\end{array}$} & \multirow{2}{*}{39} & AFRP & 2 & 65,9 & 68,6 & $-3,9$ & 0,0214 & 0,0195 & 9,7 \\
\hline & & AFRP & 3 & 104,1 & 95,3 & 9,2 & 0,0439 & 0,0295 & 48,8 \\
\hline
\end{tabular}


Observa-se que ocorre maior proximidade entre os resultados experimentais e numéricos de resistência última que variam de $-8,4 \%$ a $9,2 \%$, se comparado a deformação última do concreto confinado cuja diferença varia de $-19,4 \%$ a 48,8\%. Essa imprecisão, principalmente na previsão das deformações últimas, pode ser resultante da hipótese adotada para definição do parâmetro de encruamento ou da modificação da função potencial plástica cuja calibração, apesar de considerar um conjunto amplo de resultados experimentais, é dependente desse conjunto de dados, podendo ser menos representativa em alguns casos. Portanto, julga-se que os dois fatores citados podem ser as principais justificativas para as diferenças observadas.

4.2.3 Confinamento com camisas de aço - com e sem protensão

As curvas tensão-deformação resultantes do modelo proposto foram comparadas a resultados experimentais existentes na literatura para avaliar a precisão do modelo proposto. A Tabela 1 apresenta o resumo dos experimentos de corpos-de-prova cilíndricos confinados por PRF, que foram retirados da literatura para validação do modelo. Na Tabela 1 estão apresentadas as seguintes propriedades do concreto e do material confinante: resistência última e deformação de pico na compressão uniaxial do concreto ( $f_{c}$ e $\varepsilon_{c}$, respectivamente), módulo de elasticidade do concreto $\left(E_{c}\right)$, diâmetro do corpo-de-prova (D), tipo de carregamento (monotônico ou cíclico), espessura da camisa de aço (e), módulo de elasticidade do material confinante $\left(\mathrm{E}_{\mathrm{aço}}\right)$ e tensão de ruptura do aço $\left(\sigma_{\text {ult }}\right)$.

Tabela 4. Experimentos selecionados e propriedades dos materiais.

\begin{tabular}{ccccccccc}
\hline Experimentais & $\begin{array}{c}\mathrm{f}_{\mathrm{c}} \\
(\mathrm{MPa})\end{array}$ & $\varepsilon_{\mathrm{c}}$ & $\begin{array}{c}\mathrm{E}_{\mathrm{c}} \\
(\mathrm{GPa})\end{array}$ & $\begin{array}{c}\mathrm{D} \\
(\mathrm{mm})\end{array}$ & Tipo & $\begin{array}{c}\text { Espessura } \\
(\mathrm{mm})\end{array}$ & $\begin{array}{c}\mathrm{E}_{\mathrm{PRF}} \\
(\mathrm{GPa})\end{array}$ & $\begin{array}{c}\sigma_{\mathrm{ult}} \\
(\mathrm{MPa})\end{array}$ \\
\hline $\begin{array}{c}\text { Choi et al. } \\
(2009)\end{array}$ & 26,8 & 0,0020 & 24 & 150 & Monotônico & $1 \mathrm{e} \mathrm{1,5}$ & 200 & 400 \\
$\begin{array}{c}\text { Janke et al. } \\
(2009)\end{array}$ & 42,5 & 0,0020 & 30,6 & $150 \begin{array}{c}\text { Monotônico } \\
\text { (Com e sem } \\
\text { protensão) }\end{array}$ & 0,8 & 183,5 & 830 \\
\hline
\end{tabular}

A Tabela 5 apresenta, para cada conjunto de experimentos, todos os parâmetros utilizados na calibração do modelo: ângulo de atrito $(\phi)$, relação do limite elástico $\left(\mathrm{q}_{0}\right)$, parâmetros da função de encruamento $\left(\beta_{1}\right.$ e $\left.\beta_{2}\right)$, tensão de confinamento para calibração da função potencial plástica $\left(\sigma_{1 c c}\right)$ e parâmetros de dano $\left(\mathrm{A}_{\mathrm{c}}\right.$ e $\left.\mathrm{a}_{2}\right)$. 
Tabela 5. Parâmetros utilizados no modelo para comparação com experimentos

\begin{tabular}{cccccccc}
\hline Experimentais & $\phi$ & $\mathrm{q}_{0}$ & $\beta_{1}$ & $\beta_{2}$ & $\sigma_{1 \mathrm{cc}}(\mathrm{MPa})$ & $\mathrm{A}_{\mathrm{c}}$ & $\mathrm{a}_{2}$ \\
\hline Choi et al. (2009) & $37^{\circ}$ & 0,3 & 2,1 & 0,03 & -5 & - & - \\
Janke et al. (2009 & $37^{\circ}$ & 0,3 & 2,1 & 0,01 & -8 & - & - \\
\hline
\end{tabular}

A Figura 40 mostra a comparação entre curvas tensão-deformação do modelo com os resultados experimentais de Choi et al. (2009) que consiste de cilindros de 150x300 cm confinados por camisas de aço de 1 e 1,5 mm de espessura. Destaca-se que, segundo Choi et al. (2009), as camisão de aço apresentam altura um pouco menor que o corpo-de-prova, a fim de que não ocorra transferência de carga diretamente do equipamento de ensaio para a camisa, o que afetaria consideravelmente o resultado tensão-deformação do ensaio.

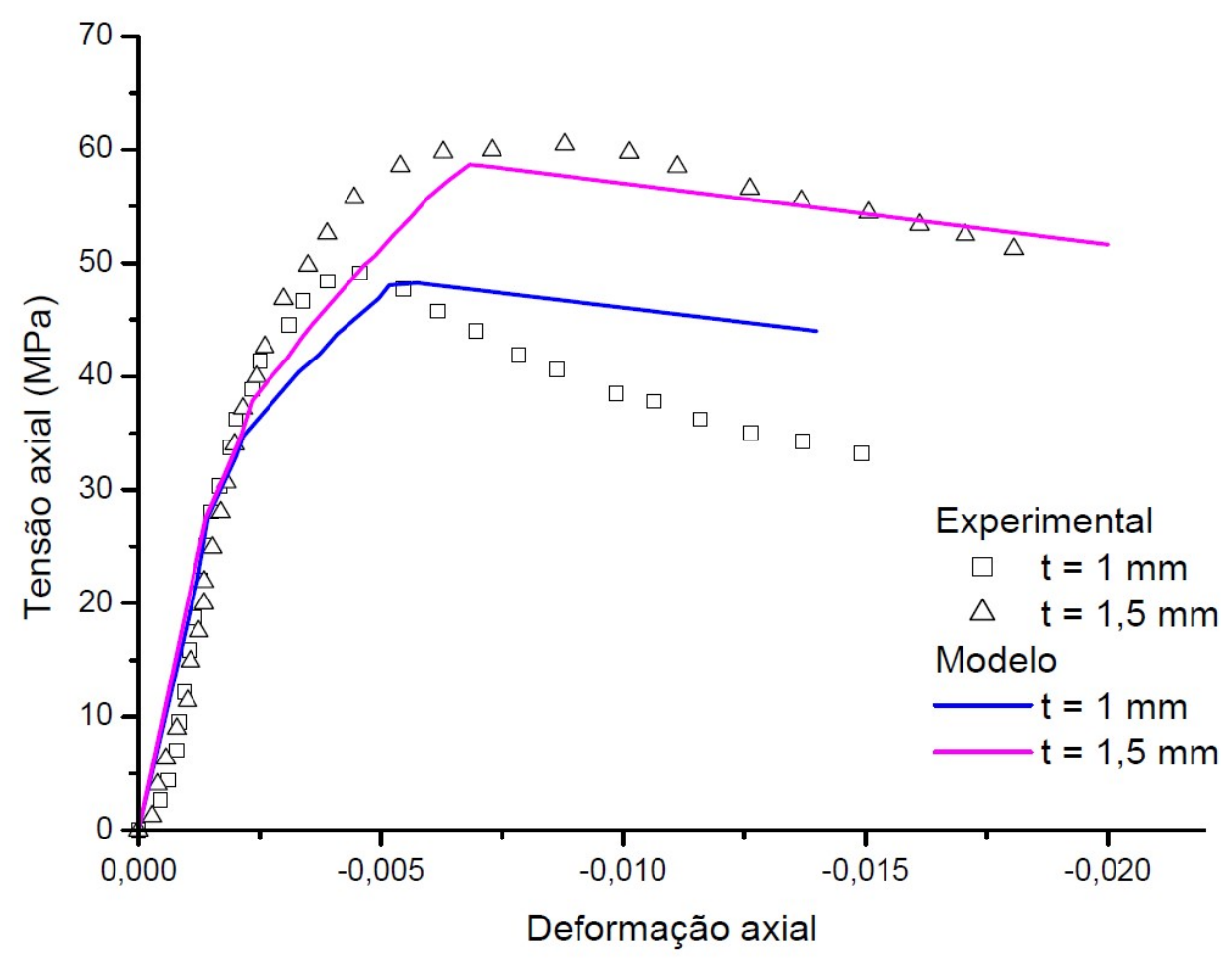

Figura 40. Comparação com experimentos de confinamento passivo por camisas de aço de Choi et al. (2009).

A comparação demonstrada na Figura 40 indica uma boa previsão da resistência e deformação de pico do concreto confinado por camisa de aço. Destaca-se que o comportamento do concreto confinado com aço assemelha mais ao comportamento do confinamento ativo. No entanto, os critérios adotados no modelo foram referentes ao confinamento passivo, ou seja, parâmetro de encruamento e função potencial plástica foram definidos conforme critérios adotados para o confinamento passivo com PRF. Portanto, as 
considerações e hipóteses adotadas a partir do confinamento com PRF mostram-se válidas também para camisas de aço.

A Figura 41 mostra a comparação entre curvas tensão-deformação do modelo com os resultados experimentais de Janke et al. (2009) que consiste de cilindros de 150x600 cm confinados por camisa de aço de $0,8 \mathrm{~mm}$ de espessura.

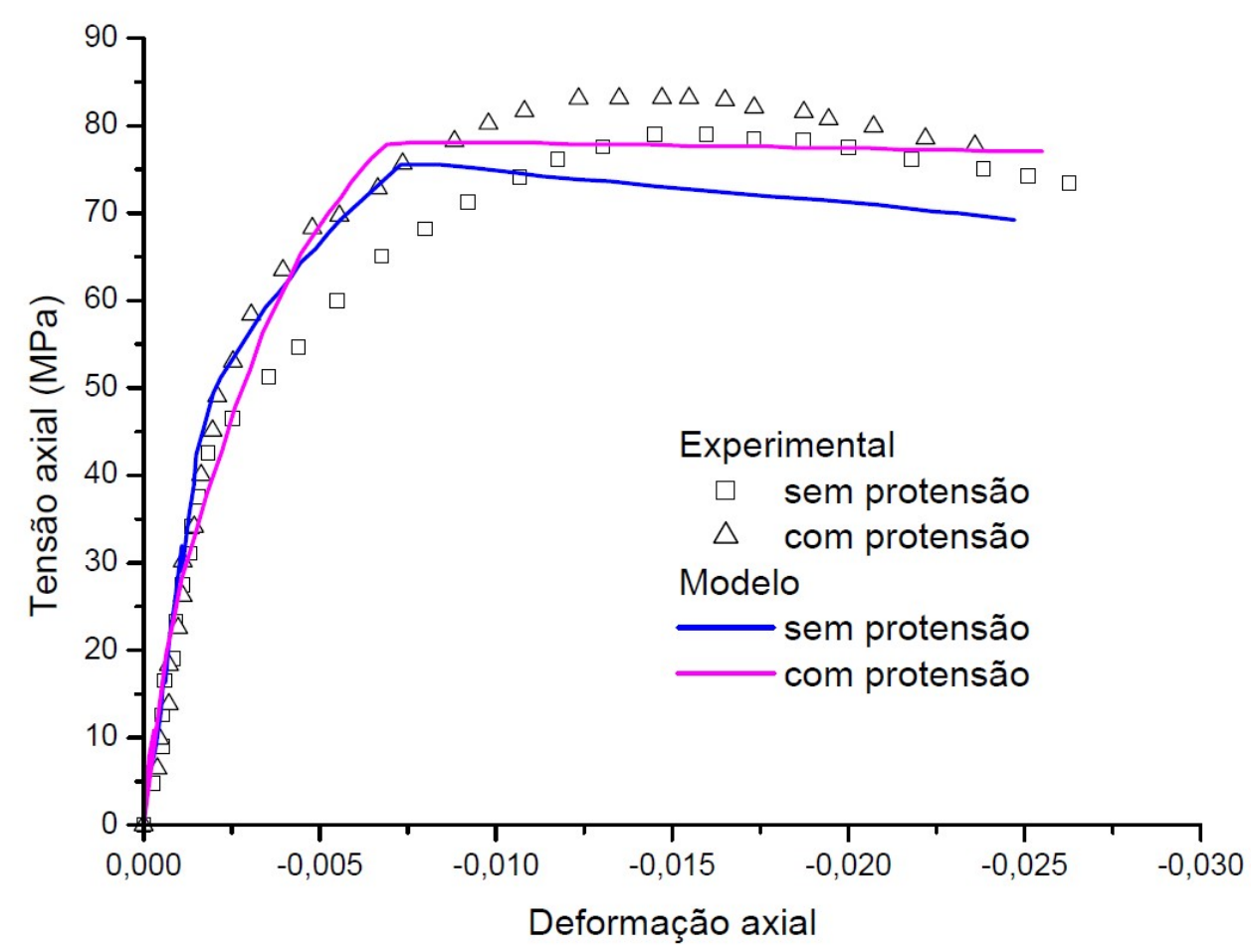

Figura 41. Comparação com experimentos de confinamento passivo pór camisas de aço de Janke et al. (2009).

A comparação com os resultados de Janke et al. (2009) indica uma boa previsão da resistência de pico do concreto confinado por camisa de aço, porém, observa-se deformações de picos menores em relação aos resultados experimentais.

A Tabela 6 indica o resumo da comparação entre as resistências e deformações de pico experimentais e as resultantes do modelo proposto, assim como os respectivos erros, calculados conforme Eq. (120). 
Tabela 6. Resumo da comparação entre modelo proposto e resultados experimentais

\begin{tabular}{ccccccccc}
\hline Experimentais & $\begin{array}{c}\mathrm{f}_{\mathrm{c}} \\
(\mathrm{MPa})\end{array}$ & Espessura (mm) & $\begin{array}{c}\mathrm{f}_{\mathrm{cc}} \\
(\mathrm{MPa})\end{array}$ & $\begin{array}{c}\mathrm{f}_{\mathrm{cc}}(\mathrm{MPa}) \\
\mathrm{MOD} .\end{array}$ & $\begin{array}{c}\text { Erro } \\
\mathrm{f}_{\mathrm{cc}}(\%)\end{array}$ & $\begin{array}{c}\varepsilon_{c c} \\
\text { EXP. }\end{array}$ & $\begin{array}{c}\varepsilon_{c c} \\
\text { MOD. }\end{array}$ & $\begin{array}{c}\text { Erro } \varepsilon_{c c} \\
(\%)\end{array}$ \\
\hline \begin{tabular}{c} 
Choi et al. \\
\multirow{2}{*}{$26009)$}
\end{tabular} & 1 & 49,1 & 48,2 & 1,9 & 0,0046 & 0,0058 & $-20,7$ \\
(20,8) & & 1,5 & 60,5 & 58,7 & 3,1 & 0,0088 & 0,0068 & 29,4 \\
$\begin{array}{c}\text { Janke et al. } \\
\text { (2009) }\end{array}$ & \multirow{2}{*}{42,5} & 0,8 (sem protensão) & 79 & 75,6 & 4,5 & 0,0145 & 0,009 & 61,1 \\
& & 0,8 (com protensão) & 83,2 & 78 & 6,7 & 0,0155 & 0,0111 & 39,6 \\
\hline
\end{tabular}

4.2.4 Confinamento com camisas de PRF - com e sem protensão

A Figura 42 mostra as curvas tensão-deformação do modelo comparadas aos resultados experimentais de Janke et al. (2009) com cilindros de 150x600 cm confinados por nove camadas de CFRP, com 0,15 mm de espessura (cada camada). Além da consideração do confinamento passivo, os corpos-de-prova também foram submetidos a uma tensão inicial de confinamento de 1,9 MPa. A resistência à compressão e a deformação última do concreto não confinado são 42,5 MPa e 0,002, respectivamente. O módulo de elasticidade e a resistência última do material confinante são iguais a $113 \mathrm{GPa}$ e 1,75 MPa, respectivamente.

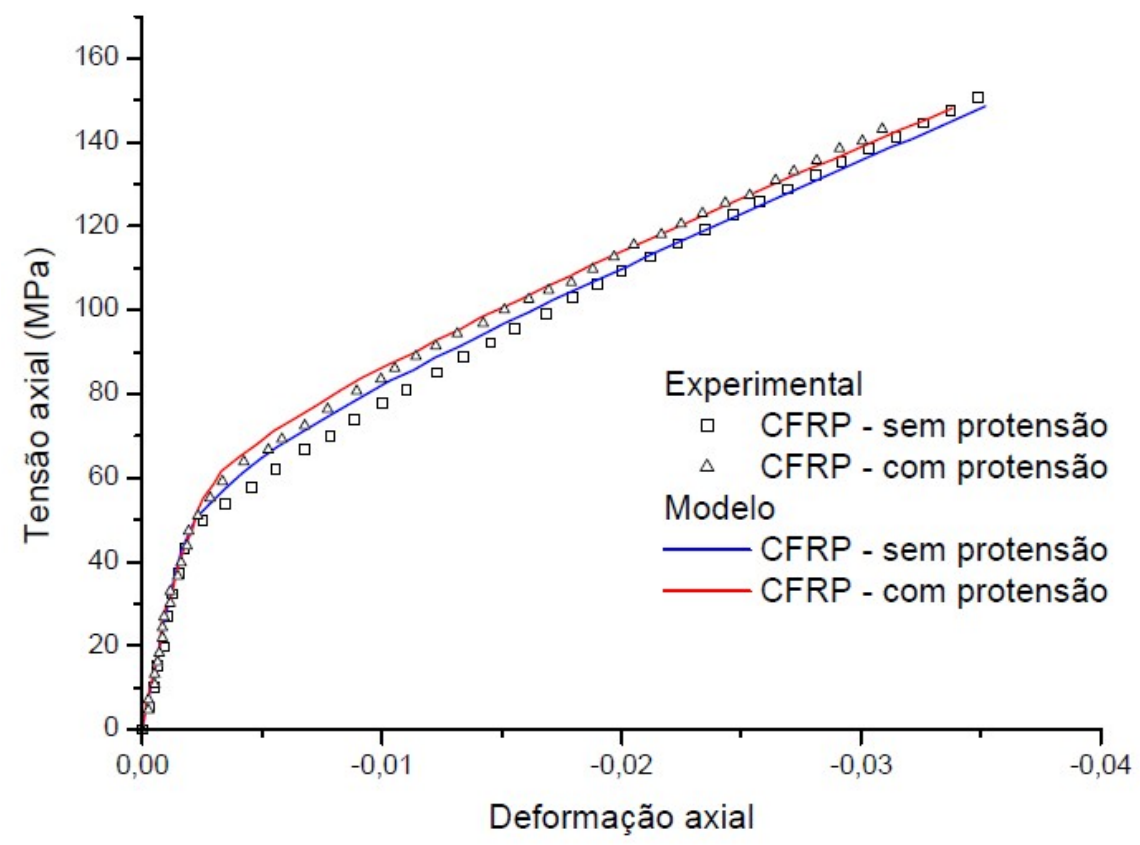

Figura 42. Comparação com experimentos de confinamento ativo de Janke et al. (2009)

No caso da existência de protensão inicial da camisa, adota-se todos os critérios referentes ao confinamento passivo, porém, com tensão lateral inicial de confinamento 
diferente de zero. Os parâmetros adotados, nesse caso, foram os mesmos adotados nos experimentos de Janke et al. (2009) para corpos-de-prova confinados por camisas de aço, já citados anteriormente.

A comparação com os resultados de Janke et al. (2009) indica boa previsão da resistência e deformação última do concreto confinado por camisa de PRF, tanto para o caso sem protensão, quanto para o caso com aplicação de protensão inicial.

\subsection{Confinamento ativo}

Também foram feitas comparações para as curvas tensão-deformação de resultados experimentais existentes na literatura de confinamento ativo a fim de avaliar a precisão do modelo proposto para esse tipo de confinamento. A Tabela 7 apresenta o resumo dos experimentos retirados da literatura utilizados para validação do modelo, juntamente com as propriedades dos materiais: resistência última e deformação de pico na compressão uniaxial do concreto $\left(f_{c}\right.$ e $\varepsilon_{c}$, respectivamente), módulo de elasticidade do concreto $\left(E_{c}\right)$, tipo de carregamento (monotônico ou cíclico) e tensão de confinamento.

Tabela 7. Resumo dos experimentos utilizados para confinamento ativo e propriedades dos materiais

\begin{tabular}{cccccc}
\hline Experimentais & $\begin{array}{c}\mathrm{f}_{\mathrm{c}} \\
(\mathrm{MPa})\end{array}$ & $\varepsilon_{\mathrm{c}}$ & $\begin{array}{c}\mathrm{E}_{\mathrm{c}} \\
(\mathrm{GPa})\end{array}$ & Tipo & $\begin{array}{c}\text { Tensão } \\
\text { confinamento (MPa) }\end{array}$ \\
\hline $\begin{array}{c}\text { Lahlou et al. } \\
(1992)\end{array}$ & 46 & 0,0027 & 26,8 & Monotônico & 7,6 e 22 \\
$\begin{array}{c}\text { Imran e } \\
\text { Pantazopoulou } \\
(2005)\end{array}$ & 47,4 & 0,00288 & 27 & Monotônico & 4,$3 ; 8,6 ; 17,2$ e 30,1 \\
$\begin{array}{c}\text { Li e Wu (2016) } \\
\text { (200) }\end{array}$ & 35 & 0,0028 & 23,4 & Cíclico & $5 ; 10 ; 15$ e 20 \\
\hline
\end{tabular}

A Tabela 8 apresenta, para cada conjunto de experimentos, todos os parâmetros utilizados na calibração do modelo: ângulo de atrito $(\phi)$, relação do limite elástico $\left(\mathrm{q}_{0}\right)$, parâmetros da função de encruamento $\left(\beta_{1}\right.$ e $\left.\beta_{2}\right)$, tensão de confinamento para calibração da função potencial plástica $\left(\sigma_{1 c c}\right)$ e parâmetros de dano $\left(\mathrm{A}_{\mathrm{c}} \mathrm{e} \mathrm{a}_{2}\right)$. 
Tabela 8. Parâmetros utilizados para comparação com experimentos

\begin{tabular}{cccccccc}
\hline Experimentais & $\phi$ & $\mathrm{q}_{0}$ & $\beta_{1}$ & $\beta_{2}$ & $\sigma_{1 \mathrm{cc}}(\mathrm{MPa})$ & $\mathrm{A}_{c}$ & $\mathrm{a}_{2}$ \\
\hline $\begin{array}{c}\text { Lahlou et al. (1992) } \\
\text { Imran e }\end{array}$ & $37^{\circ}$ & 0,3 & 2,1 & 0,06 & $\sigma_{\text {lateral }}$ & - & - \\
$\begin{array}{c}\text { Pantazopoulou } \\
\text { (2005) }\end{array}$ & $37^{\circ}$ & 0,3 & 2,1 & 0,06 & $\sigma_{\text {lateral }}$ & - & - \\
Li e Wu (2016) & $37^{\circ}$ & 0,3 & 2,1 & 0,06 & $\sigma_{\text {lateral }}$ & 0,1 & 0,3 \\
\hline
\end{tabular}

A Figura 43 mostra as curvas tensão-deformação do modelo com os resultados experimentais de Lahlou et al. (1992) com cilindros de 52x104 cm submetidos a tensões de confinamento constantes iguais a 7,6 e $22 \mathrm{MPa}$.

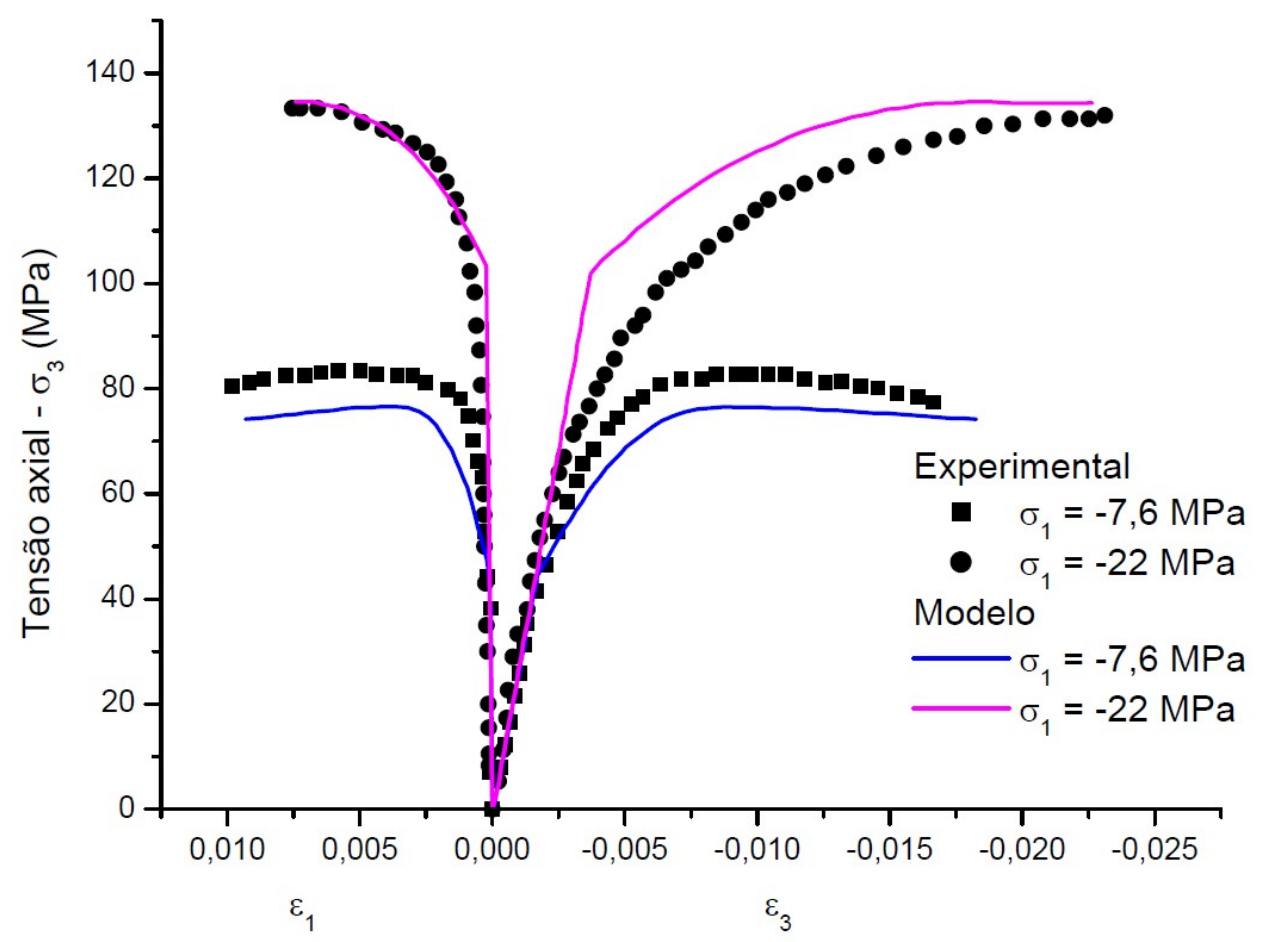

Figura 43. Comparação com experimentos de confinamento ativo de Lahlou et al. (1992).

A comparação com os resultados experimentais de Lahlou et al. (1992) indica uma boa previsão da resistência e deformação de pico e última do concreto confinado ativamente. Sendo importante observar que para níveis de confinamento menores, como é o caso do 7,6 MPa a resistência do concreto tende a ser subestimada e para maiores níveis de confinamento tende a ser superestimada. Esse fato pode ser explicado pela própria limitação do critério de ruptura, no caso, o critério de Mohr-Coulomb que assume a forma dada na Eq. (121) ao assumir como parâmetro ângulo de atrito igual a $37^{\circ}$. Portanto, o próprio critério de ruptura resulta em alguma imprecisão no aumento de resistência para alguns níveis de confinamento, 
que pode ser maior ou menor dependendo do conjunto de dados experimentais e propriedades do concreto.

$$
f_{c c}=f_{c 0}+4,02 \cdot f_{l}
$$

A Figura 44 mostra as curvas tensão-deformação do modelo com os resultados experimentais de Imran e Pantazopoulou (1996) com cilindros de 54x108 cm submetidos a tensões de confinamento constantes de 4,3, 8,6, 17,2 e 30,1 MPa.

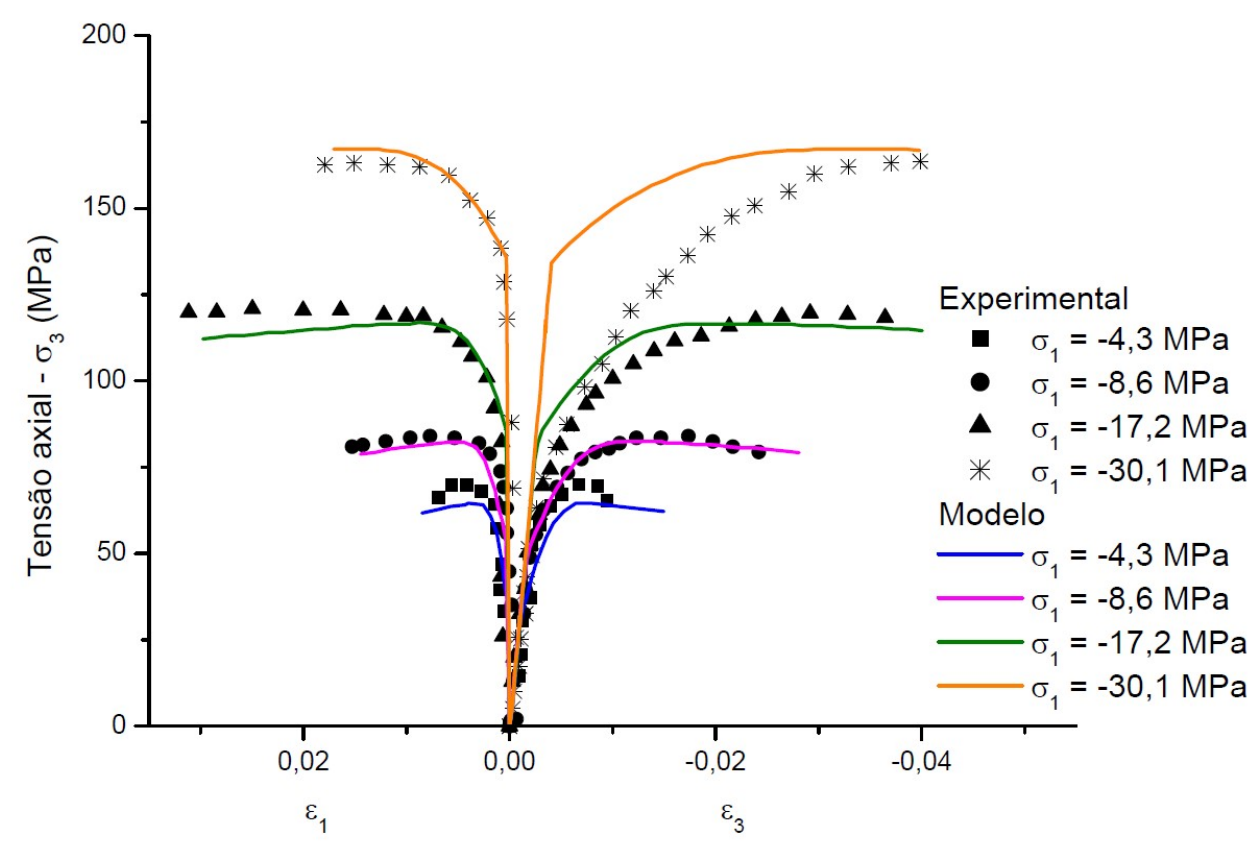

Figura 44. Comparação com experimentos de confinamento ativo de Imran e Pantazopoulou (1996)

A comparação com os resultados experimentais de Imran e Pantazopoulou (1996) indica uma boa previsão da resistência e deformação de pico e última do concreto confinado ativamente. Sendo importante observar que para níveis de confinamento menores a resistência do concreto tende a ser subestimada e para níveis de confinamento maiores a resistência tende a ser superestimada, reforçando a hipótese apresentada anteriormente. Também nota-se que para níveis mais altos de confinamento o modelo tende a superestimar o limite elástico do material, afastando a curva tensão-deformação axial dos resultados experimentais no trecho anterior ao pico de tensão, para níveis muito altos de confinamento.

As Figuras 45 a 48 mostram as curvas tensão-deformação comparadas aos resultados experimentais de $\mathrm{Li}$ e $\mathrm{Wu}$ (2016) com cilindros de 54x108 cm submetidos a tensões de confinamento constantes iguais a 5, 10, 15 e $20 \mathrm{MPa}$, respectivamente. 


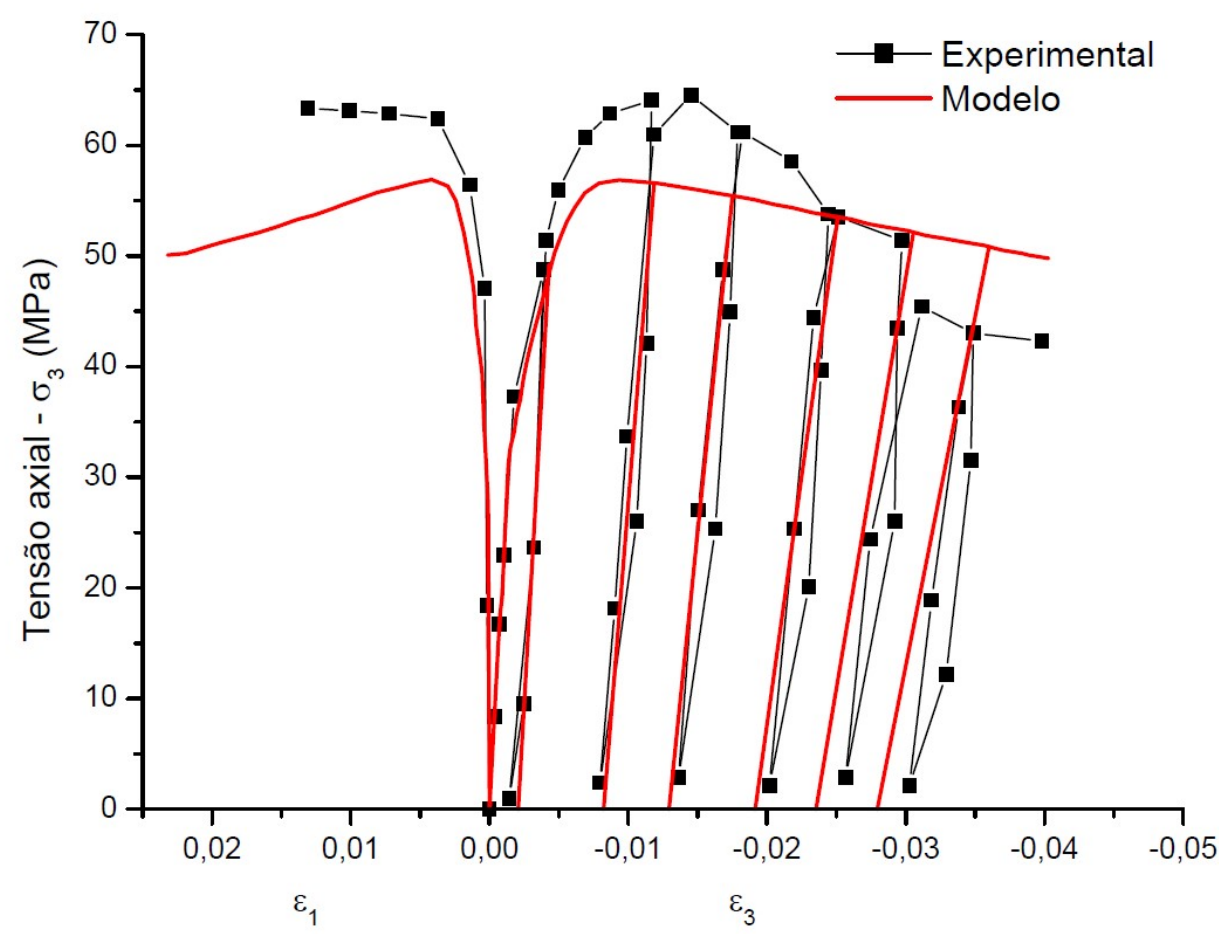

Figura 45. Comparação com experimentos de tensão de confinamento igual $5 \mathrm{MPa}-\mathrm{Li}$ e $\mathrm{Wu}$ (2016)

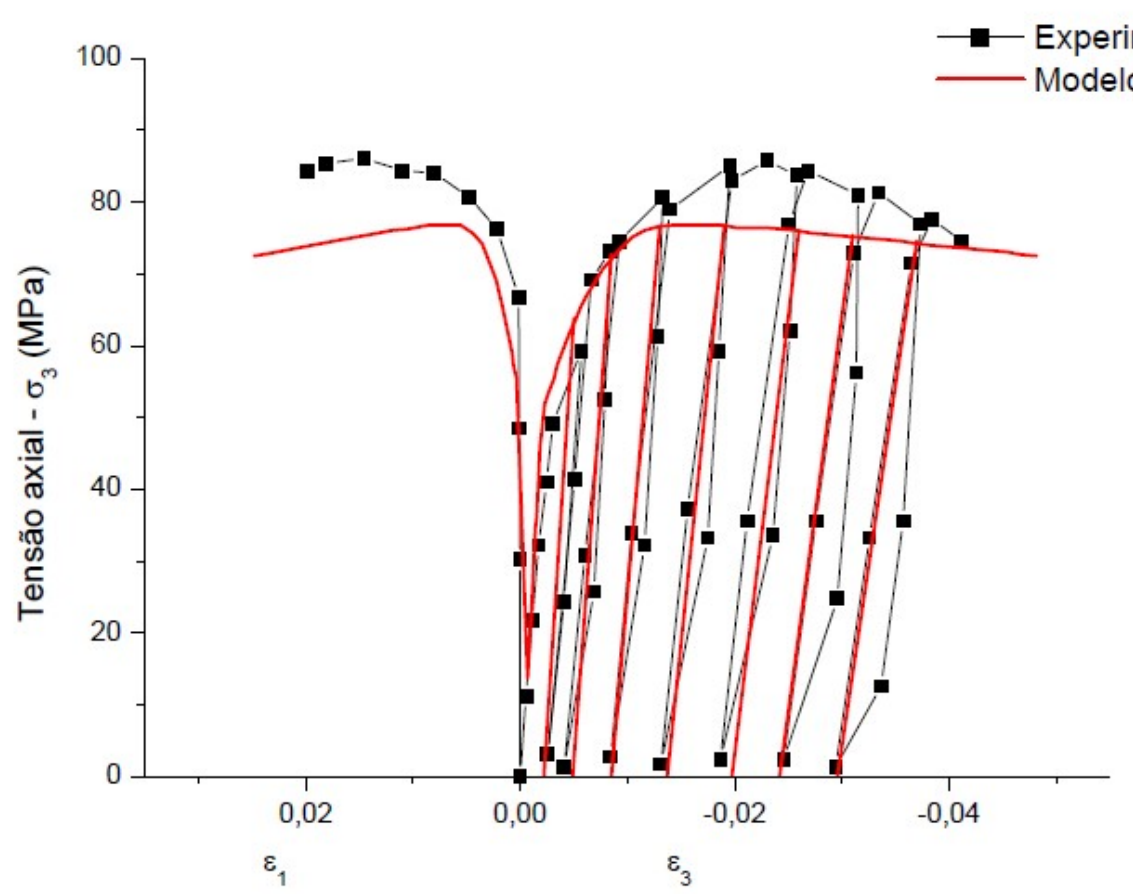

Figura 46. Comparação com experimentos de tensão de confinamento igual $10 \mathrm{MPa}$ - Li e Wu (2016) 


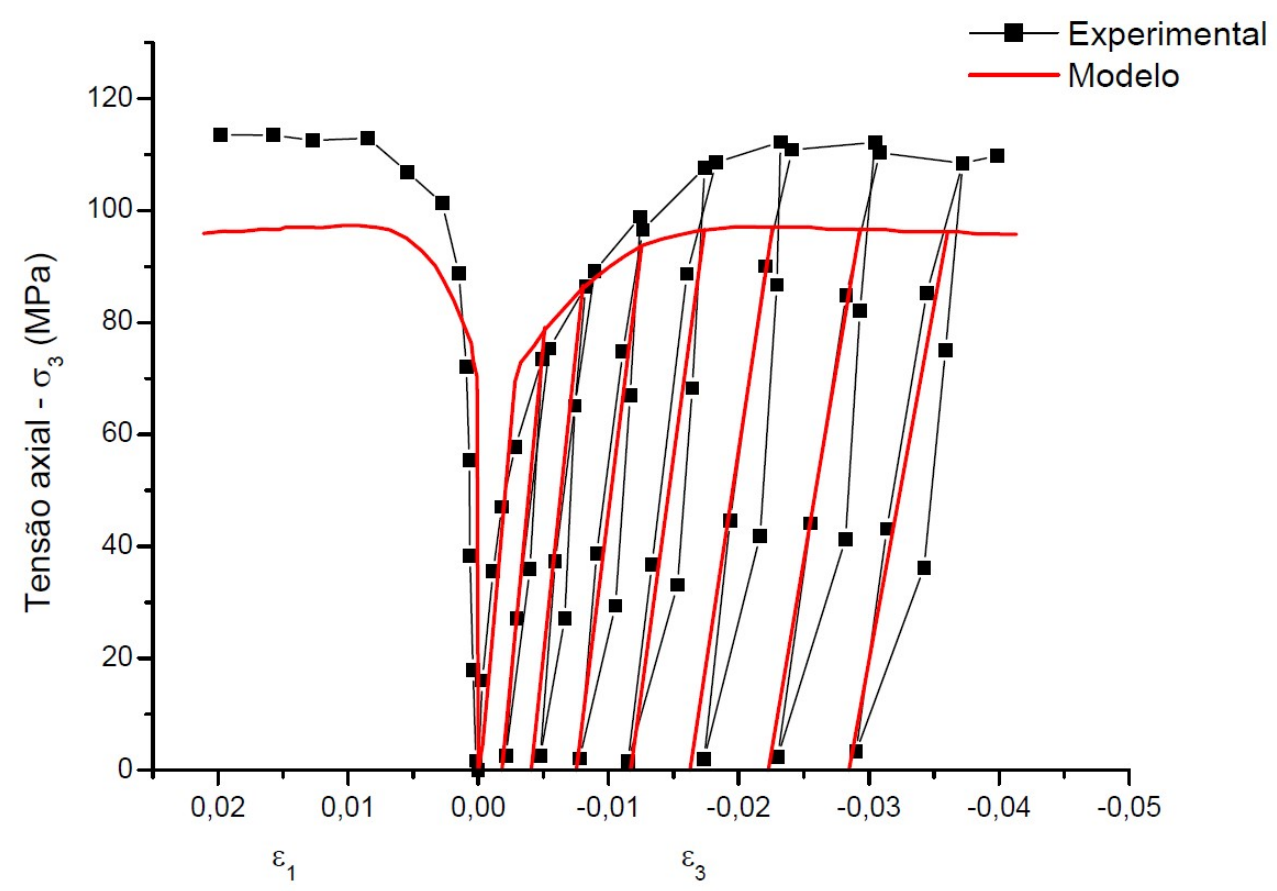

Figura 47. Comparação com experimentos de tensão de confinamento igual $15 \mathrm{MPa}$ - Li e Wu (2016)

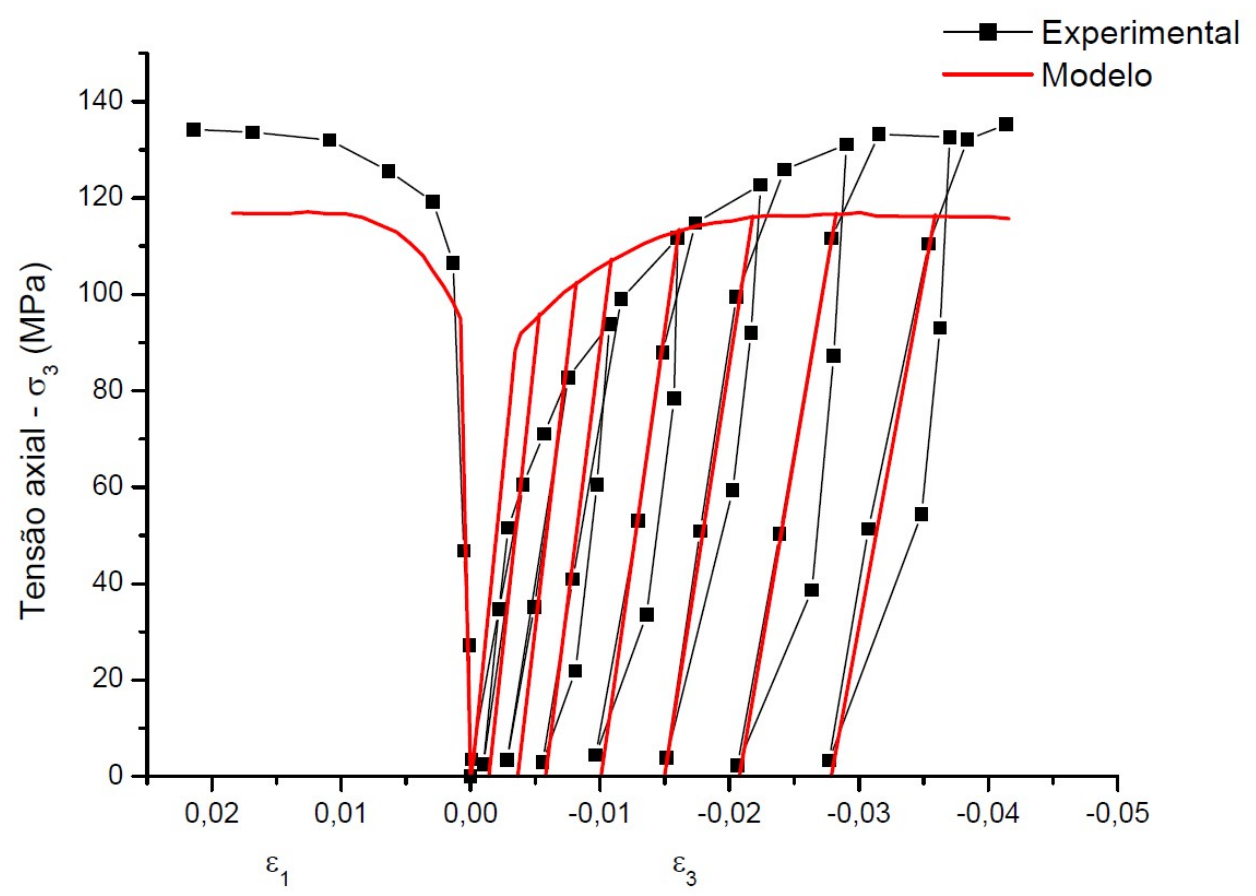

Figura 48. Comparação com experimentos de tensão de confinamento igual $20 \mathrm{MPa}-\mathrm{Li}$ e Wu (2016) 
A comparação com os resultados experimentais de Li e $\mathrm{Wu}$ (2016) indicam boa previsão da resistência e deformação de pico do concreto confinado ativamente. A perda de rigidez também é bem descrita pelo modelo. A resistência de pico do material é subestimada pelo modelo, o que pode estar relacionado com a própria função de ruptura adotada no modelo, que conforme explicado anteriormente, pode gerar maior erro na estimativa já que o parâmetro do critério de ruptura está relacionado com as propriedades do concreto, que apresentam grande variação de um conjunto de experimentos para outro.

A Tabela 9 indica o resumo das resistências e deformações de pico experimentais e resultantes do modelo proposto, além dos respectivos erros, calculados conforme Eq. (120).

Tabela 9. Resumo das comparações para confinamento ativo

\begin{tabular}{|c|c|c|c|c|c|c|c|c|}
\hline Experimentais & $\begin{array}{c}f_{c} \\
(\mathrm{MPa})\end{array}$ & $\begin{array}{l}\text { Tensão de } \\
\text { confinamento } \\
\text { (MPa) }\end{array}$ & $\begin{array}{c}f_{c c} \\
(\mathrm{MPa}) \\
\text { EXP. }\end{array}$ & $\begin{array}{c}f_{c c} \\
(\mathrm{MPa}) \\
\mathrm{MOD} \text {. }\end{array}$ & $\begin{array}{c}\text { Erro } \\
f_{c c} \\
(\%)\end{array}$ & $\begin{array}{c}\varepsilon_{c c} \\
\text { EXP. }\end{array}$ & $\begin{array}{c}\varepsilon_{c c} \\
\text { MOD. }\end{array}$ & $\begin{array}{c}\text { Erro } \varepsilon_{c c} \\
(\%)\end{array}$ \\
\hline \multirow{3}{*}{$\begin{array}{c}\text { Lahlou et al. } \\
\text { (1992) }\end{array}$} & \multirow{3}{*}{46} & 7,6 & 82,8 & 76,5 & 8,2 & 0,0098 & 0,0087 & 12,6 \\
\hline & & 22 & 132 & 134,3 & $-1,7$ & 0,023 & 0,0226 & 1,8 \\
\hline & & 4,3 & 70 & 64,6 & 8,4 & 0,0067 & 0,0064 & 4,7 \\
\hline \multirow{3}{*}{$\begin{array}{c}\text { Imran e } \\
\text { Pantazopoulou } \\
(2005)\end{array}$} & \multirow{3}{*}{36,6} & 8,6 & 84 & 82,5 & 1,8 & 0,0174 & 0,0147 & 18,4 \\
\hline & & 17,2 & 119,6 & 116,5 & 2,7 & 0,0292 & 0,0272 & 7,4 \\
\hline & & 30,1 & 163,6 & 167,1 & $-2,1$ & 0,0398 & 0,037 & 7,6 \\
\hline \multirow{4}{*}{ Li e Wu (2016) } & \multirow{4}{*}{35} & 5 & 63 & 56,9 & 10,7 & 0,012 & 0,0094 & 27,7 \\
\hline & & 10 & 84 & 76,8 & 9,4 & 0,022 & 0,018 & 22,2 \\
\hline & & 15 & 112 & 97,1 & 15,3 & 0,029 & 0,022 & 31,8 \\
\hline & & 20 & 138 & 117 & 17,9 & 0,04 & 0,03 & 33,3 \\
\hline
\end{tabular}

Para o confinamento ativo, as diferenças entre resistência de pico experimental e numérica variaram de $-2,1 \%$ a $12,9 \%$ e as diferenças entre deformação de pico experimental e numérica variaram de $1,8 \%$ a $33,3 \%$. Portanto, as diferenças observadas entre resultados do modelo e ensaios experimentais são mais significativas para as deformações de pico. Sendo que essas diferenças observadas podem ser justificadas pela própria função de ruptura adotada ou pelo critério utilizado para definição do parâmetro de encruamento, que se baseou em uma relação linear derivada de resultados experimentais. 


\section{CONCLUSÕES FINAIS}

Esta pesquisa apresentou um modelo constitutivo para representação do comportamento do concreto confinado ativa e passivamente submetido a carregamentos monotônicos e cíclicos, baseando-se em princípios da plasticidade e dano. A prioridade do modelo foi a utilização de formulações mais simplificadas, que exigissem menor número de parâmetros para calibração quando comparado à maioria dos modelos baseados na plasticidade. Além disso, as funções do modelo foram rearranjadas a fim de permitir a utilização de um processo incremental explícito para desenvolvimento do modelo em qualquer tipo de planilha e, portanto, facilitar sua aplicação prática.

Os resultados obtidos por meio da implementação do modelo na linguagem de programação Python foram comparados a um conjunto representativo de dados experimentais existentes na literatura, que abrange ensaios monotônicos e cíclicos, confinamento ativo e passivo (com e sem protensão), confinamento com diferentes tipos de camisas de PRF e com camisas de aço. Destaca-se que o modelo foi validado apenas para concreto de resistência normal, sem presença de armadura e com camisas de confinamento contínuas.

Observando as comparações, conclui-se que, para o confinamento passivo, ocorre maior proximidade entre os resultados experimentais e numéricos de resistência última (com variação de -8,4\% a 9,2\%) e menor precisão para a deformação última do concreto confinado, principalmente para elevadas rigidezes de camisa e maior número de camadas de confinamento (com variação de $-19,4 \%$ a 48,8\%). Como discutido, essa imprecisão pode ser resultante da hipótese adotada para definição do parâmetro de encruamento ou da modificação da função potencial plástica cuja calibração. Julga-se que os dois fatores citados podem ser as principais justificativas para as diferenças observadas. Ainda assim, o modelo mostrou-se capaz de representar o aumento considerável de ductilidade do concreto confinado com o aumento do número de camisas, considerando que essa estimativa é uma limitação encontrada em muitos estudos. 
Para o confinamento ativo, as diferenças entre resistência de pico experimental e numérica variaram de $-2,1 \%$ a $12,9 \%$ e as diferenças entre deformação de pico experimental e numérica variaram de $1,8 \%$ a $33,3 \%$. Observa-se que as diferenças observadas entre resultados do modelo e ensaios experimentais são mais significativas para as deformações de pico. Como discutido, as diferenças observadas podem ser justificadas pela própria função de ruptura adotada ou pelo critério utilizado para definição do parâmetro de encruamento.

Em relação à perda de rigidez elástica, conclui-se que a lei de dano, considerada desacoplada do modelo de plasticidade, foi capaz de prever a evolução da variável de dano, responsável por reduzir a rigidez elástica do material com a evolução do carregamento, tanto para o confinamento ativo quanto para o confinamento passivo. Porém, destaca-se que uma análise mais aprofundada, utilizando um maior conjunto de dados e resultados experimentais completos permitiriam uma análise mais eficiente da evolução da perda de rigidez elástica para o concreto confinado.

Assim, pode-se afirmar que o presente trabalho gerou contribuições já que superou muitas dificuldades já percebidas em muitos modelos em relação a representação do comportamento tensão-deformação do concreto confinado, principalmente em relação ao confinamento passivo com camisas de PRF, além de incorporar a previsão em carregamentos cíclicos da perda de rigidez elástica do material devido evolução do dano. Além disso, destaca-se a natureza incremental explícita do processo de implementação, que facilita a futura aplicação prática do modelo.

Trabalhos futuros podem ser realizados no sentido de ampliar a utilização do modelo a concretos de alta resistência e também a pilares com armadura, de forma que os efeitos de confinamento devido presença de armadura transversal possam ser considerados e superpostos aos efeitos de confinamento por camisas de aço ou PRF. As restrições aqui apresentadas devem ser analisadas, de forma que possam ser propostas melhorias para uma aplicação mais genérica, incluindo confinamento não uniforme, por exemplo. Portanto, o presente trabalho apresentou um estudo inicial no sentido de permitir a aplicação prática do modelo constitutivo a pilares de concreto confinado reais baseando-se na plasticidade e dano, porém, é necessário dar continuidade ao estudo a fim generalizar o uso do modelo analisando as restrições destacas nesse trabalho. 


\section{REFERÊNCIAS BIBLIOGRÁFICAS}

BAO, J. Q. et al. A new generalized Drucker-Prager flow rule for concrete under compression. EngineeringStructures, v. 56, p. 2076-2082, Nov 2013.

BAZANT, Z. P.; TSUBAKI, T. TOTAL STRAIN THEORY AND PATH-DEPENDENCE OF CONCRETE. Journal of the Engineering Mechanics Division-Asce, v. 106, n. 6, p. 1151-1173, 1980.

BERTHET, J. F.; FERRIER, E.; HAMELIN, P. Compressive behavior of concrete externally confined by composite jackets. Part A: experimental study. Construction and Building Materials, v. 19, n. 3, p. 223-232, Apr 2005.

BRECCOLOTTI, M. et al. Constitutive modeling of plain concrete subjected to cyclic uniaxial compressive loading. Construction and Building Materials, v. 94, p. 172-180, Sep 2015.

CANDAPPA, D. C.; SANJAYAN, J. G.; SETUNGE, S. Complete triaxial stress-strain curves of high-strength concrete. Journal of Materials in Civil Engineering, v. 13, n. 3, p. 209-215, May-Jun 2001.

CARRAZEDO, R. Mecanismos de confinamento e suas implicações no reforço de pilares de concreto por encamisamento com compósito de fibras de carbono. Dissertação (Mestrado) - Universidade de São Paulo - São Carlos (2002).

CARRAZEDO, R.; MIRMIRAN, A.; DE HANAI, J. B. Plasticity based stress-strain model for concrete confinement. Engineering Structures, v. 48, p. 645-657, Mar 2013.

CHEN, W.F. Constitutive equations for engineering materials.John Wiley \& Sons, 1982.

CHI, Y.; XU, L. H.; YU, H. S. Constitutive modeling of steel-polypropylene hybrid fiber reinforced concrete using a non-associated plasticity and its numerical implementation. Composite Structures, v. 111, p. 497-509, May 2014.

CHOI, E. et al. A new steel jacketing method for RC columns. Magazine of Concrete Research, v. 61, n. 10, p. 787-796, Dec 2009.

FARAHMANDPOUR, C. et al. A concrete damage-plasticity model for FRP confined columns. Materials and Structures, v. 50, n. 2, Apr 2017.

FRANTZISKONIS, G.; DESAI, C. S.; SOMASUNDARAM, S. Constitutive model for nonassociative behavior. Journal of Engineering Mechanics-Asce, v. 112, n. 9, p. 932-946, Sep 1986.

GRASSL, P. Modelling of dilation of concrete and its effect in triaxial compression. Finite 
Elements in Analysis and Design, v. 40, n. 9-10, p. 1021-1033, Jun 2004.

GRASSL, P.; JIRASEK, M. Damage-plastic model for concrete failure. International Journal of Solids and Structures, v. 43, n. 22-23, p. 7166-7196, Nov 2006a.

. Plastic model with non-local damage applied to concrete. International Journal for Numerical and Analytical Methods in Geomechanics, v. 30, n. 1, p. 71-90, Jan 2006b.

GRASSL, P.; LUNDGREN, K.; GYLLTOFT, K. Concrete in compression: a plasticity theory with a novel hardening law. International Journal of Solids and Structures, v. 39, n. 20, p. 5205-5223, Oct 2002.

GRASSL, P. et al. CDPM2: A damage-plasticity approach to modeling the failure of concrete. International Journal of Solids and Structures, v. 50, n. 24, p. 3805-3816, Nov 2013.

HAN, D. J.; CHEN, W. F. A nonuniform hardening plasticity model for concrete materials. Mechanics of Materials, v. 4, n. 3-4, p. 283-302, Dec 1985.

HEINZE, T.; GALVAN, B. Novel numerical strategy for solving strongly coupled elastoplastic damage models with explicit return algorithms: Application to geomaterials. International Journal of Solids and Structures, v. 80, p. 64-72, Feb 2016.

IMRAN, I.; PANTAZOPOULOU, S. J. Experimental study of plain concrete under triaxial stress. Aci Materials Journal, v. 93, n. 6, p. 589-601, Nov-Dec 1996.

JANKE, L. et al. Experiments on the residual load-bearing capacity of prestressed confined concrete columns. Engineering Structures, v. 31, n. 10, p. 2247-2256, Oct 2009.

JASON, L. et al. An elastic plastic damage formulation for concrete: Application to elementary tests and comparison with an isotropic damage model. Computer Methods in Applied Mechanics and Engineering, v. 195, n. 52, p. 7077-7092, 2006.

JIANG, T.; TENG, J. G. Analysis-oriented stress-strain models for FRP-confined concrete. Engineering Structures, v. 29, n. 11, p. 2968-2986, Nov 2007.

KACHANOV, L.M. Time of the rupture process under creep conditions. Izvestiya Akademii Nauk SSSR, Otdelenie Teckhnicheskikh Nauk 8, 26-31, 1958.

KARABINIS, A. I.; ROUSAKIS, T. C. Concrete confined by FRP material: a plasticity approach. Engineering Structures, v. 24, n. 7, p. 923-932, Jul 2002.

KARSAN, I. D.; JIRSA, J.O. Behavior of concrete under compressive loadings. Journal of the Structural Division, 1969.

LAHLOU, K., AITICIN, P. C., CHAALLAL O. Behaviour of high-strength concrete under confined stresses. Cement and Concrete composites. 14(3) 185-93, 1992.

LAM, L.; TENG, J.G. Design-oriented stress-strain model for FRP-confined concrete. Construction and Building Materials, v.17, n.6-7, p.471-489, Sep-Oct 2003. 
LAM, L. et al. FRP-confined concrete under axial cyclic compression. Cement \& Concrete Composites, v. 28, n. 10, p. 949-958, Nov 2006.

LEE, J. H.; FENVES, G. L. Plastic-damage model for cyclic loading of concrete structures. Journal of Engineering Mechanics-Asce, v. 124, n. 8, p. 892-900, Aug 1998.

LEMAITRE, J.; CHABOCHE, J. L. Mechanics of solid materials. Cambridge university press, 1994.

LI, P.D.; WU. Y.F. Stress-strain behavior of actively and passively confined concrete under cyclic axial load. Composite Structures, v.149, p.369-384, Aug 2016.

LIM, J. C.; OZBAKKALOGLU, T. A simple design-oriented model for FRP-confined highstrength concrete. In: XU, B. e LI, H. Y. (Ed.). Building Materials and Structural Engineering Ii, v.743, p.45-49, 2013.

LIM, J. C.; OZBAKKALOGLU, T. Comparison of Stress-Strain Relationships of FRP and Actively Confined High-Strength Concrete: Experimental Observations. Advanced Construction Technologies, v. 919-921, p. 29-34, 2014a.

Influence of silica fume on stress-strain behavior of FRP-confined HSC. Construction and Building Materials, v. 63, p. 11-24, Jul 2014 b.

LIM, J. C.; OZBAKKALOGLU, T. Investigation of the Influence of the Application Path of Confining Pressure: Tests on Actively Confined and FRP-Confined Concretes. Journal of Structural Engineering, v. 141, n. 8, Aug 2015.

LU, D. C. et al. A three-dimensional elastoplastic constitutive model for concrete. Computers\&Structures, v. 163, p. 41-55, Jan 2016.

LUBLINER, J. et al. A plastic-damage model for concrete. International Journal of Solids and Structures, v. 25, n. 3, p. 299-326, 1989.

MANDER, J. B.; PRIESTLEY, M. J. N; PARK, R. Theoretical stress-strain model for confined concrete. Journal of structural engineering, p. 1804-1826, 1988.

MAZARS, J. A description of microscale and macroscale damage of concrete structures. Engineering Fracture Mechanics, v. 25, n. 5-6, p. 729-737, 1986. ISSN 0013-7944.

MEHTA, P.K.; MONTEIRO, P.J.M. Concreto: estrutura, propriedades e materiais. São Paulo: Pini, 1994.

MEHTA, P. K; GERWICK, B. C. JR. Cracking-Corrosion Interaction in Concrete Exposed to Marine Environment. Concrete International, v. 4, n. 10. 1982

MENETREY, P.; WILLAM, K. J. Triaxial failure criterion for concrete and its generalization.. Aci Structural Journal, v. 92, n. 3, p. 311-318, May-Jun 1995.

MIRMIRAN, A.; SHAHAWY, R. Behavior of concrete columns confined by fiber composites. Journal of Structural Engineering-Asce, v. 123, n. 5, p. 583-590, May 1997. 
MIRMIRAN, A.; ZAGERS, K.; YUAN, W. Q. Nonlinear finite element modeling of concrete confined by fiber composites. Finite Elements in Analysis and Design, v. 35, n. 1, p. 79-96, Apr 2000.

NGUYEN, G. D. A thermodynamic approach to constitutive modelling of concrete using damage mechanics and plasticity theory. Diss. University of Oxford, 2005.

OMIDI, O.; VALLIAPPAN, S.; LOTFI, V. Seismic cracking of concrete gravity dams by plastic-damage model using different damping mechanisms. Finite Elements in Analysis and Design, v. 63, p. 80-97, Jan 2013.

ORTIZ, M. A constitutive theory for the inelastic behavior of concrete. Mechanics of Materials, v. 4, n. 1, p. 67-93, 1985.

OZBAKKALOGLU, T.; AKIN, E. Behavior of FRP-Confined Normal- and High-Strength Concrete under Cyclic Axial Compression. Journal of Composites for Construction, v. 16, n. 4, p. 451-463, Jul-Aug 2012.

OZBAKKALOGLU, T.; LIM, J. C.; VINCENT, T. FRP-confined concrete in circular sections: Review and assessment of stress-strain models. Engineering Structures, v. 49, p. 1068-1088, Apr 2013.

OZBAKKAlOGLU, T., GHOLAMPOUR, A., LIM, J.C. Damage-Plasticity Model for FRPConfined Normal-Strenght and High-Strength Concrete. Composites Part B: Engineering, 2016.

PANTAZOPOULOU, S. J.; MILLS, R. H. Microstructural aspects of the mechanical response of plain concrete. Aci Materials Journal, v. 92, n. 6, p. 605-616, Nov-Dec 1995.

PAPANIKOLAOU, V. K.; KAPPOS, A. J. Confinement-sensitive plasticity constitutive model for concrete in triaxial compression. International Journal of Solids and Structures, v. 44, n. 21, p. 7021-7048, Oct 2007.

PARK, J. et al. Comparing the cyclic behavior of concrete cylinders confined by shape memory alloy wire or steel jackets. Smart Materials \& Structures, v. 20, n. 9, Sep 2011.

PISCESA, B.; ATTARD, M. M.; SAMANI, A. K. A lateral strain plasticity model for FRP confined concrete. Composite Structures, v. 158, p. 160-174, Dec 2016.

PISCESA, B. et al. Plasticity Constitutive Model for Stress-Strain Relationship of Confined Concrete. Aci Structural Journal, v. 114, n. 2, p. 361-371, Mar-Apr 2017.

RAIZ, V. Concretos confinados por Polímeros Reforçados com Fibras. Relatório de Progresso de Iniciação Científica. Laboratório de Engenharia de Estruturas - Escola de Engenharia de São Carlos. 2014.

RICHART, F. E. et al. A study of the failure of concrete under combined compressive stresses. University of Illinois at Urbana Champaign, College of Engineering. Engineering Experiment Station, 1928. 
SAAMAN, M.; MIRMIRAN, A; SHAHAWY, M. Model of concrete confined by fiber composites. Journal of Structural Engineering-Asce, v.124, n.9, p.1025-1031, Sep 1998.

SALARI, M. R. et al. A coupled elastoplastic damage model for geomaterials. Computer Methods in Applied Mechanics and Engineering, v. 193, n. 27-29, p. 2625-2643, 2004.

SFER, D. et al. Study of the behavior of concrete under triaxial compression. Journal of Engineering Mechanics-Asce, v.128, n,2, p.156-163, Feb 2002.

SINHA, B. P.; GERSTLE, K. H.; TULIN L. G. Stress-strain relations for concrete under cyclic loading. Journal Proceedings. Vol. 61. No. 2. 1964.

SHAO, Y.; ZHU, Z.; MIRMIRAN, A. Cyclic modeling of FRP-confined concrete with improved ductility. Cement \& Concrete Composites, v. 28, n. 10, p. 959-968, Nov 2006.

SHEHATA, I.; CARNEIRO, L. A. V.; SHEHATA, L. C. D. Strength of short concrete columns confined with CFRP sheets. Materials and Structures, v. 35, n. 245, p. 50-58, JanFeb 2002.

SIMA, J. F.; ROCA, P.; MOLINS, C. Cyclic constitutive model for concrete. Engineering Structures, v. 30, n. 3, p. 695-706, Mar 2008.

SOON, K, A. Behavior of pressure confined concrete in monotonic and cyclic loadings. Diss. Massachusetts Institute of Technology, 1987.

TENG, J. G. et al. Refinement of a Design-Oriented Stress-Strain Model for FRP-Confined Concrete. Journal of Composites for Construction, v. 13, n. 4, p. 269-278, Jul-Aug 2009.

VINCENT, T.; OZBAKKALOGLU, T. Influence of concrete strength and confinement method on axial compressive behavior of FRP confined high- and ultra high-strength concrete. Composites Part B-Engineering, v. 50, p. 413-428, Jul 2013.

VU, V. D. et al. A thermodynamics-based formulation for constitutive modelling using damage mechanics and plasticity theory. Engineering Structures, v. 143, p. 22-39, Jul 2017.

WU, J. Y.; LI, J.; FARIA, R. An energy release rate-based plastic-damage model for concrete. International Journal of Solids and Structures, v. 43, n. 3-4, p. 583-612, Feb 2006.

XIAO, Y.; WU, H. Compressive behavior of concrete confined by carbon fiber composite jackets. Journal of Materials in Civil Engineering, v. 12, n. 2, p. 139-146, May 2000.

YU, T. et al. Finite element modeling of confined concrete-I: Drucker-Prager type plasticity model. Engineering Structures, v. 32, n. 3, p. 665-679, Mar 2010. 